\author{
UNIVERSITY OF SÃO PAULO \\ SÃO CARLOS SCHOOL OF ENGINEERING
}

ANA CAROLINA SARMENTO BUARQUE

Socio-Hydrology Observatory for Water Security under Climate Change: Novel Global Methods for Local Solutions

São Carlos

2020 



\title{
SOCIO-HYDROLOGY OBSERVATORY FOR WATER SECURITY UNDER CLIMATE CHANGE: NOVEL GLOBAL METHODS FOR LOCAL SOLUTIONS
}

\author{
Master thesis presented at São Carlos \\ School of Engineering, University of \\ São Paulo, in partil fulfillment of the \\ requirements for obtaining the Degree of \\ Master in Science: Hydraulics and \\ Sanitation Engineering. \\ Advisor: Prof. Dr. Eduardo Mario \\ Mendiondo
}

\section{VERSÃO CORRIGIDA}

São Carlos 
I AUTHORIZE THE TOTAL OR PARTIAL REPRODUCTION OF THIS WORK, THROUGH ANY CONVENTIONAL OR ELECTRONIC MEANS, FOR STUDY AND RESEARCH PURPOSES, SINCE THE SOURCE IS CITED.

Buarque, Ana Carolina Sarmento

Socio hydrological observatory for water security under climate change : novel global methods for local solutions / Ana Carolina Sarmento Buarque ; Thesis directed by Eduardo Mario Mendiondo. -- São Carlos, 2020.

Master (Thesis) Graduate Program in Hydraulic and Sanitation Engineering and Research Area in Hydraulic and Sanitation - São Carlos School of Engineering, at University of São Paulo, 2020.

1. Socio-Hydrology. 2. Floods. 3. Climate change. 4. Water security. 5. Citizen observatory. 6. Risk. I. Title. 


\section{FOLHA DE JULGAMENTO}

Candidato: Engenharia ANA CAROLINA SARMENTO BUARQUE.

Título da dissertação: "Observatório sócio-hidrológico para segurança hídrica sob cenários de mudanças climáticas: utilizando soluções locais de memórias sociais para desafios globais".

Data da defesa: 03/03/2020.

Comissão Julgadora:

Prof. Dr. Eduardo Mario Mendiondo (Orientador)

(Escola de Engenharia de São Carlos/EESC)

Prof. Dr. Christopher Freire Souza

(Universidade Federal de Alagoas/UFAL)

Prof. Dr. Giuliano Di Baldassarre

(Uppsala University)
Resultado:
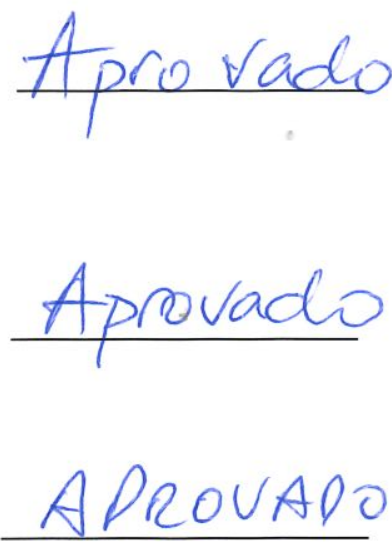

Coordenador do Programa de Pós-Graduação em Engenharia Hidráulica e Saneamento:

Prof. Dr. Eduardo Mario Mendiondo

Presidente da Comissão de Pós-Graduação:

Prof. Titular Murilo Araujo Romero 


\section{ACKNOWLEDGMENTS}

Firstly, I am extremely thankful for the public, free, and quality education that I received in both my undergraduate and graduate studies. At a time when science is being discredited in Brazil, this opportunity is a great privilege.

I also would like to thank my family for the support provided throughout my life and, especially, for the past two years. Without your support, none of this would have been possible. I am especially grateful to my mother, Rejane, and my father, Alexandre, who always believed in my potential and encouraged me to be a critical person.

I am thankful to my advisor, Eduardo Mario Mendiondo, who also believed in my potential by welcoming me to the laboratory to develop this work and provided me with all the necessary support.

I would also like to thank my friends at the WadiLab. Especially, Felipe, Maria, Marina, Txe, Marcus, and Denise, who were always available to help me with the research and to live a more lightly academic life.

I would also like to thank my friends who became my family in São Carlos: Aline, Gley, Gus, and Manu. Life away from home is lighter knowing that I can count on you. Thank you for all the support and the happy moments.

I am thankful to my friends from Maceió, in particular, Fred, Luanne, Chica, Yuri, and Yan, who stayed in my life, helped me in difficult times, and listened to my complaints from afar. I am also thankful to my former teacher who became a friend, Christopher Freire Souza, for all the encouragement to seek growth and to broaden my horizons.

Finally, I would like to thank the University of São Paulo, CAPES, CNPq and FAPESP for granting me the scholarship and the necessary support for the development of this study. 


\section{RESUMO}

BUARQUE, A. C. S. (2020). Observatório Socio-Hidrológico para Segurança Hídrica sob Cenários de Mudanças Climáticas: Utilizando Soluções Locais de Memórias Sociais para Desafios Globais. (Dissertação de Mestrado). Escola de Engenharia de São Carlos, Universidade de São Paulo, São Carlos.

Atualmente, a sociedade se encontra num estado de frequente mudança e isso não é diferente no campo de gestão de risco de desastres. Respostas a desastres sociais, que antes eram tratadas de maneira isolada, exigem cada vez mais planejamento e tomada de decisão diante da grande complexidade. No caso de eventos de inundação, as projeções climáticas combinadas com as tendências de urbanização, mostram um aumento em sua intensidade. Aspectos sociais, como a memória social de eventos passados, podem desempenhar um papel importante na redução dos danos gerados por inundações através do deslocamento voluntário de pessoas para fora de áreas de risco ou de um aumento na resiliência. Tais fatores demonstram que a análise de risco deve ser executada de maneira dinâmica, considerando que sistema sociedade-água evolui de maneira integrada, para reduzir o risco de inundações. A primeira hipótese desse estudo é explorada no segundo capítulo e é de que o risco de inundações pode ser reduzido através da manutenção da memória de eventos passados viva por mais tempo em áreas suscetíveis a inundação. A segunda hipótese, explorada no terceiro capítulo, é de que cenários de mudanças climáticas e aspectos sociais podem ser incorporados na análise de risco a longo prazo, aprimorando o planejamento de medidas de redução de risco. Com isso, esse estudo desenvolveu conceitualmente um Observatório Socio-Hidrológico para Segurança Hídrica (SHOWS) que agrega informações climáticas, sociais e hidrológicas para análise de risco de inundações. Para tanto, foi aplicado um modelo socio-hidrológico utilizando dados históricos e projeções climáticas para os anos entre 1940 e 2099 para estimar o risco de inundações em uma bacia hidrográfica brasileira. Esses resultados serviram como base para identificação de estratégias para redução de risco através de medidas ambientais e sociais e para a elaboração do modelo de observatório.

Palavras-chave: Socio-Hidrologia, Risco de Inundações, Mudanças Climáticas, Segurança Hídrica, Observatório Cidadão, Planejamento Urbano. 


\begin{abstract}
BUARQUE, A. C. S. (2020). Socio-Hydrology Observatory for Water Security under Climate Change: Novel Global Methods for Local Solutions. (Master Thesis). São Carlos School of Engineering, University of São Paulo, São Carlos.

Today, society is in a state of frequent change, and this is not different in the disaster risk management field. Responses to social disasters, which were previously treated isolated, are increasingly demanding planning and decision in face of great complexity. In the case of flood events, climate projections combined with urbanization trends show an increase in their intensity. Social aspects, such as the social memory of past events, can play an important role in reducing flood damage through the voluntary displacement of people outside risk areas or the resilience improvement. Such factors demonstrate that the risk analysis must be carried out dynamically, considering that the human-water system co-evolves, to reduce flood risk. The first hypothesis in this study is explored in the second chapter and is that the flood risk can be reduced by keeping the memory of past events alive for longer periods in flood-prone areas. The second hypothesis, explored in the third chapter, is that climate change scenarios and social aspects can be incorporated in long-term risk analysis, improving the risk reduction measures planning. Thus, this study conceptually developed a Socio-Hydrological Observatory for Water Security (SHOWS) that aggregates climatic, social, and hydrological information for flood risk analysis. To this end, a socio-hydrological model was applied using historical data and climate projections for the years between 1940 and 2099 to estimate flood risk in a Brazilian catchment. These results served as a basis for identifying strategies to reduce risk through social and environmental measures and for the elaboration of the observatory model.
\end{abstract}

Keywords: Socio-Hydrology, Flood Risk, Climate Change, Water Security, Citizen Observatory, Urban Planning. 


\section{LIST OF FIGURES}

Figure 1: Paradigm shift in flood risk assessment.

Figure 2: Extended risk assessment framework including behavioral factors and disaster risk reduction.

Figure 3: Gregório creek catchment (highlighted in blue) in the city of São Carlos - Brazil (highlighted in pink).

Figure 4: Population density values with time in the different periods mentioned in Mendes and Mendiondo (2007).

Figure 5: Adaptive measures in a jewellery store in the Municipal Market area. The floor level enhancement is highlighted in yellow, and the supports for the flood barrier are highlighted in red.

Figure 6: Representation of the construction of the Living Memory². SR is Sensory Register, ST and LT are the Short- and Long-Term storage, respectively. ${ }^{1}$ Atkinson and Shiffrin (1968), ${ }^{2}$ Fanta et al., (2019), ${ }^{3}$ Hallbwacks (1992).

Figure 7: Number of events occurred (bars) and mean flood water level per class (red dots), classified according to the mean return period and their tendency (dotted blue and dot-dashed red lines, respectively).

Figure 8: Picture of submerged cars in a street from the 2018 flood event. The car highlighted in orange was used to estimate the flood water level.

Figure 9: Annual maximum water levels represented by their associated uncertainty intervals. The mean return periods are two, 10, and 18 years (black, green, and yellow markers, respectively). The grey shaded/white areas divide the graph into the four urbanisation stages.

Figure 10: Socio-hydrological model input data (flood magnitude, in black) and outcomes (represented in red with uncertainty in a lighter tone) with the observed population density (yellow points). The grey and white areas represent the first and third and second and fourth urbanisation stages, respectively.

Erro! Indicador não definido.

Figure 11: Section of Gregório Creek showing commerce square on the right bank. 31

Figure 12: Memory, Risk and Population Density according to the actual (black, $\alpha_{-} \mathrm{H}=13$ ) and lower (blue, $\alpha \_H=67$ ) vulnerability conditions. The grey and white areas represent the odds and even urbanisation stages, respectively.

Figure 13: Risk variation for the actual (blue line, $\mu S=0.5$ ) and minimum (red line, $\mu S=0.01$ ) memory loss rate values. 
Figure 14: (a) Regional Climate Change Index (RCCI) and (b) Socio-Climatic Vulnerability

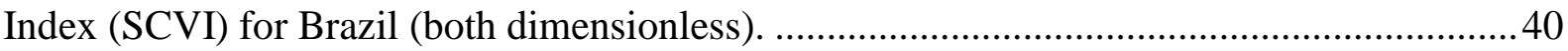

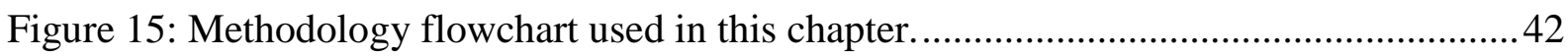

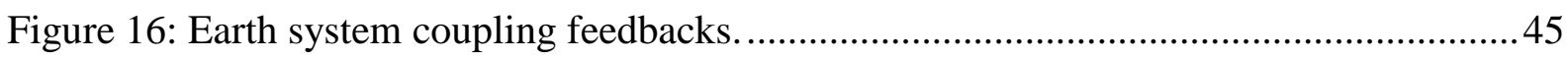

Figure 17: Boxplot of the rainfall intensities for the RCP 4.5 and 8.5 scenarios (represented in

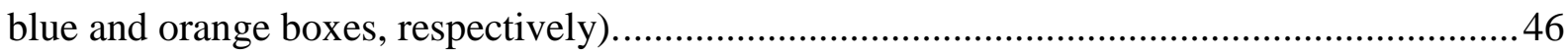

Figure 18: Flood inundation map for the highest flood event of 2020 for the RCP 4.5 and 8.5

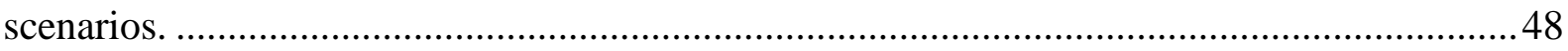

Figure 19: Socio-hydrological model input data (flood magnitude) and outcomes (losses, population density, memory and risk) for the radiative forcing RCP 4.5 and 8.5 (represented in blue and red, respectively). 49

Figure 20: Accumulated losses over the time for the RCP 4.5 and 8.5 scenarios (represented in

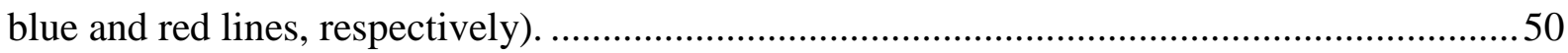

Figure 21: Boxplot of losses data for each 20-year period.................................................. 51

Figure 22: Boxplot of population density data for each 20 -year period..................................52

Figure 23: Boxplot of memory data for each 20-year period. ............................................52

Figure 24: Boxplot of flood risk data for each 20-year period.................................................53

Figure 25: Conceptual Framework of the Socio-Hydrological Observatory for Water Security

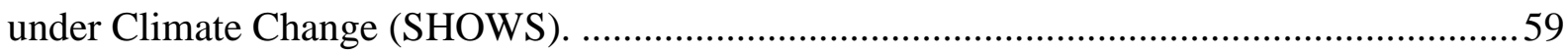




\section{LIST OF TABLES}

Table 1: Description of parameters and their adopted values. ............................................22

Table 2: Rainfall duration and intensity of the eighteen most intense events and of the initial and final years of the simulation period for each RCP scenario. 46 


\section{LIST OF ACRONYMS}

CA - Cellular Automata

CA2D - CADDIES 2D

DEM - Digital Elevation Model

DRR - Disaster Risk Reduction

FRA - Flood Risk Assessment

FRM - Flood Risk Management

GEV - Generalized Extreme Value

IAHS - International Association of Hydrological Sciences

RCCI - Reginal Climate Change Index

RCP - Representative Concentration Pathway

SCVI - Socio-Climatic Vulnerability Index

SHOWS - Socio-Hydrology Observatory for Water Security

UN - United Nations

UNISDR - United Nations Office for Disaster Risk Reduction.

USP - University of São Paulo 


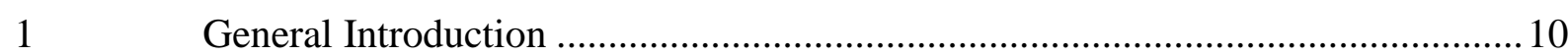

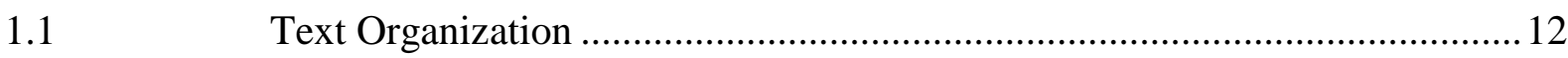

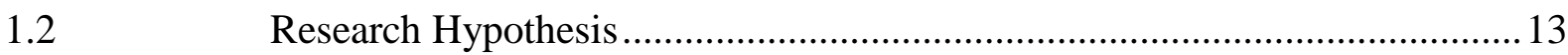

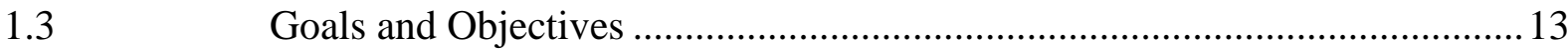

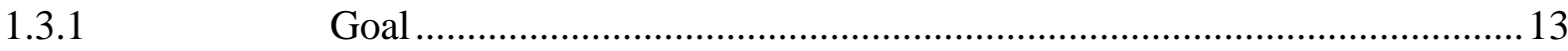

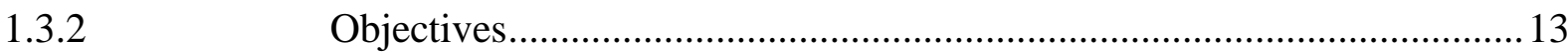

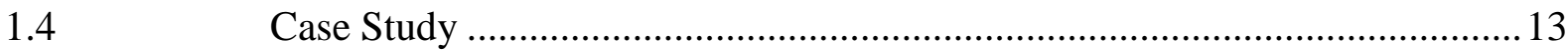

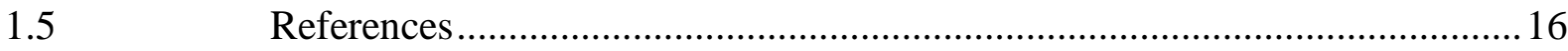

2 Using Historical Source Data to Understand Urban Flood Risk: A SocioHydrological Modelling Application at Gregório Creek, Brazil ................................................ 18

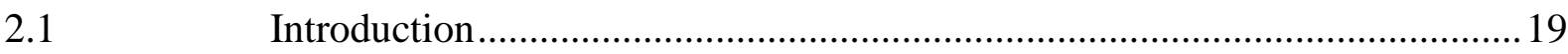

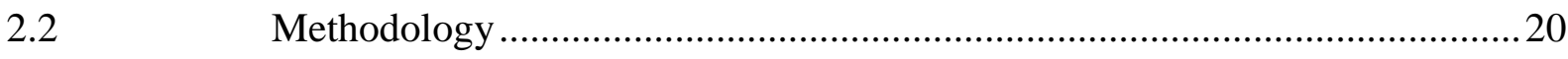

2.2.1 Socio-Hydrology Modelling ………………....................................21

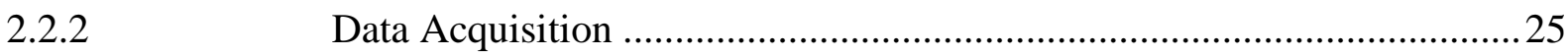

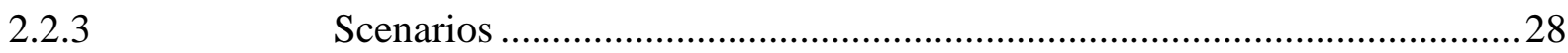

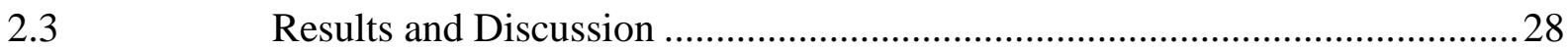

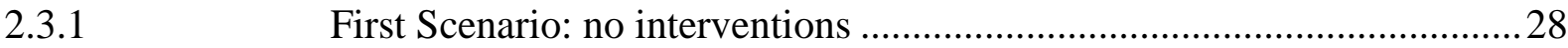

2.3.2 Second Scenario: environmental interventions ...........................................31

2.3.3 Third Scenario: social interventions ...................................................... 31

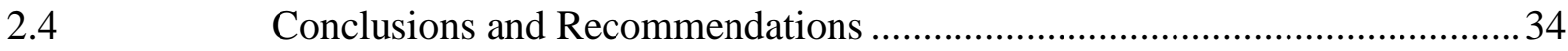

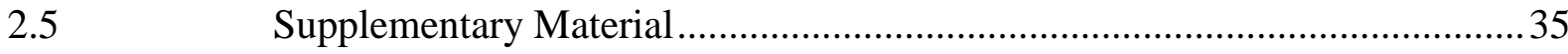

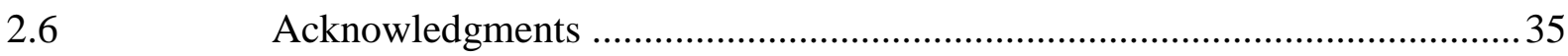

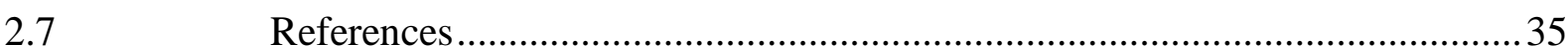

3 Socio-Hydrological Modelling of Long-term Flood Risk under Climate Change

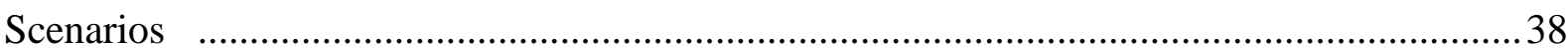

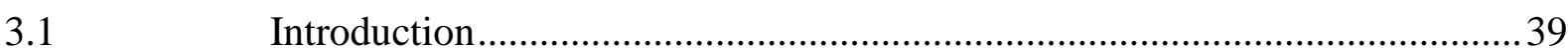


5.1

Conclusions 60 


\section{GENERAL INTRODUCTION}

The turn of the century came with a paradigm shift on the web. According to O'Reilly (2005), the so-called Web 2.0 emerges with a strong foundation in collectivity. This paradigm shift provided us a collaborative system model that influenced not only the relationship between society and the web but also the relationship between society and science.

In this context, Science 2.0 emerged, integrating a strong part of the social sciences in different areas of study. Observations, interventions and data collection in "real-world" environments are necessary for this science model and researchers are promoting an integrated thinking that combines the expertise of computer science with the sensitivity of the social sciences (Shneiderman, 2008).

Following this shift in science, the Global Assessment Risk Report on Disaster Risk Reduction (UN, 2019) states that major renovations of approaches to risk assessment and analysis are needed to fully realize the challenge and call of the Sendai Framework (UNISDR, 2015). This implies a paradigm shift (Figure 1) from managing "conventional" hazards to engineering an improved understanding of the dynamic interactions with systemic risks (UN, 2019).

Figure 1: Paradigm shift in flood risk assessment.

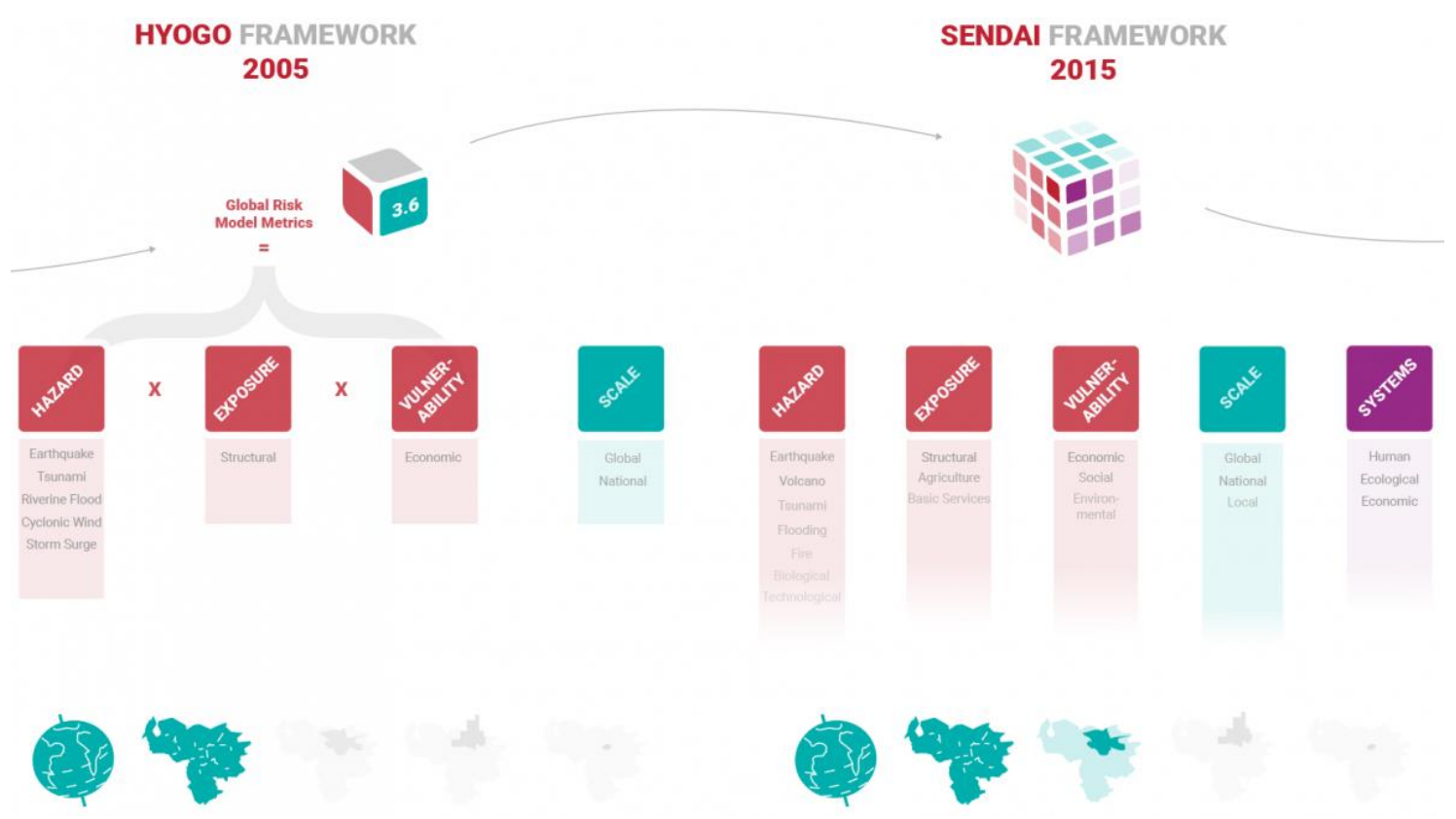

Source: UN (2019). 
In flood risk assessment, the intensity of events is often estimated disregarding the effects of climate change when many studies show that they have an impact the flooding dynamics (Hirabayashi et al., 2013; Arnell et al., 2016; Blöschl et al., 2017; Blöschl et al., 2019). In addition, the vulnerability is often analysed in a purely economic perspective, disregarding social aspects such as memory of antecedent events or risk-taking attitude, which can affect the flood risk (Viglione et al., 2014; Di Baldassarre et al., 2015; Ciullo et al., 2017).

In this context, Aerts et al. (2018) propose an extended risk assessment framework that includes social factors and Disaster Risk Reduction (DRR) measures. In this framework's structure, the influence on the risk of the society's level of information about floods is recognized. However, including the dynamics of risk perception, behavioural dynamics, and DRR in risk assessment requires a multi-disciplinary approach that integrates methods from the natural sciences with the social sciences (Aerts et al., 2018).

Figure 2: Extended risk assessment framework including behavioral factors and disaster risk reduction.

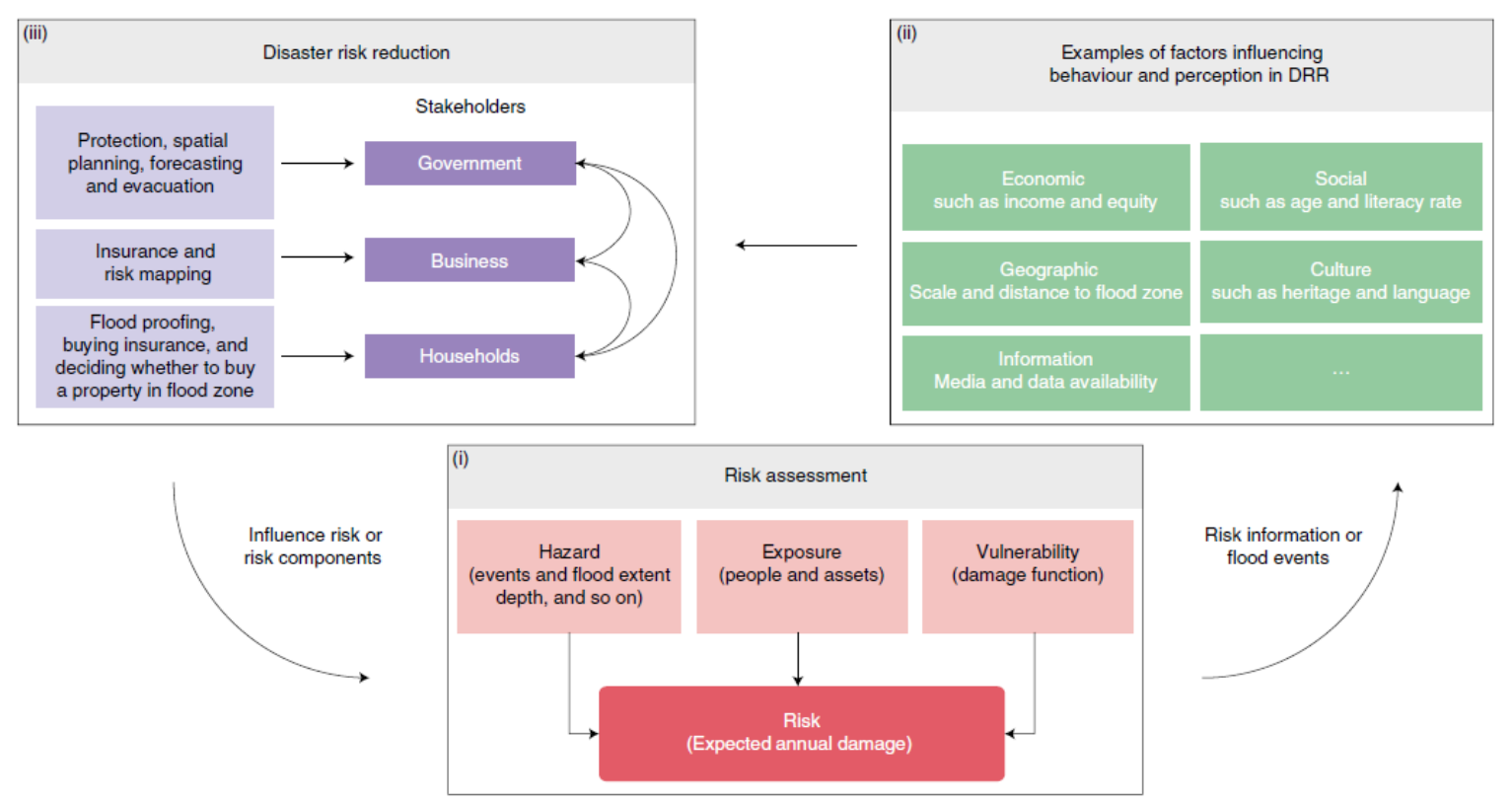

Source: Aerts et al. (2018).

An alternative approach and multi-disciplinary approach to estimate flood risk is the socio-hydrological. Socio-hydrology is the science of people and water, a new science that is aimed at understanding the dynamics and co-evolution of coupled human-water systems (Sivapalan et al., 2012). This approach has been used in several studies to analyse the dynamics of the relationship between society and floods (Viglione et al., 2014; Gober \& Wheater, 2015; Di Baldassarre et al., 2017; Ciullo et al., 2017; Fuchs et al., 2017). 
Thus, this study's aim was to develop conceptually a framework that combines climate change projections and a socio-hydrological approach to estimate flood risk and communicates this risk to the society, in order to increase flood risk awareness. To achieve this goal, the sociohydrological model developed by Di Baldassarre et al. (2015) and adapted by Ciullo et al. (2017) was applied with historical and projected rainfall data and the results were analysed based on their applicability in the planning of risk reduction measures and on their capacity to translate the society behaviour in the study area.

This study integrates the water security component in the face of climate change of INCT-MC2 (FAPESP 2014 / 50848-9), was developed in collaboration with the UK Academies (FAPESP 2011 / 51305-0) and it was funded by CAPES PROEX [grant nº 88882.328899/201901]. This work is also a contribution to the international Panta Rhei Decade Water \& Society (Montanari et al., 2013).

\subsection{TEXT ORGANIZATION}

Five chapters compose this master thesis. This chapter is dedicated to a general overview of the study. It presents the study's hypothesis, goals and objectives, and the area in which the case study was applied. The second and third chapters address, respectively, the historical and future analysis of the flood risk in the study area.

In Chapter 2, the socio-hydrological model is applied using historical data, collected through newspaper articles, to estimate the flood risk in the basin between the years of 1940 and 2018. This chapter's results present the impacts of the social and environmental flood risk reduction measures on flood risk over time.

In Chapter 3, rainfall data from a climate model is used as input to a framework that couples a cellular automata and the socio-hydrological model to evaluate the flood risk between the years of 2020 and 2099.

Chapter 4 gathers the information generated in the previous chapters and serves as a foundation for the presentation of the Socio-Hydrology Observatory for Water Security conceptual model. Finally, Chapter 5 presents the general conclusions and the recommendations for future works. 


\subsection{RESEARCH HYPOTHESIS}

This study hypothesis is that climate change projections and social aspects can be embodied in Flood Risk Management (FRM) steps to improve the techniques currently used.

\subsection{GOALS AND OBJECTIVES}

\subsubsection{Goal}

Develop conceptually a platform cooperative to acquire and provide information about urban flood risk coevolution under climate change scenarios, using the Socio-Hydrology Observatory for Water Security (SHOWS).

\subsubsection{Objectives}

- Analyse flood risk reduction measures related to social aspects;

- Incorporate social and climate change aspects in the flood risk analysis.

\subsection{CASE STUDY}

The Gregório Creek catchment is located in the city of Sao Carlos - SP, in Brazil's southeast region, and has a total area of $18.9 \mathrm{~km}^{2}$. The flood events in the catchment are related to convective precipitation (Barros et al. 2007). Urbanisation started in the city of São Carlos in the 18th century at the western part of the Gregório Creek catchment. At the beginning of the twentieth century, the Municipal Market was built on the creek's bank. Since then, this region has been shaped by intense commercial activity and has been a key area for the city's economic development. Historical records indicate that this region already suffered from impacts caused by floods during that time (Mendes \& Mendiondo, 2007). 
Figure 3: Gregório creek catchment (highlighted in blue) in the city of São Carlos - Brazil (highlighted in pink).

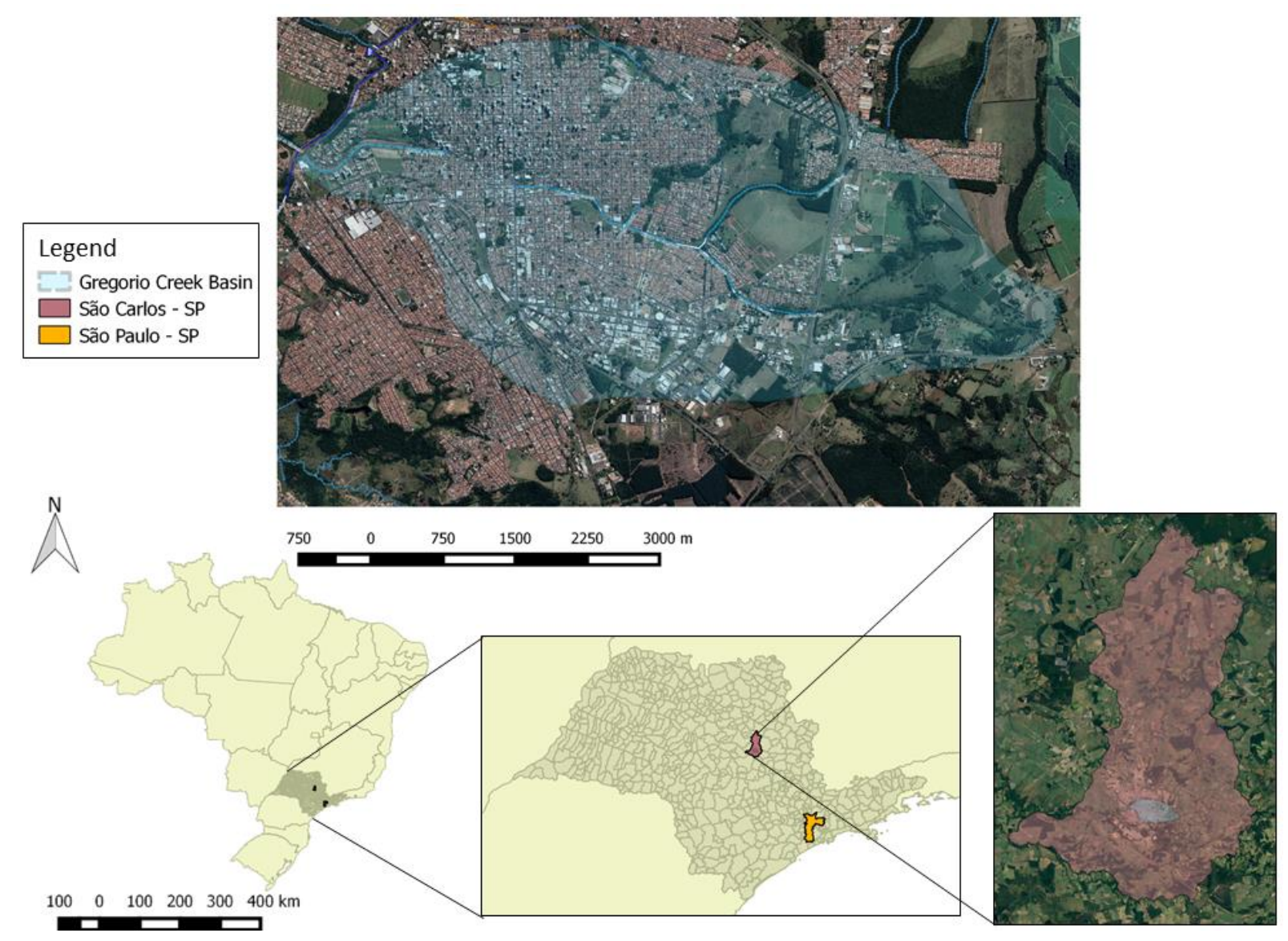

Mendes and Mendiondo (2007) divided the period after the first flood record into three stages related to the urbanization rate in the catchment. In the first stage, from 1950 to 1970, the catchment underwent intense urbanisation. For the next ten years, the catchment experienced an urbanisation slowdown, characterising the second stage. From 1980 to 2002, in the third stage, the urbanised area in the catchment started growing again as in the first stage. In this study, the third stage was extended to 2004, which shows a similar urbanisation trend, and then the fourth stage was introduced, ranging from 2004 to 2018, where the urbanisation rate nearly doubled (Figure 2).

From 1940 to 2018, the urbanised area in the catchment increased from three to $14 \mathrm{~km}^{2}$, approximately $75 \%$ of the total catchment area. In terms of inhabitants, the first stage presented a mean annual growth rate of $0.4 \%$. Despite the stabilisation of the urban area size in the second stage, the mean annual growth rate rose to $2 \%$. In the third stage, this index reduced to $0.6 \%$, followed by growth in the fourth stage, leading to a value of $2.8 \%$. 
Figure 4: Population density values with time in the different periods mentioned in Mendes and Mendiondo (2007).

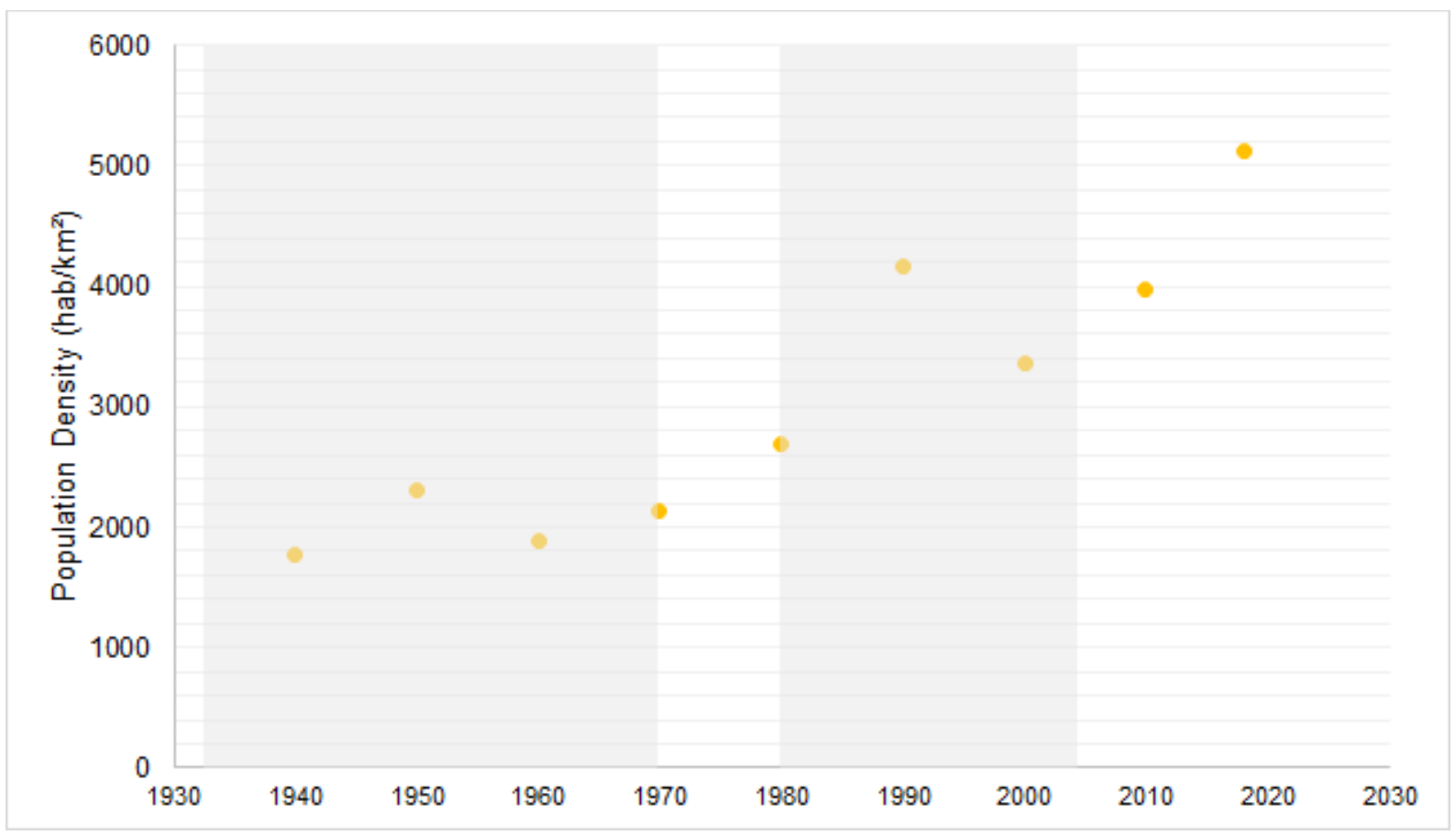

Around the middle of the first stage, the new Municipal Market building was opened, also on the creek's bank. At the same time, the media depicted the creek as an obstacle to the city's progress, as the flood events damaged commercial activities, indicating the need for structural measures to reduce the occurrence of extreme events (Lima, 2017). During the second stage, the most substantial structural measures were built in the creek, such as a lining bed and walls and a changing cross-section, which shows that the intense urbanisation in the first stage overloaded the catchment's drainage network (Mendes \& Mendiondo, 2007). In that period, avenues were also built on the creek's banks (Lima, 2017).

The shopkeepers in the region affirmed that the flood magnitudes were intensified in the third stage. However, the sense of belonging to and identifying with a place shows that the shopkeepers consider the city's central area as their place and, because of this, want to stay there despite the flood problem (Marotti et al., 2014). Instead of moving to another place, they would rather adopt coping strategies, such as building protective measures (Figure 3) or lifting the products to higher places in the store. 
Figure 5: Adaptive measures in a jewellery store in the Municipal Market area. The floor level enhancement is highlighted in yellow, and the supports for the flood barrier are highlighted in red.

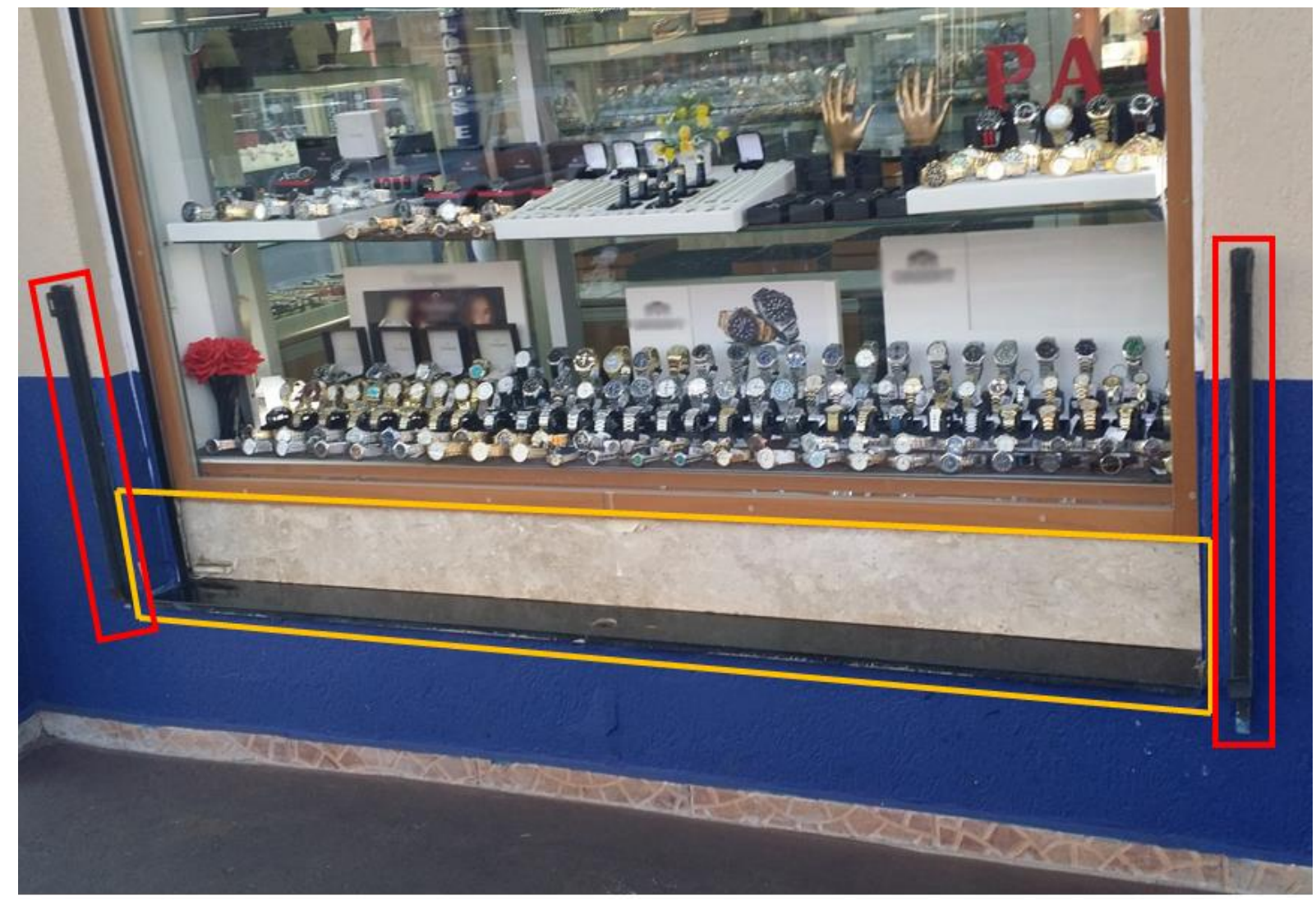

Marotti et al. (2014) interviewed the shopkeepers and identified that the notion of place, such as belonging and identity, makes it clear that shopkeepers regard the centre as their place and therefore wish to remain there despite the flood problem. When asked if they would leave the area, some responded that they would not know where to go and others replied that they would not leave because they love that region.

\subsection{REFERENCES}

Aerts, J. C., Botzen, W. J., Clarke, K. C., Cutter, S. L., Hall, J. W., Merz, B., ... \& Kunreuther, H. (2018). Integrating human behaviour dynamics into flood disaster risk assessment. Nature Climate Change, 8(3), 193-199.

Arnell, N. W., \& Gosling, S. N. (2016). The impacts of climate change on river flood risk at the global scale. Climatic Change, 134(3), 387-401.

Barros, R., Mendiondo, E. \& Wendland, E. (2007). Cálculo de Áreas Inundáveis Devido a Enchentes para o Plano Diretor de Drenagem Urbana de São Carlos (PDDUSC) na Bacia Escola do Córrego do Gregório. Rev. Bras. Recur. Hídr, 12, 5-17.

Blöschl, G., Hall, J., Parajka, J., Perdigão, R. A., Merz, B., Arheimer, B., ... \& Čanjevac, I. (2017). Changing climate shifts timing of European floods. Science, 357(6351), 588590. 
Blöschl, G., Hall, J., Viglione, A., Perdigão, R. A., Parajka, J., Merz, B., ... \& Boháč, M. (2019). Changing climate both increases and decreases European river floods. Nature, 573(7772), 108-111.

Ciullo, A., Viglione, A., Castellarin, A., Crisci, M. \& Di Baldassarre, G. (2017). Sociohydrological modelling of flood-risk dynamics: comparing the resilience of green and technological systems. Hydrological Sciences Journal, v. 62, n. 6, p. 880-891, 2017.

Di Baldassarre, G.; Viglione, A.; Carr, G.; Kuil, L.; Yan, K.; Brandimarte, L. \& Blöschl, G. (2015). Debates - perspectives on socio-hydrology: Capturing feedbacks between physical and social processes. Water Resources Research, v. 51, n. 6, p. 4770-4781, 2015.

Di Baldassarre, G., Saccà, S., Aronica, G. T., Grimaldi, S., Ciullo, A., \& Crisci, M. (2017). Human-flood interactions in Rome over the past 150 years. Adv. Geosci, 44, 9-13.

Fuchs, S., Karagiorgos, K., Kitikidou, K., Maris, F., Paparrizos, S., \& Thaler, T. (2017). Flood risk perception and adaptation capacity: a contribution to the socio-hydrology debate. Hydrology and Earth System Sciences, 21(6), 3183-3198.

Global Assessment Report on Disaster Risk Reduction. (UN Report 2019). (2019). Geneva, Switzerland: United Nations.

Gober, P., \& Wheater, H. S. (2015). Debates-Perspectives on socio-hydrology: Modeling flood risk as a public policy problem. Water Resources Research, 51(6), 4782-4788.

Hirabayashi, Y., Mahendran, R., Koirala, S., Konoshima, L., Yamazaki, D., Watanabe, S., ... \& Kanae, S. (2013). Global flood risk under climate change. Nature Climate Change, 3(9), 816-821.

Lima, M. C. P. B. (2017). Urban processes in São Carlos, SP: two river catchments, two periods. Paper presented at the National Association of Urban and Regional Post-graduate and Research Programs Meeting - ENANPUR. São Paulo, Brazil.

Marotti, A. C. B., Santos, K. E. L., Macera, L. G., de Lima Neves, L., Gonçalves, J. C., \& Pugliesi, É. (2014). Historical survey and reports of flooding of the Gregório stream at the central region of São Carlos municipality. Revista Eixo, 3(1).

Mendes, H. C. \& Mendiondo, E. M. (2007). Histórico da expansão urbana e incidência de inundações: O Caso da Bacia do Gregório, São Carlos-SP. Revista Brasileira de Recursos Hídricos, 12(1), 17-27.

Montanari, A., Young, G., Savenije, H. H. G., Hughes, D., Wagener, T., Ren, L. L., ... \& Blöschl, G. (2013). "Panta Rhei-everything flows": change in hydrology and societythe IAHS scientific decade 2013-2022. Hydrological Sciences Journal, 58(6), 12561275.

O’Reilly, T. What is web 2.0. (2005). Disponível em: <http://www.oreilly.com/pub/a/ web2/archive/what-is-web-20.html .

Sendai framework for disaster risk reduction 2015-2030. (UNISDR Report 2015). (2015). Geneva, Switzerland: United Nations Office for Disaster Risk Reduction.

Shneiderman, B. (2008). Copernican challenges face those who suggest that collaboration, not computation are the driving energy for socio-technical systems that characterize web 2.0. Science, v. 319, n. 5868, p. 1349-1350.

Sivapalan, M., Savenije, H. H. G. \& Blöschl, G. (2012). Socio-hydrology: A new science of people and water. Hydrological Processes, 26(8), 1270-1276.

Viglione, A., Di Baldassarre, G., Brandimarte, L., Kuil, L., Carr, G., Salinas, J. L., ... \& Blöschl, G. (2014). Insights from socio-hydrology modelling on dealing with flood risk-roles of collective memory, risk-taking attitude and trust. Journal of Hydrology, 518, 71-82. 
2 USING HISTORICAL SOURCE DATA TO UNDERSTAND URBAN FLOOD RISK: A SOCIO-HYDROLOGICAL MODELLING APPLICATION AT GREGÓRIO CREEK, BRAZIL

* A modified version of this chapter has been published as: Buarque, A. C. S.; Bhattacharya-Mis, N.; Fava, M. C.; Souza, F. A. A; Mendiondo, E. (2020). Using Historical Source Data to Understand Urban Flood Risk: A Socio-Hydrological Modelling Application at Gregório Creek, Brazil. Hydrological Sciences Journal, 65:7, 1075-1083, DOI: 10.1080/02626667.2020.1740705.

Abstract: The city of São Carlos, state of São Paulo, Brazil, has a historical coexistence between society and floods. Unplanned urbanization in this area is a representative feature of how Brazilian cities have developed, undermining the impact of natural hazards. The Gregório Creek catchment is an enigma of complex dynamics concerning the relationship between humans and water in Brazilian cities. Our hypothesis is that social memory of floods can improve future resilience. In this chapter we analyse flood risk dynamics in a small urban catchment, identify the impacts of social memory on building resilience and propose measures to reduce the risk of floods. We applied a socio-hydrological model using data collected from newspapers from 1940 to 2018. The model was able to elucidate human-water processes in the catchment and the historical source data proved to be a useful tool to fill gaps in the data in small urban basins.

Keywords: Urban Floods; Socio-Hydrology; Flood Risk; Social Memory of Floods; Historical Data Source. 


\subsection{INTRODUCTION}

Floods affect more people worldwide than any other hazard and Brazil has the second highest flood loss potential in the world (UNISDR, 2015a). To reduce disaster risk and losses, one of the priorities for focus actions set up by the UN Sendai Framework (UNISDR, 2015b) was understanding disaster risk and enhancing preparedness. Risk preparedness is influenced by individual risk perception, which is based on an individual's prior expectations, information about risk and personal vulnerability (Miceli et al., 2008; Aerts et al. 2018). According to Garde-Hansen et al. (2017), for communities to be aware of flooding (and very important to prepare and take action) as a form of 'socio-ecological resilience', they need to record memories and remember events in some way.

Memory is a fundamental underpinning of individual and collective life in place, and thus needs attention in any deliberation of individual and collective resilience (McEwen et al., 2017). Memory is an extremely interdisciplinary subject of study. Psychologists, neuroscientists, anthropologists, computer scientists, philosophers, among others, have been discussing this topic for a long time. Over the years, scholars have fractionated memory into various processes and systems according to the objective of their studies (Roediger and Wertsch, 2008).

In the philosophical field, Hallbwacks (1992) distinguishes two types of memory: individual or personal, and collective or social. In the field of psychology, Atkinson and Shiffrin (1968) divided memory structural components into three features: sensory register, short-term store, and long-term store. More recently, socio-hydrological research (Sivapalan et al., 2012) has identified memory as an important driver that affects individual values, which are responsible for shifting the feedback between societies and water management. Di Baldassarre et al. (2013) and Viglione et al. (2014) proposed a set of differential equations to simulate the dynamics of a floodplain. Viglione et al. (2014) identified that collective memory, risk-taking attitudes and trust have a high impact in the process of building up a flood risk culture.

Di Baldassarre et al. (2015) proposed a simplification of the previous model (Di Baldassarre et al., 2013; Viglione et al., 2014) to decipher changes in flood risk using highwater levels to estimate relative flood damage, social memory of floods, population density and flood protection level. The model is a mathematical formalization of general, plausible 
hypotheses about human-flood interactions and does not attempt to perfectly schematize the dynamics of a specific case study, which would be impossible to generalize (Di Baldassarre et al., 2015).

Ciullo et al. (2017) applied this model in two real-world case studies. The first one, applied in the city of Rome, used the maximum water level as input in the model, while the second one, applied in the city of Bangladesh, used the flooded area as a proxy for the flood intensity. Since time series might not be available in small basins, alternative sources of data are required to evaluate the magnitude of flood events, such as the possibility to acquire information from photographs. Government-installed cameras or researchers can take these photographs, but a low-cost alternative is using photographs taken by citizens on their cellphones.

In this study, we gathered information from newspaper articles to estimate the maximum water level in several flood events. Our hypothesis is that information provided by the society, such as narratives or photographs, can fill the gap left by the absence of observational networks in small urban catchments. Having this historical dataset, we applied the model proposed by Di Baldassarre et al. (2015) to analyse the flood risk dynamics in the Gregório Creek catchment, located in the city of São Carlos - SP, from 1940 to 2018. The aim of this paper is to understand the role of the social memory of floods in the flood risk variation and identify what adaptation strategies could be undertaken in order to reduce flood risk.

\subsection{METHODOLOGY}

We employed the socio-hydrological equations from Di Baldassarre et al. (2015) and adapted to the Gregório Creek's case study. Although this model is based on simplified equations, we selected it due to the possibility of comparing real-world observations as it uses the floodplain population density instead of community wealth and the average distance from the river, as in the previous version of the model. The model is a System Dynamics framework, which investigates system outcomes and identifies correlations to determine system behaviours (Blair and Buytaert, 2016), to model human-water dynamics in a floodplain, linking hydrological, demographic, societal and technological aspects.

According to Di Baldassare et al. (2015), the model is a simplification of the previous onde (Di Baldassarre et al., 2013; Viglione et al., 2014) and it is a mathematical formalisation 
of general, plausible hypotheses about human-flood interactions. It does not attempt to perfectly schematise the dynamics of a specific case study, which would be impossible to generalise.

According to Lättilä et al. (2010), in System Dynamics modelling, leverage points for intervention can be identified fairly effectively. However, this is not possible at an individual level. Top-down approaches, such as this one, are popular because the data are relatively easy to collect and are inherently comparable (Srinivasan et al. 2012). For this reason, it is more suitable to apply this approach for studies in small and ungauged watersheds. Hence, in this study an analysis of coupled human-water systems with a "human-in-the-loop" approach is proposed, using photographs made available in physical and online newspapers by the society to improve the socio-hydrological model for the Gregório Creek catchment.

\subsubsection{Socio-Hydrology Modelling}

The model developed by Di Baldassarre et al. (2015) estimates the variation of floodplain density $(D)$, societal memory of floods $(M)$, flood protection level $(H)$, the amount of levee heightening $(R)$ and relative losses $(F)$ over time using flood magnitude $(W)$ as input data. In case of flooding, the reduction of population density due to people displacement immediately after the event, as well as the contemporaneous building of societal memory and heightening of levees (for the technological society) are modelled as instantaneous (Di Baldassarre et al., 2015). More details about the model are reported in Di Baldassarre et al. (2013, 2015) and Viglione et al. (2014). The source code of the model can be found in the supplementary material of this study.

$$
\begin{gathered}
F=1-\exp \left(\frac{-W}{\alpha_{H}}\right) \\
\frac{d D}{d t}=\rho_{D}\left(1-D\left(1+\alpha_{D} M\right)\right)-\Delta(\psi(t)) \cdot F D_{-} \\
\frac{d M}{d t}=\Delta(\psi(t)) F D_{-}-\mu_{S} M \\
\frac{d H}{d t}=\Delta(\psi(t)) R-\kappa_{T} H \\
\mathrm{R}=\varepsilon_{T}\left(W+\xi_{H} H_{-}-H_{-}\right)
\end{gathered}
$$

where the Greek letters $\alpha, \rho$, and $\mu$ represent time invariant parameters, as presented in Table 1; $\Delta(\psi(t)), \kappa_{T}, \varepsilon_{T}$, and $\xi_{H}$ are, respectively, a nonperiodic Dirac comb, the protection level decay rate, the safety factor for levee heightening and, flood enhancement due to the presence 
of levees over time. The variables with the underscore represent the value immediately before the flood event. The subscript $\mathrm{T}$ stands for the technological equation, which was not used in this study.

Table 1: Description of parameters and their adopted values.

\begin{tabular}{cccc}
\hline Parameter & Description & Unit & Adopted value \\
\hline$\alpha_{H}$ & Parameter related to flood depth-damage curve & $\mathrm{L}$ & $13^{\mathrm{a}}$ \\
$\rho_{D}$ & Maximum relative growth rate & $1 /$ year & $0.009^{\mathrm{a}}$ \\
$\alpha_{D}$ & Ratio between preparedness and awareness $^{\mathrm{a}}$ & - & $5^{\mathrm{a}}$ \\
$\mu_{S}$ & Memory loss rate $^{\mathrm{a}}$ & $1 /$ year & $0.5^{\mathrm{b}}$ \\
\hline
\end{tabular}

Source: ${ }^{\mathrm{a} D i}$ Baldassarre et al. $(2015),{ }^{\mathrm{b}}$ Author.

The equation that refers to the societal memory of floods (Equation 3) is calculated based on what Di Baldassarre et al. (2015) calls magnitude of psychological shock experienced by the community, which is calculated based on the proportion of flood damage. Many studies have recognised that individual memory intensity is not a function of disaster exposure (Sotgiu and Galati, 2007). However, in this study, we assumed that collective memory may be accumulated if more people are affected by flood events. We assumed that, by experiencing a flood event, an individual receives inputs that are transmitted to the short- and long-term store sequentially.

The exposure of individuals to stressful events, such as natural disasters, leads to the secretion of adrenocorticotrophin hormone (ACTH) and subsequently, the secretion of cortisol into the bloodstream (Shaley, 2000). Some studies have identified that stress-induced cortisol enhances the long-term memory of experiences that have a degree of arousal (Buchanan and Lovallo, 2001; Cahill et al., 2003; Jelicic et al., 2004; LaBar and Cabeza, 2006). Flood memories can be considered as a feeling of arousal because people have a strong emotional attachment to their homes and can experience severe distress if their homes are damaged or destroyed (Tapsell and Tunstall, 2008).

Based on this, we assume that more intense flood events affect more people and thereby increase the number of individuals in the community with enhanced long-term memory by releasing cortisol during events. Fanta et al. (2019) divide collective memory into living and distant. The living memory is the memory of witnesses who are still alive in the population; it has an emotional charge and can be passed on through narratives. The distant memory is the one transferred through history textbooks or academic works. In this study, we analyse the 
memory modelled through equations developed by Di Baldassarre et al. (2015) as the living memory of the community. We assume that living memory increases proportionally to the flood damage because, as more people are affected by the flood, more people will have an enhanced long-term memory in the community, and more narratives can be shared to build up the living memory (Figure 6).

Figure 6: Representation of the construction of the Living Memory ${ }^{2}$. SR is Sensory Register, ST and LT are the Short- and Long-Term storage, respectively. ${ }^{1}$ Atkinson and Shiffrin (1968), ${ }^{2}$ Fanta et al., (2019), ${ }^{3}$ Hallbwacks (1992).

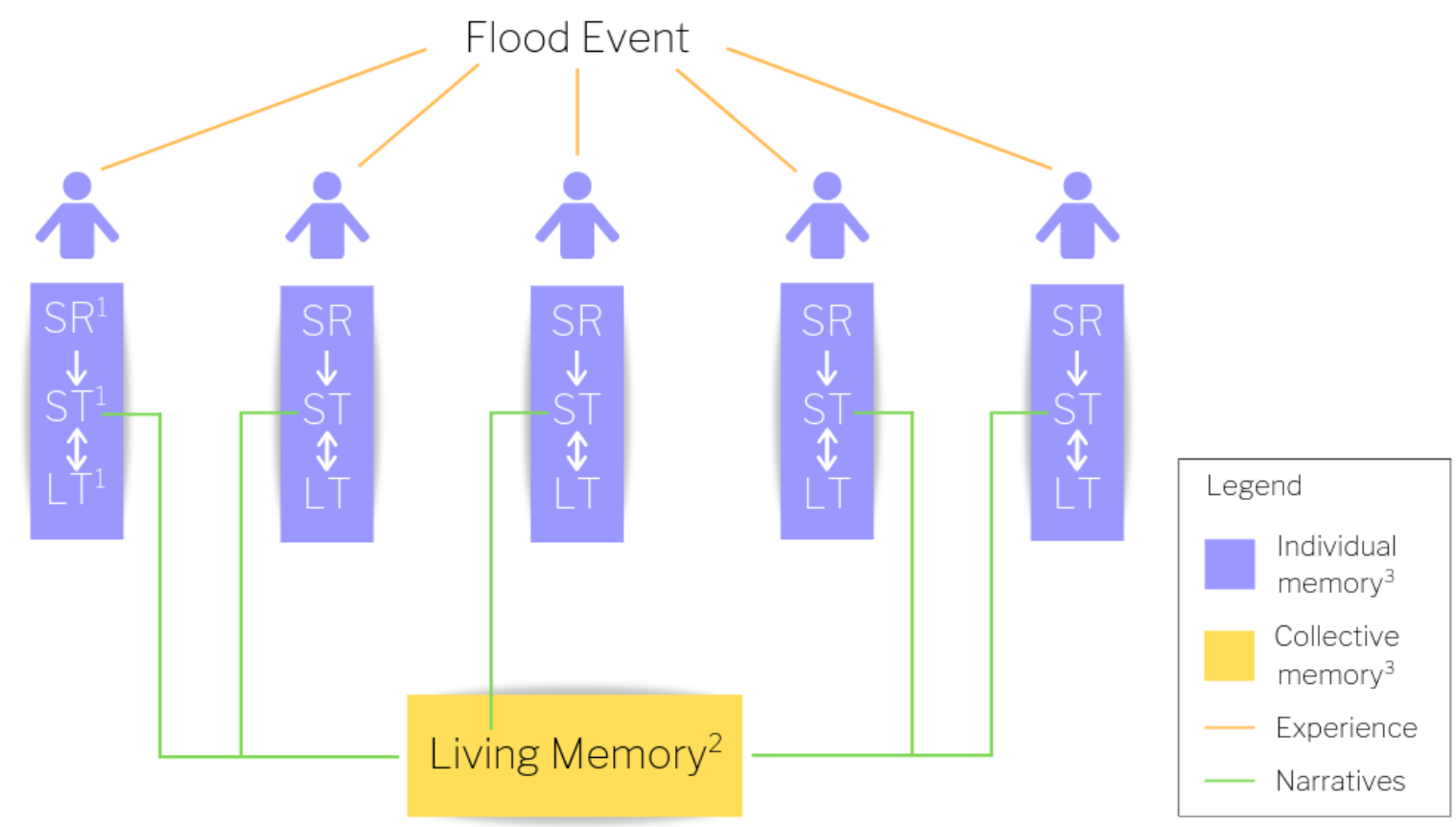

In our case study, the community is assumed to behave as a technological society, as they did not move away from the creek after the flood events and structural measures were constructed in the creek. However, there is no way to insert the measures adopted in this area in the model because the model assumes the flood protection level as the levee height, which is not the measure adopted there.

We modelled community behaviour assuming that no levees were built (i.e. the amount of levee heightening $(R)$ equals to zero), so there was no amount of flood enhancement due to the presence of levees over time $\left(\xi_{H} H_{-}=0\right)$. Hence, Equations (1)-(3) were used in this study. However, the maximum water levels used as input data in the model consider the flood enhancement due to the structural measures built in the creek, thus reducing the uncertainty brought about by the disregard of the technological equation. 


\subsubsection{Model Parameters}

The parameter $\alpha_{H}$ (see Table 1) for the current state of the basin (without any technological and social solutions applied) was estimated using the definition from Viglione et al. (2014): the relation between the critical distance from the river beyond which the settlement can no longer grow, the mean flood water level and distance of the settlement center of mass to the river. Whereas $\rho_{D}$ is the urbanisation rate maximum value $\left(\mathrm{km}^{2} /\right.$ year $)$ in this basin, which was obtained through a spatial analysis of urbanised areas per year. The total urbanised area in each year was divided by the total area of the basin, and the maximum of these values was used.

Parameters $\alpha_{D}$ and $\mu_{S}$ refer to social aspects, for which we do not have related data. To understand their behaviour, we performed a sensitivity analysis of the model regarding these two parameters and the model showed less sensitivity to parameter $\alpha_{D}$. Therefore, we chose to adopt the value established by Di Baldassarre et al. (2015) for parameter $\alpha_{D}$ and to adjust the $\mu_{S}$ parameter so that the values of the Population Density, resulting from the model, were adjusted to the observed ones.

Although parameter $\mu_{S}$ does not appear directly in the equation related to the Population Density (Equation 2), it is inserted into the equation that models the Social Memory of Floods (Equation 3), which is a variable that Equation 2 is dependent. Considering this, the variation of the parameter $\mu_{S}$ will generate different results for all variables of the model.

\subsubsection{Risk Estimation}

The risk $(R)$ was estimated adopting the method proposed by Ciullo et al. (2017), which is defined by Equation 4. The Hazard is assumed to be the probability of the event to occur $\left(f_{w_{a}}\right)$, and the Losses are the product between relative losses $(F)$ and floodplain density $(D)$ (Equation 5). The term $f_{w_{a}}$ is represented by the generalized extreme value (GEV) probability density function of variable $W$, which has the parameters of shape, scale and location equal to $0.6,0.06$ and 0.02 , respectively.

$$
\text { Risk }=\text { Hazard } \times \text { Losses }
$$




$$
\operatorname{Risk}=\int_{0}^{+\infty} f_{w_{a}}(w) L(w, D, H) d w
$$

where $W$ is annual high water level.

\subsubsection{Data Acquisition}

The flood water level dataset used in this work was collected from newspaper articles by Mendes and Mendiondo (2007), as well as the authors of this paper for the periods 19322004 and 2005-2018, respectively. The events were divided into four classes by the water level measurements during the event: (i) no water-level measurements (32 events); (ii) water level below $0.6 \mathrm{~m}$ (eight events); (iii) between 0.6 and $1.2 \mathrm{~m}$ (three events); and (iv) greater than 1.2 $\mathrm{m}$ (one event).

According to the tendency of the occurrence of events we adjusted an exponential trend line (Figure 7) linking the mean water level of events and the return period of each class. This was done using events only from classes (ii) and (iii), since there was only one event in class (iv). The return period of each class was adopted as the mean time between the events in each class. Hence, the mean water level $(0.2 \mathrm{~m})$ was estimated during the events registered in class (i), which has a mean return period of 1.9 years. 
Figure 7: Number of events occurred (bars) and mean flood water level per class (red dots), classified according to the mean return period and their tendency (dotted blue and dot-dashed red lines, respectively).

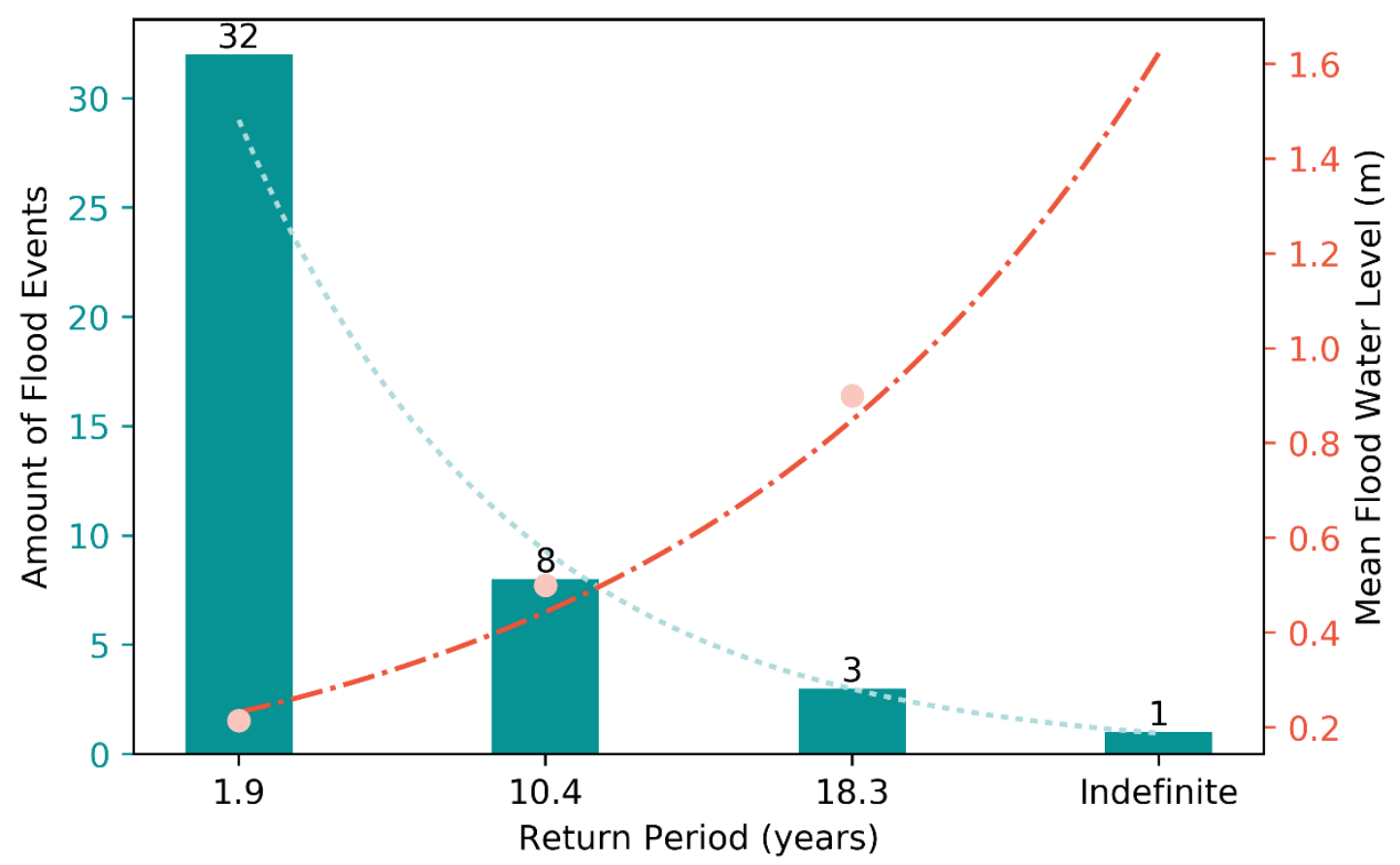

The water level in the streets from 2005 to 2018 was estimated by visual analysis of these events' photographs, available in local newspaper articles. The water level was identified as a comparison was made with strategic elements, whose dimensions could be easily identified, such as submerged vehicles (Figure 6). Concerning data insertion into the socio-hydrological model, the annual maximum values were selected, giving 28 flood events for analysis. The intensity of each event was adopted as the mean water level measurement of its class, and the uncertainty intervals were the values between the maximum and minimum data of its class (Figure 9). 
Figure 8: Picture of submerged cars in a street from the 2018 flood event. The car highlighted in orange was used to estimate the flood water level.

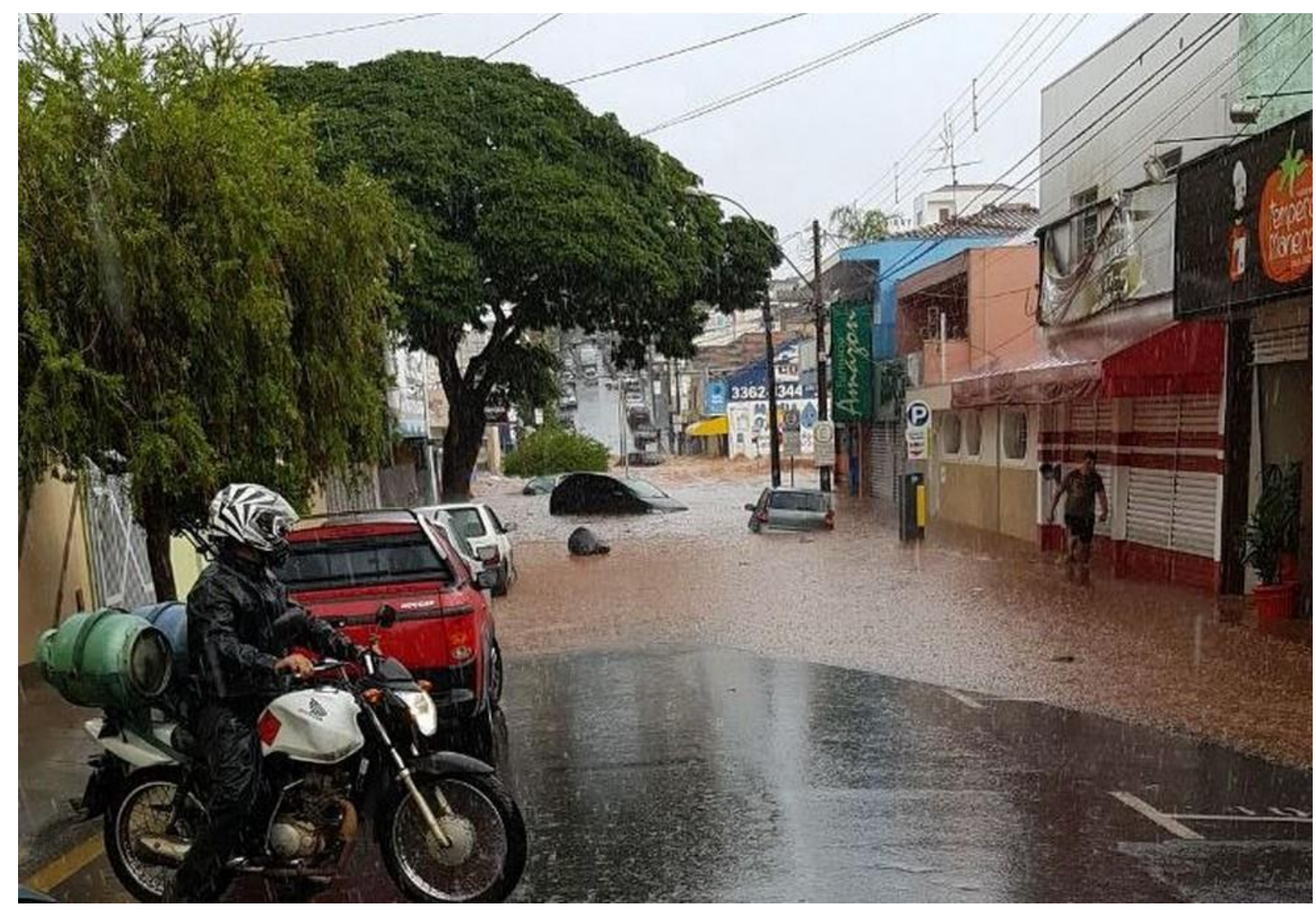

\section{Source: G1 (2018).}

Figure 9: Annual maximum water levels represented by their associated uncertainty intervals. The mean return periods are two, 10, and 18 years (black, green, and yellow markers, respectively). The grey shaded/white areas divide the graph into the four urbanisation stages.

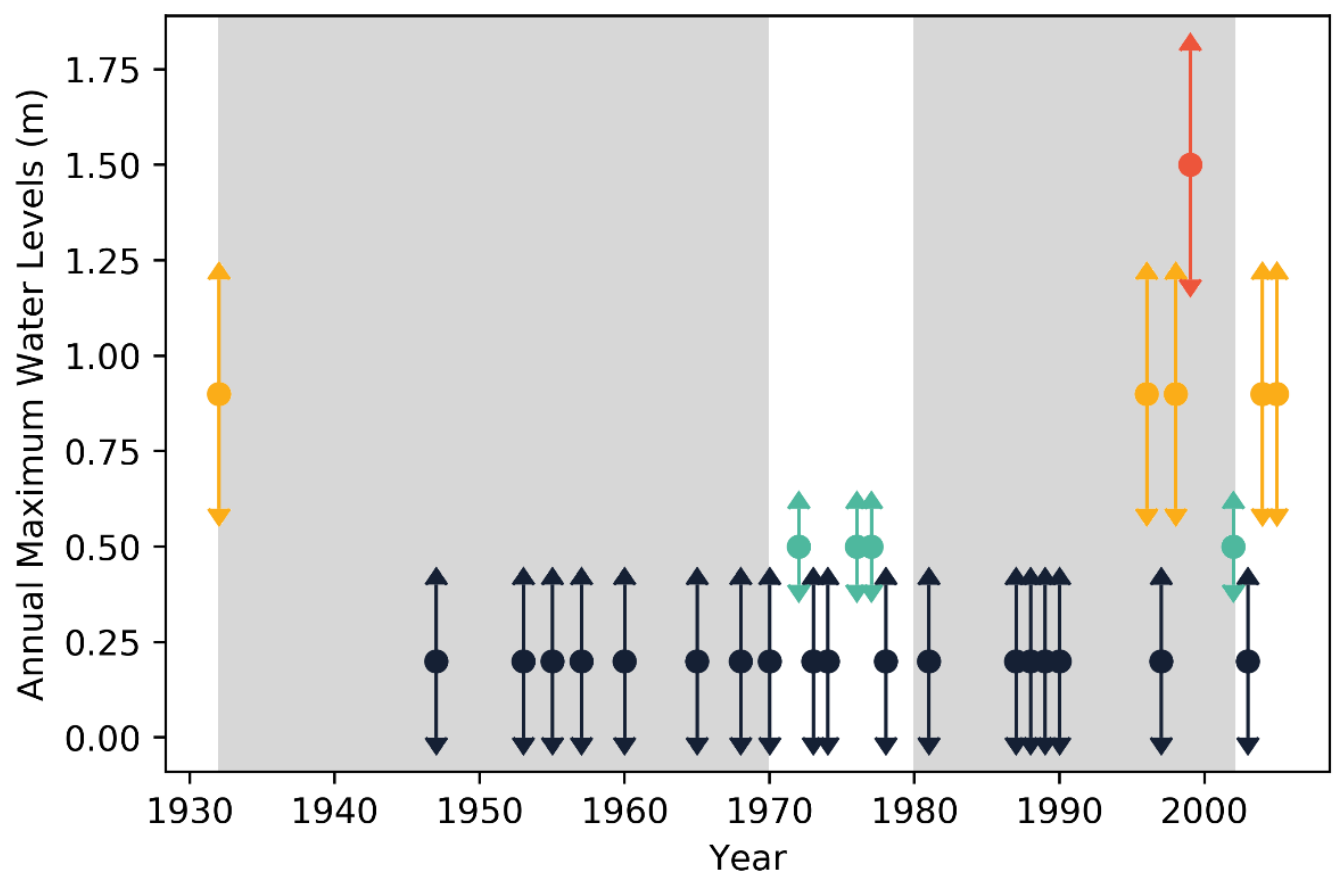




\subsubsection{Scenarios}

According to Ciullo et al. (2017), given the model capability of capturing empirically observed complex human-flood dynamics, the challenge now is to find out how different model components respond according to different possible societal attitudes. Thus, after applying the model to the current scenario of the region, we decided to analyse the model responses to changes related to awareness-raising attitude measures $\left(\mu_{S}\right.$ variation) and reduced vulnerability ( $\alpha_{H}$ variation). The first option suggests a decrease in the community vulnerability through an increase in the distance between the creek and the urban settlement from $0.2 \mathrm{~m}$ to $1 \mathrm{~m}$, varying the parameter related to the flood depth-damage curve $\left(\alpha_{H}\right)$ from 13 to 67.

The second hypothesis is that it is possible to reduce the risk of flooding by maintaining society's memory higher for a longer period. One way that this could be done is by putting up signs indicating the highest flood water level in different locations. For this purpose, the memory loss rate $\left(\mu_{S}\right)$ was changed from 0.5 to 0.01 . This new value represents that when a flood occurs, the people remember $99 \%$ of what they remembered during the previous flood (Viglione et al. 2014).

\subsection{RESULTS AND DISCUSSION}

\subsubsection{First Scenario: no interventions}

Erro! Fonte de referência não encontrada. presents the outcomes of the socioydrological model, with the flood magnitude levels (top graph) used as input data, and the normalised observed population density used to calibrate the model. It may be seen from Erro! onte de referência não encontrada. that the social memory of floods became stronger in the final part of the third stage of urbanisation (1980-2004), a period during which the frequency of more intense flood events increased. This first stage analysed is marked by the population density growth in the catchment. With the repeated occurrence of lower magnitude floods, a certain amount of memory remains in the community, but not enough to interfere in the urbanisation trend. In the second stage of urbanisation, the mean water level increased and the 
urbanisation trend stabilised, while the main structural measures and the marginal roads were built in and along the creek.

In the third stage, a resumption in growth can be identified, which is likely to have been due to greater accessibility as a result of new roads and the perception of safety provided by the structural measures. This dynamic is similar to the so-called "levee-effect" described by White (1945) and Di Baldassarre et al. (2018). The most significant flood event since 1932 occurred in 1996, leading to a decrease in the population density, and this was followed by the largest recorded event in 1999. Taking the reduction in the population in the catchment into account, the city authorities began to develop policies to encourage people to return to the area. However, instead of focusing on flood risk reduction or adaptation measures, the target was to revive the historical buildings and build new squares (FUSP, 2011).

In 2003, the Commerce Square (Figure 11), popularly known as Beira Rio (Riverside) Shopping, was opened with the aim of organizing and regulating the street hawkers who traded at the front of the Municipal Market; thus, another square was created in 2011. Such actions may have been responsible for the renewed growth in population density from 2006, even though at this time the social memory of floods achieved the second-greatest peak of the analysed period, a factor that should have stimulated the migration away from the floodplain. 
Figure 10: Socio-hydrological model input data (flood magnitude, in black) and outcomes (red, with uncertainty shown as shaded areas), with the observed population density (yellow dots). The grey shaded/white areas divide the graph into the four urbanization stages.

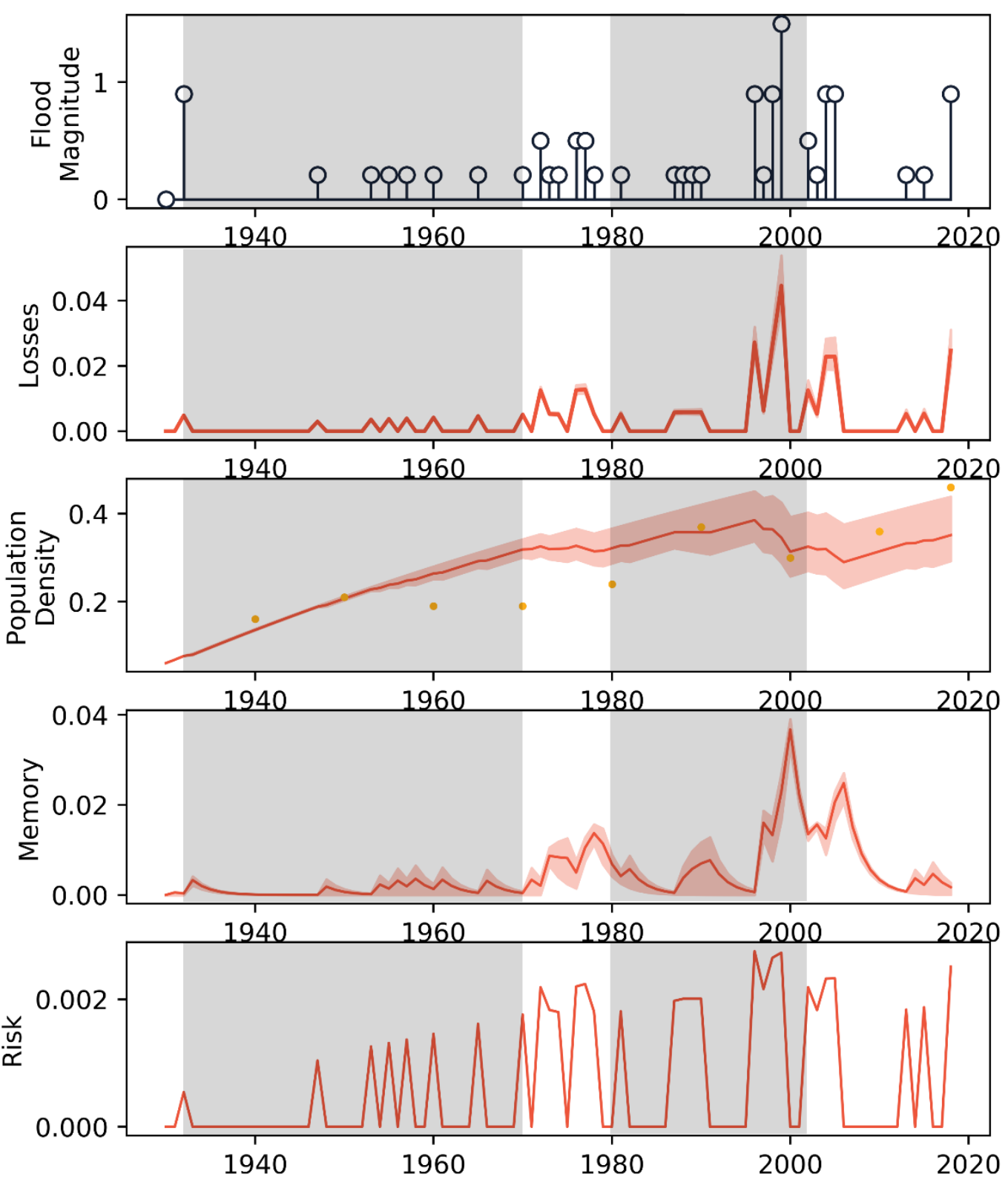


Figure 11: Section of Gregório Creek showing commerce square on the right bank.

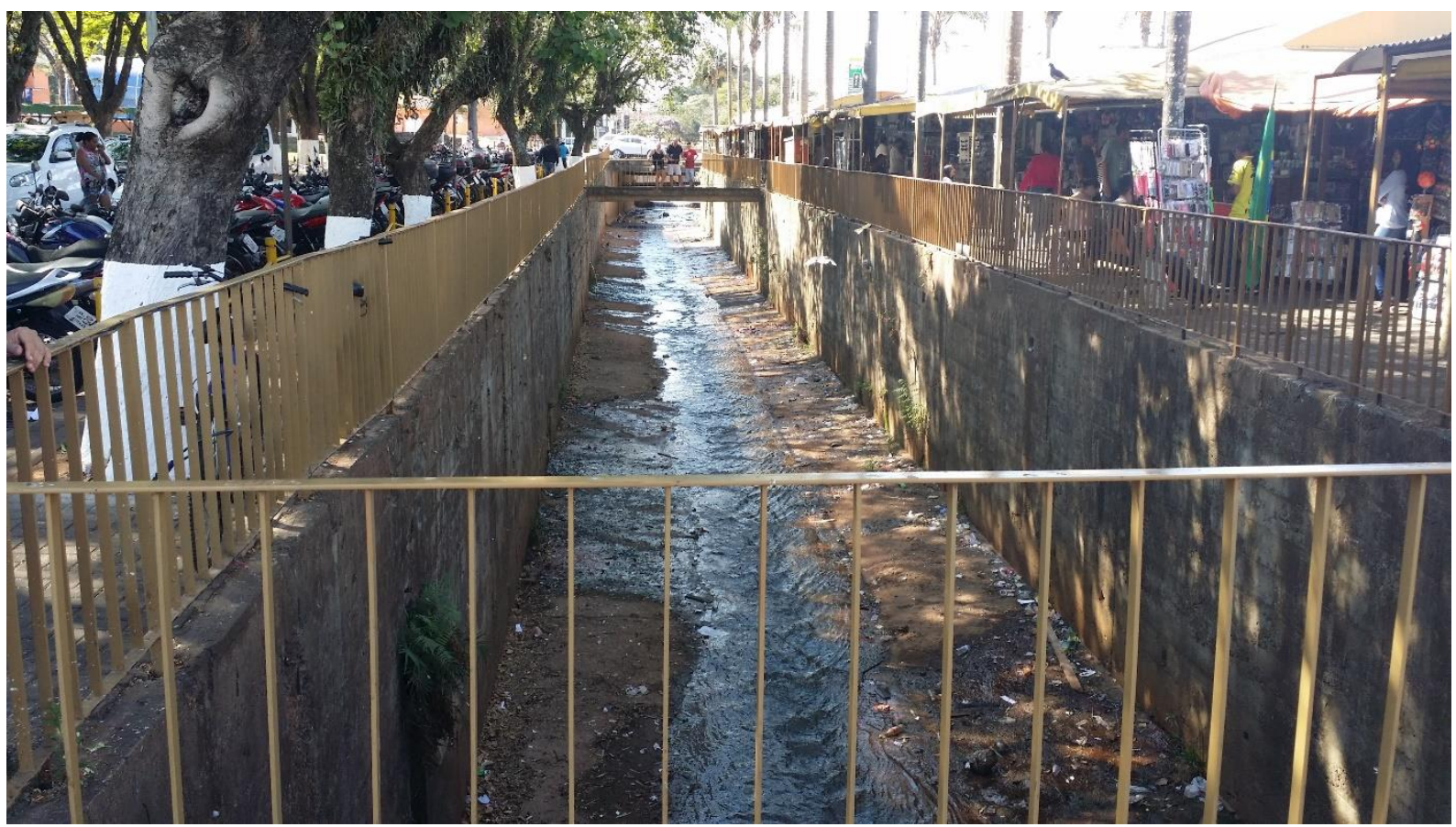

2.3.2 Second Scenario: environmental interventions

Figure 12 shows the results of memory, flood risk and population density dynamics under the second scenario (with variation in $\alpha_{H}$; see Table 1). It may be seen from Figure 12 that with a slight increase in the distance between the creek and urban settlement, the risk decreased, even with an almost constant population density growth. Although simple, the application of this measure implies moving commercial stands away from Commerce Square, which would bring about cultural and social issues, since the shopkeepers have a sense of belonging with this place.

\subsubsection{Third Scenario: social interventions}

The results of the third scenario are shown in Figure 13. It may be observed that the decrease in rate of memory loss had not brought about any changes in flood risk until the 1970s, a point in time when the structural measures were built in the creek and the flood magnitude intensified. One factor that may have induced this dynamic is the smaller losses in the first period, a characteristic behaviour of a "green" society (Ciullo et al., 2017). This process has not built up a noticeable level of social memory as the scale of loss and injury and the past 
impacts of past incidents would have contributed to an increase in the level of physical memory in a system (Bhattacharya-Mis and Lamond, 2014).

These results suggest that investments in policies to maintain the flood memory in technological societies can reduce the flood risk, but with a smaller effect than the option mentioned in the second scenario. When adopted simultaneously, the environmental and technological measures can complement each other by accepting the limitations of, possibly unreliable, human memories. According to Di Baldassarre et al. (2015), the presence of flood protection structures leads to a rapid decay in the memory of flooding, and, therefore, higher vulnerability and exposure of societies. However, despite the fact that society we studied behaved as a technological society, as people do not move away from the creek and build structural measures, the community is constantly experiencing flood events, because the measures adopted do not prevent the water from reaching the ground level.

Thus, the social memory of floods of this community was kept alive during almost the completely analysed period unlike the technological society analysed by Di Baldassarre et al. (2017) and Ciullo et al. (2017), who experienced long periods without living through memories of floods. Thus, a decrease in the parameter related to the rate of memory loss in the Gregório Creek catchment did not significantly reduced community vulnerability. 
Figure 12: Memory, Risk and Population Density according to the actual (black, $\alpha \_H=13$ ) and lower (blue, $\left.\alpha \_\mathrm{H}=67\right)$ vulnerability conditions. The grey and white areas represent the odds and even urbanisation stages, respectively.
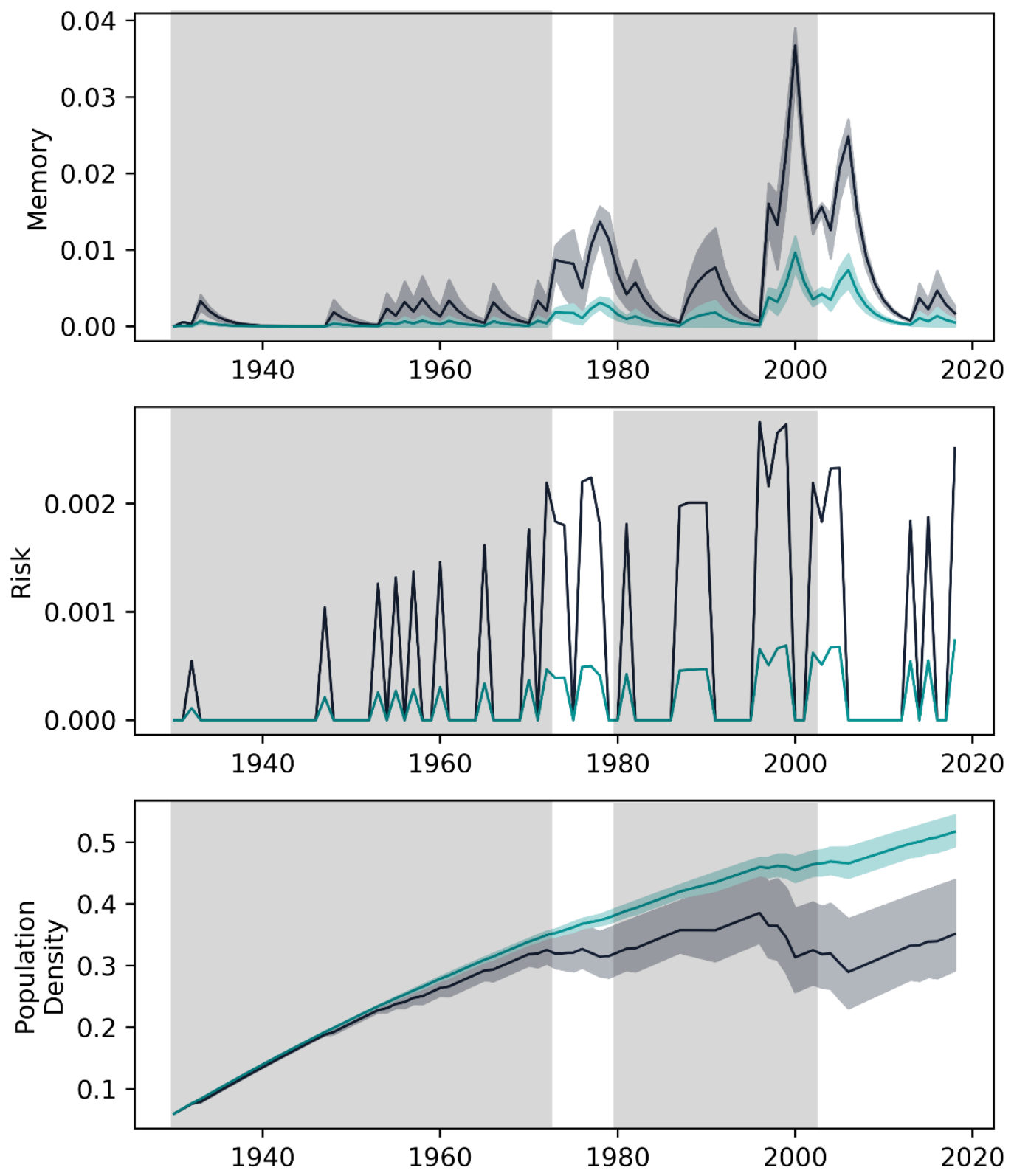
Figure 13: Risk variation for the actual (blue line, $\mu_{S}=0.5$ ) and minimum (red line, $\mu_{S}=0.01$ ) memory loss rate values.

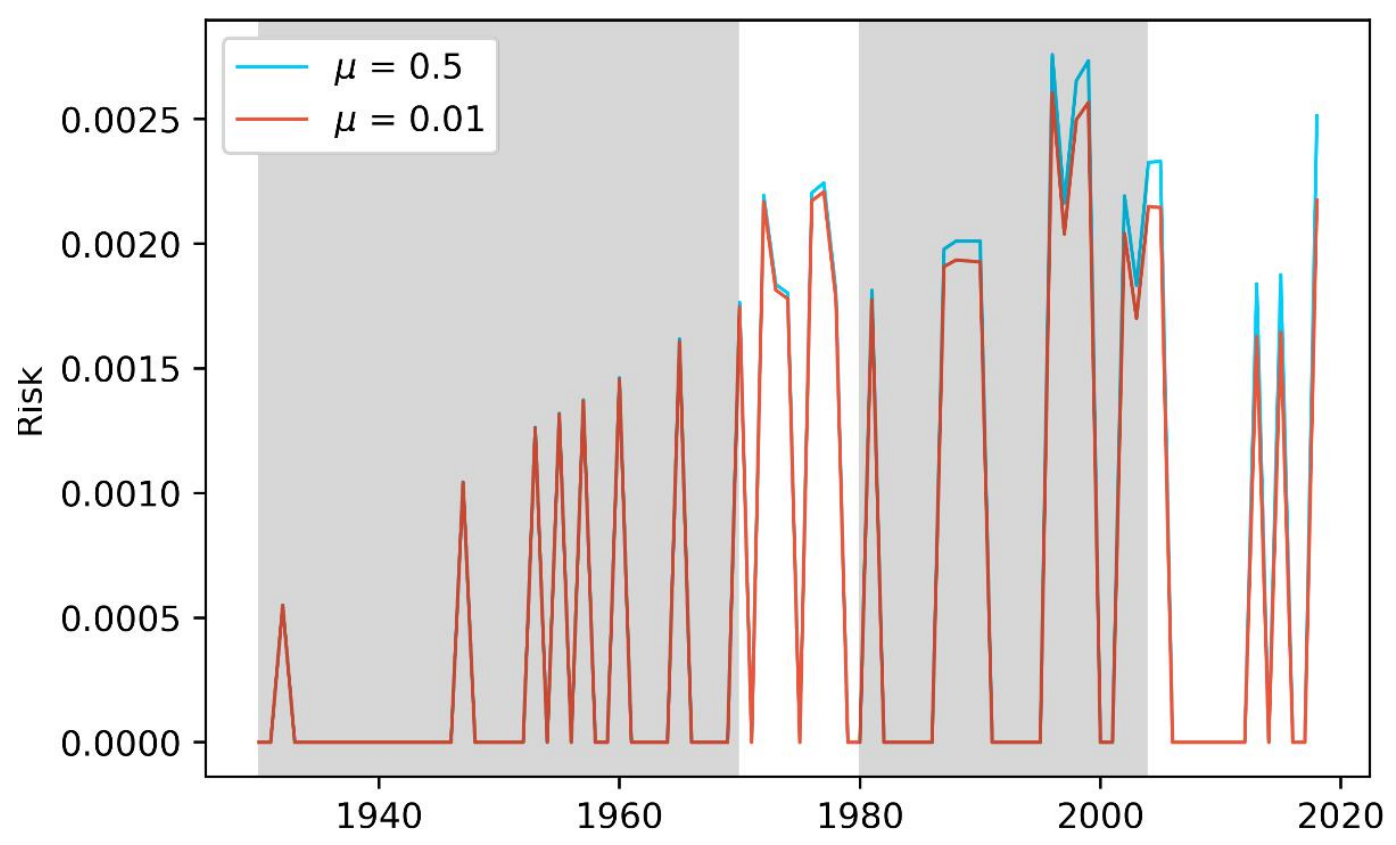

\subsection{CONCLUSIONS AND RECOMMENDATIONS}

This chapter shows that information provided by society through narratives and photographs can be a useful tool to fill the information gap in small urban catchments. In addition, combining historical source data and recent modelling techniques can help to understand human-water systems.

The population density growth at the catchment in 2003, stimulated by land-use policies, with a high level of social memory floods, illustrate people's unreliable memory. This behaviour emphasises that policies focused on social and environmental memory should be adopted in combination.

Even the society under analysis showed technological behaviour after the 1970s, it was modelled as a green society because levees were the only type of structural measure that could be adopted in the model used. This assumption may have underestimated the losses, and consequently the flood risk in this period. We recommend that future works include different structural measures in the socio-hydrological modelling. However, we decided to adapt the same equations from Di Baldassarre et al. (2015) to the Gregório Creek case to make a 
comparison across cases where the model has already been applied and to understand what its shortcomings may be when applied to the reality of Brazilian cities.

Even though the structural measures were not considered through the model's technological equation, the water levels used as input data in the model carries with it the flood enhancement due to the structural measures built in the creek. This shaped the results differently when looking at periods before and after the construction of these measures. One can observe an increase in the risk in the last three stages (illustrated in Figure 9) and the fact that the variation in memory loss rate only reduces the risk in this stages; this suggests that policies focusing on maintaining society's memory for a longer period are more effective in technological societies.

Despite the limitations described above, the model employed in this study provided results that helped to understand this community's behaviour and to consider alternatives to improve their quality of life. The output has elucidated some relations between water and society in the catchment, which will be used as a basis for future in-depth studies.

\subsection{SUPPLEMENTARY MATERIAL}

Supplementary data related to this article can be found at the Appendix of this work.

\subsection{ACKNOWLEDGMENTS}

The present work was developed using the data collected by Heloisa Cecatto Mendes during her master's degree. The authors are grateful to the information provided.

\subsection{REFERENCES}

Aerts, J. C., Botzen, W. J., Clarke, K. C., Cutter, S. L., Hall, J. W., Merz, B., ... \& Kunreuther, H. (2018). Integrating human behaviour dynamics into flood disaster risk assessment. Nature Climate Change, 8(3), 193-199.

Atkinson, R. C., \& Shiffrin, R. M. (1968). Human memory: A proposed system and its control processes. In Spence, K. W. \& Spence, J. T. (Org.), Psychology of Learning and Motivation (pp 89-195). Academic Press. 
Bhattacharya-Mis, N., \& Lamond, J. (2014). An investigation of patterns of response and recovery among flood-affected businesses in the UK: a case study in Sheffield and Wakefield. WIT Transactions on Ecology and the Environment, 184, 163-173.

Blair, P., \& Buytaert, W. (2016). Socio-hydrological modelling: a review asking" why, what and how?". Hydrology and Earth System Sciences, 20(1), 443-478.

Buchanan, T. W., \& Lovallo, W. R. (2001). Enhanced memory for emotional material following stress-level cortisol treatment in humans. Psychoneuroendocrinology, 26(3), 307-317.

Cahill, L., Gorski, L., \& Le, K. (2003). Enhanced human memory consolidation with postlearning stress: Interaction with the degree of arousal at encoding. Learning \& memory, 10(4), 270-274.

Chuva forte em São Carlos, SP, causa pontos de alagamento; veja fotos e vídeo. G1, São Carlos, 23 mar. 2018. Disponível em: https://g1.globo.com/sp/sao-carlos-regiao/noticia/chuvaforte-em-sao-carlos-sp-causa-alagamento-em-diversos-pontos-veja-fotos.ghtml. Acesso em: 22 nov. 2019.

Ciullo, A., Viglione, A., Castellarin, A., Crisci, M., \& Di Baldassarre, G. (2017). Sociohydrological modelling of flood-risk dynamics: comparing the resilience of green and technological systems. Hydrological sciences journal, 62(6), 880-891.

Di Baldassarre, G., Viglione, A., Carr, G., Kuil, L., Salinas, J. L., \& Blöschl, G. 2013. Sociohydrology: conceptualising human-flood interactions. Hydrology and Earth System Sciences, 17(8), 3295-3303.

Di Baldassarre, G., Viglione, A., Carr, G., Kuil, L., Yan, K., Brandimarte, L., \& Blöschl, G. (2015). Debates - Perspectives on socio-hydrology: Capturing feedbacks between physical and social processes. Water Resources Research, 51(6), 4770-4781.

Di Baldassarre, G. (2017). Socio-Hydrology of Floods. In Oxford Research Encyclopedia of Natural Hazard Science.

Di Baldassarre, G., Kreibich, H., Vorogushyn, S., Aerts, J., Arnbjerg-Nielsen, K., Barendrecht, M., ... \& Bubeck, P. (2018). An interdisciplinary research agenda to explore the unintended consequences of structural flood protection. Hydrology and Earth System Sciences, 22(11), 5629-5637.

Fanta, V., Šálek, M., and Sklenicka, P. (2019). How long do floods throughout the millennium remain in the collective memory?. Nat Commun, 10, 1105. doi:10.1038/s41467-01909102-3.

Garde-Hansen, J., McEwen, L., Holmes, A., \& Jones, O. (2017). Sustainable flood memory: Remembering as resilience. Memory Studies, 10(4), 384-405.

Global Assessment Report on Disaster Risk Reduction. (UN Report 2015a). (2015a). Geneva, Switzerland: United Nations.

Halbwachs, M., 1992. On collective memory. Chicago, IL: University of Chicago Press..

Jelici, M., Geraerts, E., Merckelbach, H., \& Guerrieri, R. (2004). Acute stress enhances memory for emotional words, but impairs memory for neutral words. International Journal of Neuroscience, 114(10), 1343-1351.

LaBar, K. S., \& Cabeza, R. (2006). Cognitive neuroscience of emotional memory. Nature Reviews Neuroscience, 7(1), 54.

Lättilä, L., Hilletofth, P., \& Lin, B. (2010). Hybrid simulation models-when, why, how? Expert Systems with Applications, 37(12), 7969-7975.

McEwen, L., Garde-Hansen, J., Holmes, A., Jones, O., \& Krause, F. (2017). Sustainable flood memories, lay knowledges and the development of community resilience to future flood risk. Transactions of the Institute of British Geographers, 42(1), 14-28.

Mendes, H. C. \& Mendiondo, E. M. (2007). Histórico da expansão urbana e incidência de inundações: O Caso da Bacia do Gregório, São Carlos-SP. Revista Brasileira de Recursos Hídricos, 12(1), 17-27. 
Miceli, R., Sotgiu, I., \& Settanni, M. (2008). Disaster preparedness and perception of flood risk: A study in an alpine valley in Italy. Journal of environmental psychology, 28(2), 164173.

Revisão do Plano Diretor do Município de São Carlos - Produto I. (FUSP Report 2011). (2011). São Paulo, Brazil: Fundação de Apoio à Universidade de São Paulo.

Roediger III, H. L., \& Wertsch, J. V. (2008). Creating a new discipline of memory studies. Memory Studies, 1(1), 9-22.

Sendai framework for disaster risk reduction 2015-2030. (UNISDR Report 2015b). (2015). Geneva, Switzerland: United Nations Office for Disaster Risk Reduction.

Shalev, A. Y. (2000). Biological responses to disasters. Psychiatric Quarterly, 71(3), 277-288.

Sivapalan, M., Savenije, H. H. G. \& Blöschl, G. (2012). Socio-hydrology: A new science of people and water. Hydrological Processes, 26(8), 1270-1276.

Sotgiu, I., \& Galati, D. (2007). Long-term memory for traumatic events: experiences and emotional reactions during the 2000 flood in Italy. The Journal of Psychology, 141(1), 91-108.

Srinivasan, V., Lambin, E. F., Gorelick, S. M., Thompson, B. H., \& Rozelle, S. (2012). The nature and causes of the global water crisis: Syndromes from a meta-analysis of coupled human-water studies. Water Resources Research, 48(10).

Tapsell, S. M., \& Tunstall, S. M. (2008). "I wish I'd never heard of Banbury": The relationship between 'place'and the health impacts from flooding. Health \& place, 14(2), 133-154.

Viglione, A., Di Baldassarre, G., Brandimarte, L., Kuil, L., Carr, G., Salinas, J. L., ... \& Blöschl, G. (2014). Insights from socio-hydrology modelling on dealing with flood risk-roles of collective memory, risk-taking attitude and trust. Journal of Hydrology, 518, 71-82.

White, G. F. (1945). Human adjustment to floods: a geographical approach to the flood problem in the United States. University of Chicago. 
3 SOCIO-HYDROLOGICAL MODELLING OF LONG-TERM FLOOD RISK UNDER CLIMATE CHANGE SCENARIOS

*A modified version of this chapter has been submitted as: Buarque, A. C. S., Souza, C. F., Souza, F. A. A., Mendiondo, E. M. (2021). Urban flood risk under global changes: a sociohydrological and cellular automata approach in a Brazilian catchment. Hydrological Sciences Journal.

Abstract Society is facing increasingly rapid and frequent changes, which are transforming the decision-making paradigm from a static, value-based perspective, to a dynamic, scenario-based perspective. Flood risk assessment is moving towards an approach that encompasses social, climatic, and environmental changes. Advances in climate and hydraulic modelling allow the development of longterm scenarios with greater reliability. However, the coupling of human behaviour in the process of flood risk assessment is still on an embryonic phase. Here we attempt to fill this gap by: i) coupling a socio-hydrological model with a cellular automata model, and (ii) using climate change projections in order to estimate flood risk in the coming decades. We illustrate our analytical framework with an application in a Brazilian catchment, showing its potential in developing long-term scenarios that can ultimately improve the process of flood risk assessment.

Keywords: Climate Change, Socio-Hydrology, Urban Planning, Flood Map, Urban Drainage, Disaster Management 


\subsection{INTRODUCTION}

One of the biggest challenges in urban planning is how to deal with changes. Whether climatic, land use, technological or social changes, they are occurring more and more rapidly and have to be considered in the decision-making process. These changes are the cause of different impacts, such as floods, in urban environments. Between 2003 and 2016, 47.5\% of Brazilian municipalities $(2,641)$, the majority located in the South and Southeast regions, declared at least once an Emergency Situation or State of Public Disaster due to floods (ANA, 2019). Brazil has 13,948 flood-prone stretches of rivers, of which $30 \%$ are considered to be highly vulnerable. (ANA, 2014).

Climate change affects this scenario through the expected intensification of floods (Hirabayashi et al. 2013; Arnell et al. 2016; Blöschl et al., 2017; Blöschl et al., 2019). In the São Paulo metropolitan area, the climate projections of the Eta-CPTEC regional model show an increase in total rain, in intense rainfall, and in days with precipitation greater than $10 \mathrm{~mm}$ for the period between the years 2030 and 2090 (Nobre et al., 2010). Torres et al. (2012) analysed the Regional Climate Change Index (RCCI, Figure 14a) and the Socio-Climatic Vulnerability Index (SCVI, Figure 14b) in Brazil and state that floods and other events that are closely linked to the urbanization pattern will express the future impacts of climate change on Brazilian metropolitan areas. Therefore, to understand how events might unfold and what kinds of responses will be most effective, Earth-system models need to capture human-climate dynamics (Palmer and Smith, 2014).

The need to capture human-climate dynamics is also stressed by The Global Assessment Risk Report on Disaster Risk Reduction (UN, 2009), which states that major renovations of approaches to risk assessment and analysis are needed to fully realize the challenge and call of the Sendai Framework (UNISDR, 2015). This implies a paradigm shift from managing "conventional" hazards to engineering an improved understanding of the dynamic interactions with systemic risks (UN, 2009). 
Figure 14: (a) Regional Climate Change Index (RCCI) and (b) Socio-Climatic Vulnerability Index (SCVI) for Brazil (both dimensionless).
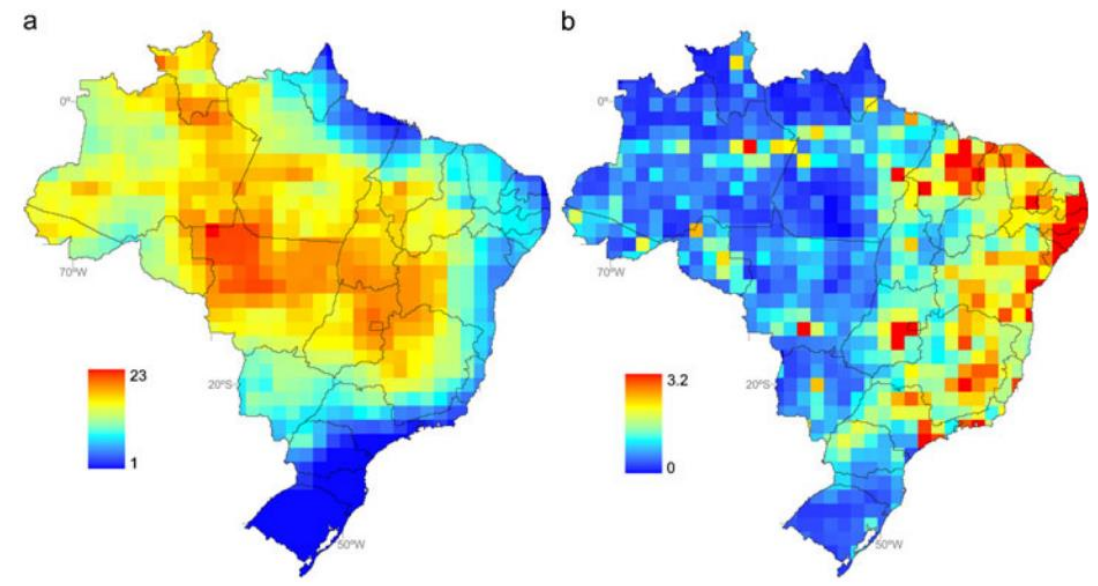

Source: Torres et al. (2012).

While many studies show that floods might change in the coming decade (Hirabayashi et al., 2013; Arnell et al., 2016; Blöschl et al., 2017; Blöschl et al., 2019), the intensity of future events is often estimated disregarding the effects of climate change in traditional flood risk assesments. In addition, social vulnerability is often analysed in a purely economic perspective, disregarding the dynamics of social aspects such as the changing memory of antecedent events or risk-taking attitude, which can affect the actual flood losses (Viglione et al., 2014; Di Baldassarre et al., 2015; Ciullo et al., 2017). Lastly, depth-damage curves, which are used to translate the physical phenomenon to its economic impacts, typically stipulate loss as a monotonic function of inundation depth and overestimate damages induced by shallow-water flooding — which comprises the large majority of losses - and generally underestimate damages by deep inundation (Wing et al., 2020).

Aerts et al. (2018) propose an extended risk assessment framework that includes social factors and DRR measures. DRR is defined as the concept and practice of reducing disaster risks through systematic efforts to analyse and manage the causal factors of disasters, including through reduced exposure to hazards, lessened vulnerability of people and property, wise management of land and the environment, and improved preparedness for adverse events (ISDR, 2009).

In its framework, Aerts et al. (2018) recognizes the influence of society's level of information about floods on the risk. However, including the dynamics of risk perception, behavioural dynamics, and DRR in risk assessment requires a multidisciplinary approach that integrates methods from the natural sciences with the social sciences (Aerts et al., 2018). These 
aspects demonstrate that a methodology to determine the nature and extent of risk, knowing as Flood Risk Assessment (FRA) (ISDR, 2009), in urban areas needs to take into account the complexity of the multiple factors involved, thus adopting a holistic approach.

Ciullo et al. (2017) propose an adaptation to FRA based on the socio-hydrological model developed by Di Baldassarre et al. (2015). This approach consists in a set of differential equations aimed to assess the dynamics of societal memory of floods, population density, flood damage, and flood protection in an integrated way. However, those memories are not considered in FRA because of the lack of citizens' engagement in water-related governance (Souza et al., submitted).

In this chapter, we hypothesize that assessment of coupled hydrological and societal mechanisms provides alternatives to tackle effects of unexpected rainfall intensities and hazard occurrence. Therefore, we present an analytical framework for flood risk assessment under climate change scenarios by coupling the aforementioned socio-hydrological model with a cellular automata model and climate projections. We test the working hypothesis in a Brazilian flood-prone catchment, where we simulate the possible dynamics of flood risk from 2020 to 2099.

\subsection{METHODOLOGY}

The methodology of this study consists in the development of a FRA framework through the coupling of a cellular automata model to a socio-hydrological model and climate projections and subsequent application of this framework in a flood-prone catchment. Four main modules compose the structure of this framework: two modules of data wrangling, the cellular automata model, and the socio-hydrological model (Figure 15). The first step was to collect and wrangle the hydrological and topographic data. The hydrological data corresponds to 3-hour rainfall projections from a regionalized climate model for the period between 2020 and 2099 and for the Representative Concentration Pathways (RCP) 4.5 and 8.5 (Chou et al., 2012). The topographic data is a Digital Elevation Model with 30m resolution (Valeriano and Rosseti, 2009). This dataset was used as input to run the Cellular Automata Model in the second step and generate the flood maps for the highest daily rainfall of each year. The values of annual maximum water level were extracted from those maps and used as input to the socio- 
hydrological model (Di Baldassarre et al., 2015). These steps resulted in the Flood Risk Scenarios for the years between 2020 and 2099 and are detailed as follows.

Figure 15: Methodology flowchart used in this chapter.

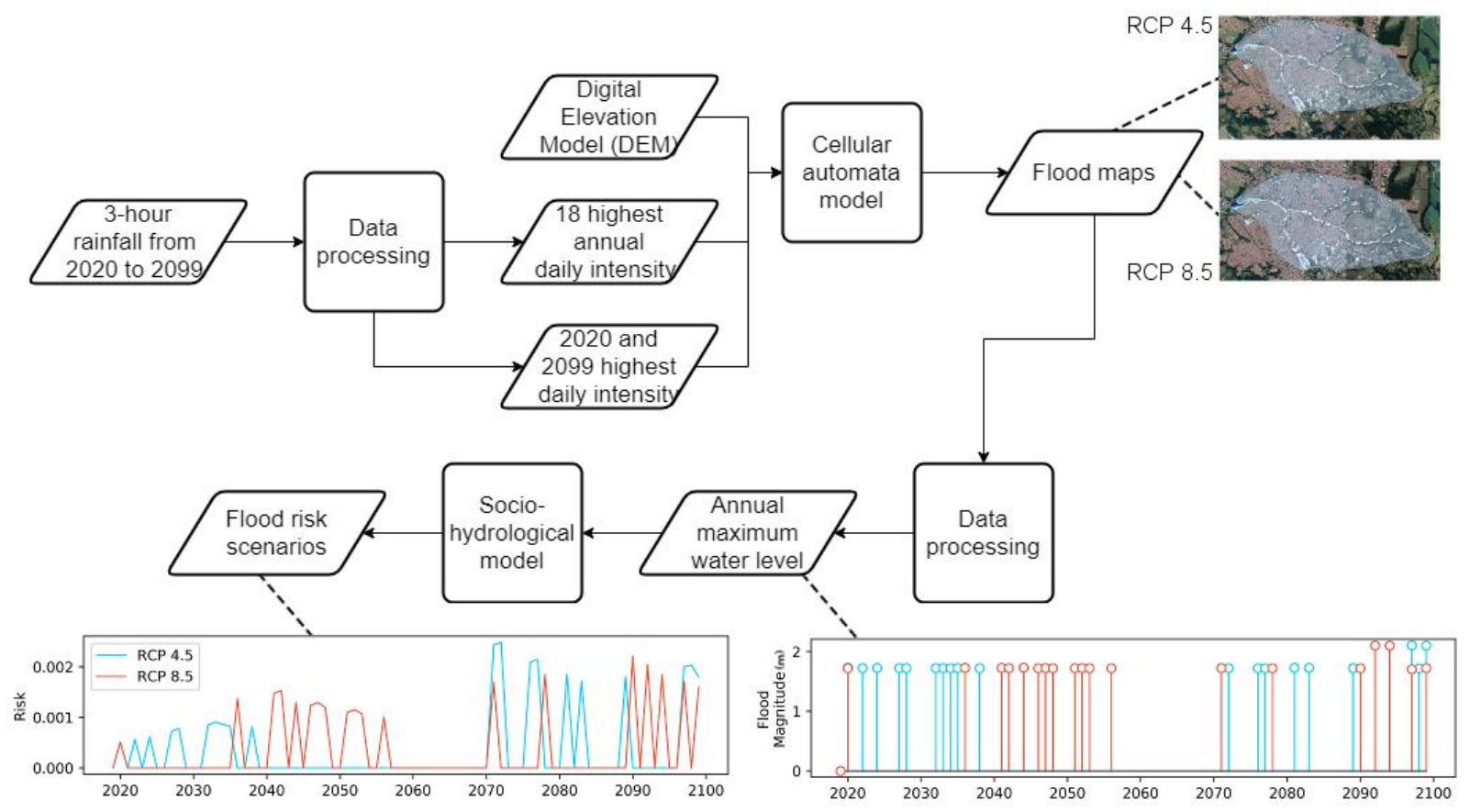

\subsubsection{Cellular Automata Modelling}

Cellular automata (CAs) are computational methods based on the simulation of a discrete space in which a set of universal laws apply (Ghimire et al., 2013). The CA methods have five fundamental features: a finite space, the transition functions, the neighbourhood or 'influencer set', the states and the time step (Itami, 1994). CA models have been used in applications with multiple focuses, such as urban planning (Liu et al., 2017), epidemic analysis (Sun et al., 2016), robot path planning (Tariq et al., 2016), among others. Since CA relies on the ability to discretize time and space and thus reduce the computational overhead associated with the computation based on solving hydraulic equations (Ghimire et al., 2013), it has been tested in the context of flood hazards (Dottori and Todini, 2011).

CADDIES (standing for: Cellular Automata Dual DraInagE System) is a reduced-complexity model for fast and accurate urban flood simulations, based on the CA approach (Ghimire et al., 2013). The model attempts to reduce the necessity for physically-based equations and complex mathematical operations in the transition rules used to simulate an inundation event (Guidolin et al., 2016). CADDIES-2D (CA2D) (Guidolin et al., 2012) uses a ranking technique to 
compute the volume of water transferring from the central cell to its neighbourhood, called intercellular-volume (Guidolin et al., 2016). Although being a simplified model, in its simulations, CA2D imposes a physically-based limitation on the total intercellular-volume by using the critical flow equation and the Manning's formula (Guidolin et al., 2016).

In this study, the CA2D was used for the elaboration of flood maps for the eighteen events of greatest annual intensity that occurred in the analyzed period (2020-2099) and for the beginning and end years of the period. The annual maximum water levels were used as input to the sociohydrological model and were extracted from those maps. The input data to the CA2D were the rainfall intensity and duration of the selected events and the catchment area DEM with $30 \mathrm{~m}$ of spatial resolution, which is also the simulation pixel size. The rainfall intensity was distributed uniformly throughout the catchment area and through the event duration. The simulation time step in this model is adaptive and changes according to the velocity (Guidolin et al., 2016), so, for this case, the upper limit for the time step was defined as one minute.

\subsubsection{Socio-Hydrology Modelling}

In the previous chapter, the socio-hydrological model proposed by Di Baldassarre et al. (2015) and improved by Ciullo et al. (2017) was adapted and tested in the Gregório Creek catchment. It was verified that an adapted version of this socio-hydrological model was capable to address important feedbacks between societal and floods processes across different case studies. This model conceptualization is based on:

Considering a community that settles and develops in a coastal or river flood-prone area (urbanizing delta or floodplain) to gain associated economic benefits, e.g., trading. However, the occurrence of flooding causes losses and displacement of people. After experiencing an event, the community is shocked and builds memory (M) of flooding. People respond by reducing population density ( $\mathrm{D}$, ranging between 0 and 1 ) in the floodplain, and they can respond by building or heightening levees $(\mathrm{H})$ to protect the floodplain (i.e., nonstructural and structural measures). As the memory of flooding decays with time, the tendency to resettle closer to the river and increase population density in the floodplain resumes. (Di Baldassarre et al., 2015)

This variables are interconnected in a feedback loop by Equations (1) to (5), which are described in section 2.2.1. In addition, Ciullo et al. (2017) incorporated Equation (6) and (7) to improve flood risk estimation. In this approach, the flood risk is defined as a product between hazard and losses (Equation 6), where Hazard represents the probability of the event to occur and follows a GEV distribution and the variable Losses is assigned as the product between relative losses (F) and floodplain density (D) (Equation 7) (Ciullo et al., 2017). In this chapter, the socio-hydrological model was applied with the twenty highest values of maximum annual 
flood intensity in the period between 2020 and 2099 for each RCP, resulting in forty simulations. The initial values for each simulation were set to zero.

\subsubsection{Data Gathering}

The rainfall data that was used as input to the CA2D model was made available by the Center for Weather Forecasting and Climatic Studies of the National Institute for Space Research (CPTEC / INPE) in partnership with the University of Passo Fundo (UPF) through the PROJETA platform (https://projeta.cptec.inpe.br). These data correspond to climate change projections for South America regionalized by the Eta model (Black, 1994; Mesinger et al., 1988), from the global climate models HadGEM2-ES (Collins et al., 2011), MIROC5 (Watanabe et al., 2010) and CanESM2 (Arora et al., 2011). The regional model simulations used two radiative forcing concerning $\mathrm{CO} 2$ emissions, $\mathrm{RCP} 4.5$, which is a more optimistic scenario where the concentration of $\mathrm{CO} 2$ reaches about $650 \mathrm{ppm}$, and 8.5 , which is a pessimistic scenario in which the concentration of CO2 exceeds 1000 ppm (Chou et al., 2012; Marengo et al., 2012).

The spatial scale of the HadGEM2-ES model is 5 kilometers, whereas the other models have a spatial scale of 20 kilometers. Therefore, considering that the total area of the basin is $18.9 \mathrm{~km}^{2}$, only data from the HadGEM2-ES model were used. The HadGEM2-ES is an earthsystem model and has five main components (greenhouse gases, chemistry, aerosols, physical climate and aquatic and terrestrial ecosystems), which are connected according to the feedbacks represented in the Figure 16.

The data collected correspond to the period between the years 2020 and 2099 and have a 3-hours time step. The daily intensity of rainfall was calculated for the entire period and the highest values for each year were selected. For each RCP scenario, the eighteen highest annual values of daily rainfall intensity were used as input to the model, as well as the highest values of daily rainfall intensity for the years 2020 and 2099, totalling forty simulated events. 
Figure 16: Earth system coupling feedbacks.

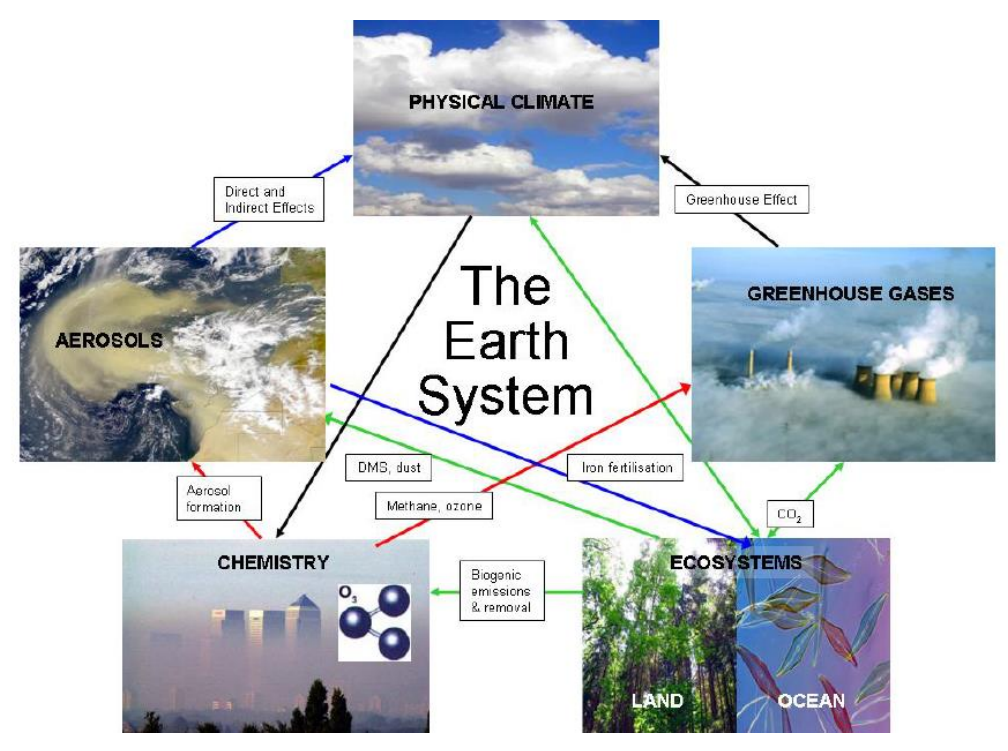

Source: Collins et al., 2011.

\subsection{RESULTS AND DISCUSSION}

The first outcome of this chapter is the flood inundation maps of the eighteen most intense rainfall events and the initial and final years of the analysed period for each radiative forcing (RCP 4.5 and 8.5) (Table 2), resulting in 40 maps. Through the boxplot of the rainfall intensities (

In front of the municipal market begins a buried stretch of the creek, which increases the velocity in the point by diminishing the section area and causes fluvial floods. Since the cellular automata model simulates a simplified scheme of this dynamic, it does not capture some dynamics induced by structures that could be explored using a physically-based model. This is a limitation of the chosen approach and demonstrates that the CA2D can be more suitable to analyse cases of pluvial flooding or fluvial flooding derived from less modified streams. Thus, the application of CA2D to analyse this case study can be underestimating the flood intensity in the municipal market region. Despite the possible underestimation of high water level values by the cellular automata model, this study carried the analysis with the focus on the municipal market region, since the highest economic losses are concentrated in this region (Macêdo et al., 2004; Righetto and Mendiondo, 2004; Righetto, 2005). 
Figure 17) it is possible to perceive that the values did not differ significantly between the analysed scenarios, with RCP 8.5 showing a slightly higher mean value than the RCP 4.5. Figure 18 shows the maps generated for the highest flood event of 2020 for the RCP 4.5 and 8.5 , with rainfall intensity of $3.9 \mathrm{~mm} / \mathrm{h}$ and $1.4 \mathrm{~mm} / \mathrm{h}$, respectively. The maps of the other flood events can be found in the supplementary material. The most significant difference resulted from the simulations using the two RCP scenarios is the corresponding date for the largest flood events, which had similar values of intensity for the municipal market region. Through a visual analysis of the flood inundation maps, we can notice that the most significant water depth variation between the two radiative forcing scenarios is located in the catchment outlet area, while in the municipal market region, the water depth during flood events did not vary as expected.

Table 2: Rainfall duration and intensity of the eighteen most intense events and of the initial and final years of the simulation period for each RCP scenario.

\section{RCP $4.5 \quad$ RCP 8.5}

\begin{tabular}{cccccc}
\hline Year & Intensity $(\mathrm{mm} / \mathrm{h})$ & Duration $(\mathrm{h})$ & Year & Intensity $(\mathrm{mm} / \mathrm{h})$ & Duration $(\mathrm{h})$ \\
\hline 2020 & 3.95 & 15 & 2020 & 1.43 & 24 \\
2022 & 2.47 & 18 & 2036 & 3.97 & 15 \\
2024 & 4.26 & 15 & 2041 & 3.12 & 15 \\
2027 & 2.45 & 15 & 2042 & 3.26 & 12 \\
2028 & 5.03 & 9 & 2044 & 6.45 & 9 \\
2032 & 2.82 & 24 & 2046 & 4.47 & 12 \\
2033 & 2.77 & 21 & 2047 & 3.69 & 24 \\
2034 & 4.37 & 21 & 2048 & 4.48 & 21 \\
2035 & 2.66 & 21 & 2051 & 7.11 & 6 \\
2038 & 2.51 & 24 & 2052 & 3.66 & 9 \\
2071 & 3.05 & 18 & 2053 & 4.59 & 12 \\
2072 & 2.83 & 24 & 2056 & 4.20 & 12 \\
2076 & 2.80 & 18 & 2071 & 3.42 & 21 \\
2077 & 2.59 & 24 & 2075 & 3.31 & 24 \\
2081 & 3.18 & 12 & 2078 & 3.25 & 18 \\
2083 & 2.88 & 15 & 2090 & 4.88 & 9 \\
2089 & 5.42 & 21 & 2092 & 3.43 & 15 \\
2097 & 3.16 & 24 & 2094 & 3.88 & 12 \\
2098 & 2.75 & 12 & 2097 & 3.81 & 21 \\
2099 & 9.45 & 9 & 2099 & 2.28 & 18 \\
\hline
\end{tabular}

In front of the municipal market begins a buried stretch of the creek, which increases the velocity in the point by diminishing the section area and causes fluvial floods. Since the 
cellular automata model simulates a simplified scheme of this dynamic, it does not capture some dynamics induced by structures that could be explored using a physically-based model. This is a limitation of the chosen approach and demonstrates that the CA2D can be more suitable to analyse cases of pluvial flooding or fluvial flooding derived from less modified streams. Thus, the application of CA2D to analyse this case study can be underestimating the flood intensity in the municipal market region. Despite the possible underestimation of high water level values by the cellular automata model, this study carried the analysis with the focus on the municipal market region, since the highest economic losses are concentrated in this region (Macêdo et al., 2004; Righetto and Mendiondo, 2004; Righetto, 2005).

Figure 17: Boxplot of the rainfall intensities for the RCP 4.5 and 8.5 scenarios (represented in blue and orange boxes, respectively).

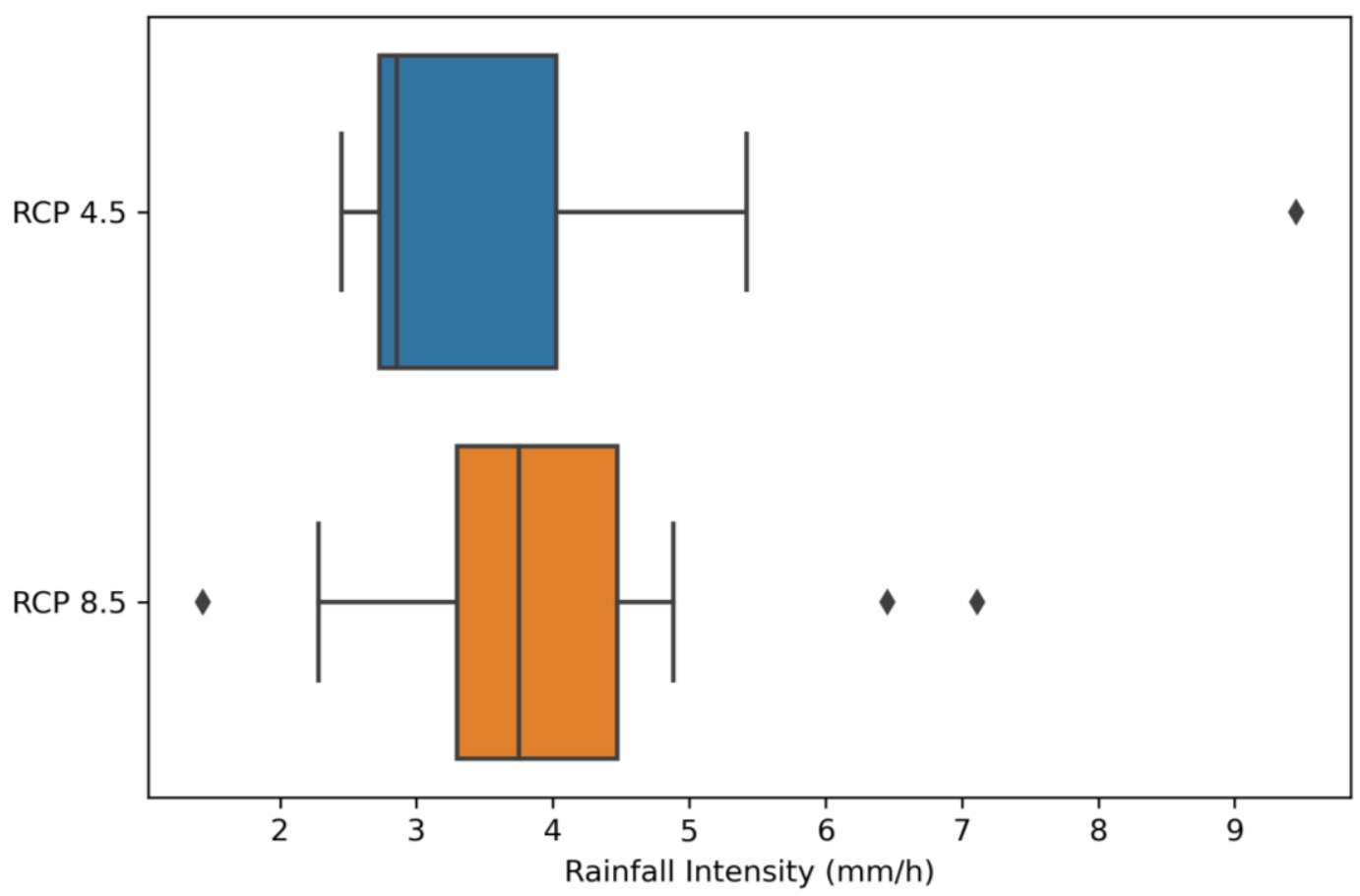

Figure 19a presents the flood magnitude in the municipal market area for the forty flood events used as input in the socio-hydrological model and Figure 19b, c, d and e presents the values for the simulated losses, population density, memory and risk, respectively. In standard risk analysis, the risk is considered a function of damage and vulnerability, which is adopted as a function of economic damage and is usually established by a curve that relates the water level and the respective damage. Considering this approach, the risk for the RCP 4.5 and 8.5 would 
have similar behaviours, since the water level values did not present significant differences between them $(0.2 \%$ variation in the mean and in the highest value).

Figure 18: Flood inundation map for the highest flood event of 2020 for the RCP 4.5 and 8.5 scenarios.

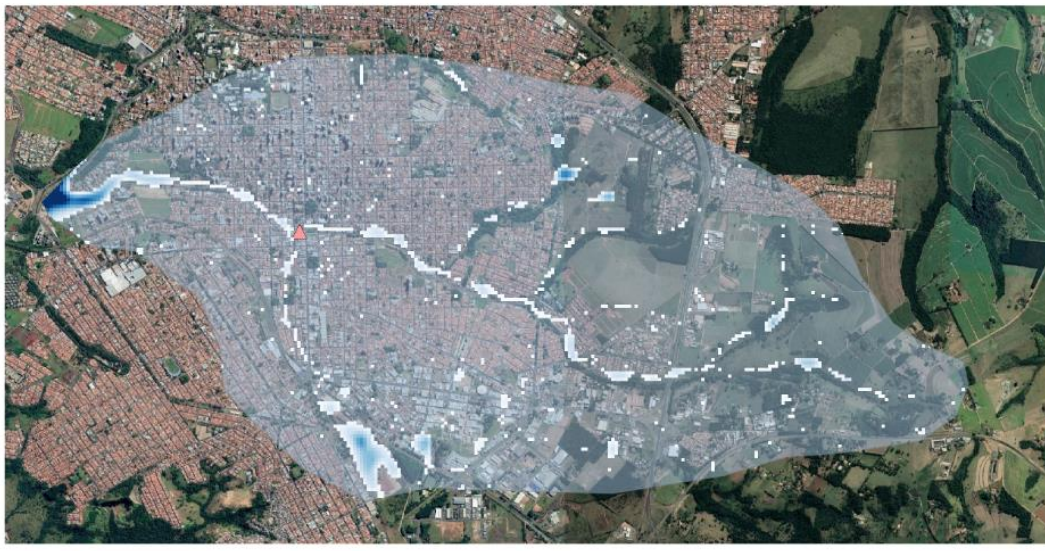

\section{Caption}

Maximum Water Depth $(\mathrm{m})$

$\square 0.01$

$\square$
$\square .17$
$\square \quad 2.34$

$\square .51$
$\square \quad 68$

5.85

7.02
8.10

7.10
9.00

$\triangle$ Municipal Market

Gregório Creek Catchment

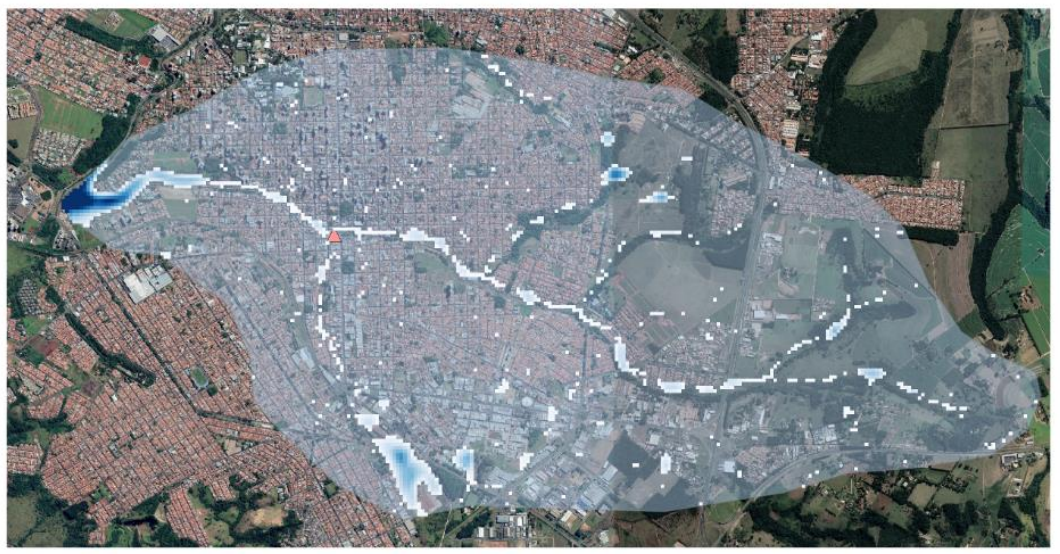

\section{Caption}

Maximum Water Depth (m)

0.01

$\square .11$

$\square 2.22$

3.33
4.44

4.55
$\square$

6.66
$\square .68$

8.53

$\triangle$ Municipal Market

$\square$ Gregório Creek Catchment

The coupled analysis of hydrological and societal systems and their interactions reveals that rainfall intensity is not the only cause of increasing risk, but cumulated memory (Figure 19d) and distance between major events play an important role as well. In the RCP 4.5 scenario, there is a long period without floods between the years 2039 and 2071. This caused a memory decay, which led to a population density (Figure 19c) increase in the floodplain. Thereby, when the 2071 event occurs the losses end up being greater and, consequently, the risk as well.

In the RCP 8.5 scenario, as the intervals between flood events are shortened, the memory remains alive for a longer period and the population density in the floodplain reaches lower values. As a result, the values of losses and risk are lower than those of the RCP 4.5 scenario for events of the same intensity. These results suggest that if structural measures, such as levees, were applied to the area based on the water level of events that occur until 2090, the damage generated by events that occurred after 2097, which have greater intensity, would generate much greater losses, since the population density in the floodplain would continue to increase. 
Therefore, structural measures aimed to reduce flood intensity in the catchment must be designed in conjunction with zoning regulation projects, in order to control the areas that can be occupied in the floodplain.

Figure 19: Socio-hydrological model input data (flood magnitude) and outcomes (losses, population density, memory and risk) for the radiative forcing RCP 4.5 and 8.5 (represented in blue and red, respectively).
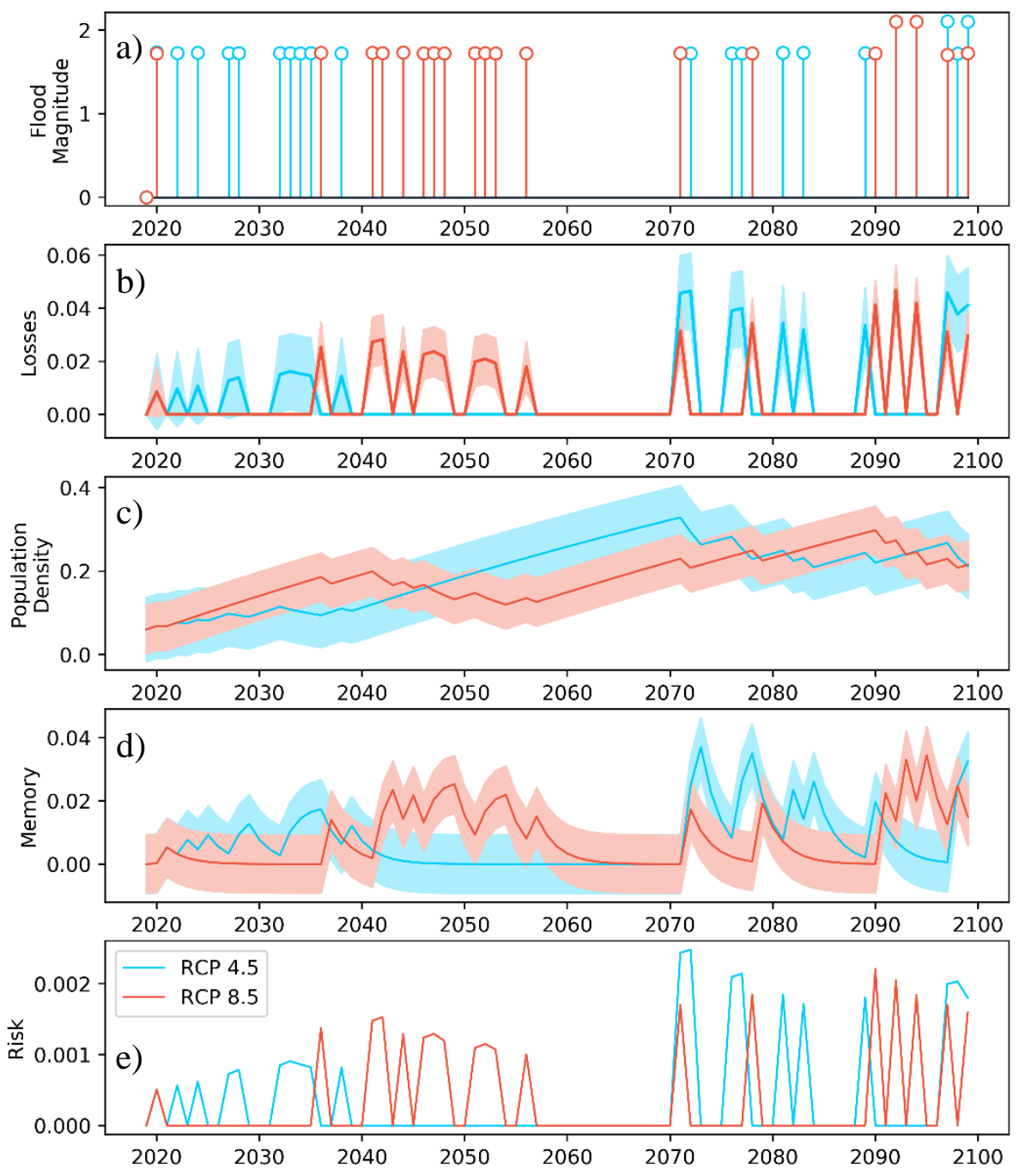

Figure 20 shows the plot of accumulated losses over the analysed period and reinforces the need for the FRA to be carried out dynamically over time. Through this graph, it is possible to perceive the importance of the moment that the stakeholder chooses to implement risk reduction and adaptation measures. For example, if these measures are implemented before the year 2070 in this case study, the accumulated losses in the year 2100 can be reduced by up to $50 \%$.

Given the differences in rainfall intensity and recurrences of major events, maintaining flood memories alive is a plausible solution to tackle hazards for any scenario. These measures 
can be monuments or signs indicating the flood level in previous events or the dissemination of risk-related information on the area. One way to achieve this dissemination of information is through an observatory. This study is part of the development of data analysis and processing modules that will compose the Socio-Hydrological Observatory for Water Security (SHOWS), developed by the research group (Souza et al., submitted, Mendiondo et al., 2019).

Figure 20: Accumulated losses over the time for the RCP 4.5 and 8.5 scenarios (represented in blue and red lines, respectively).

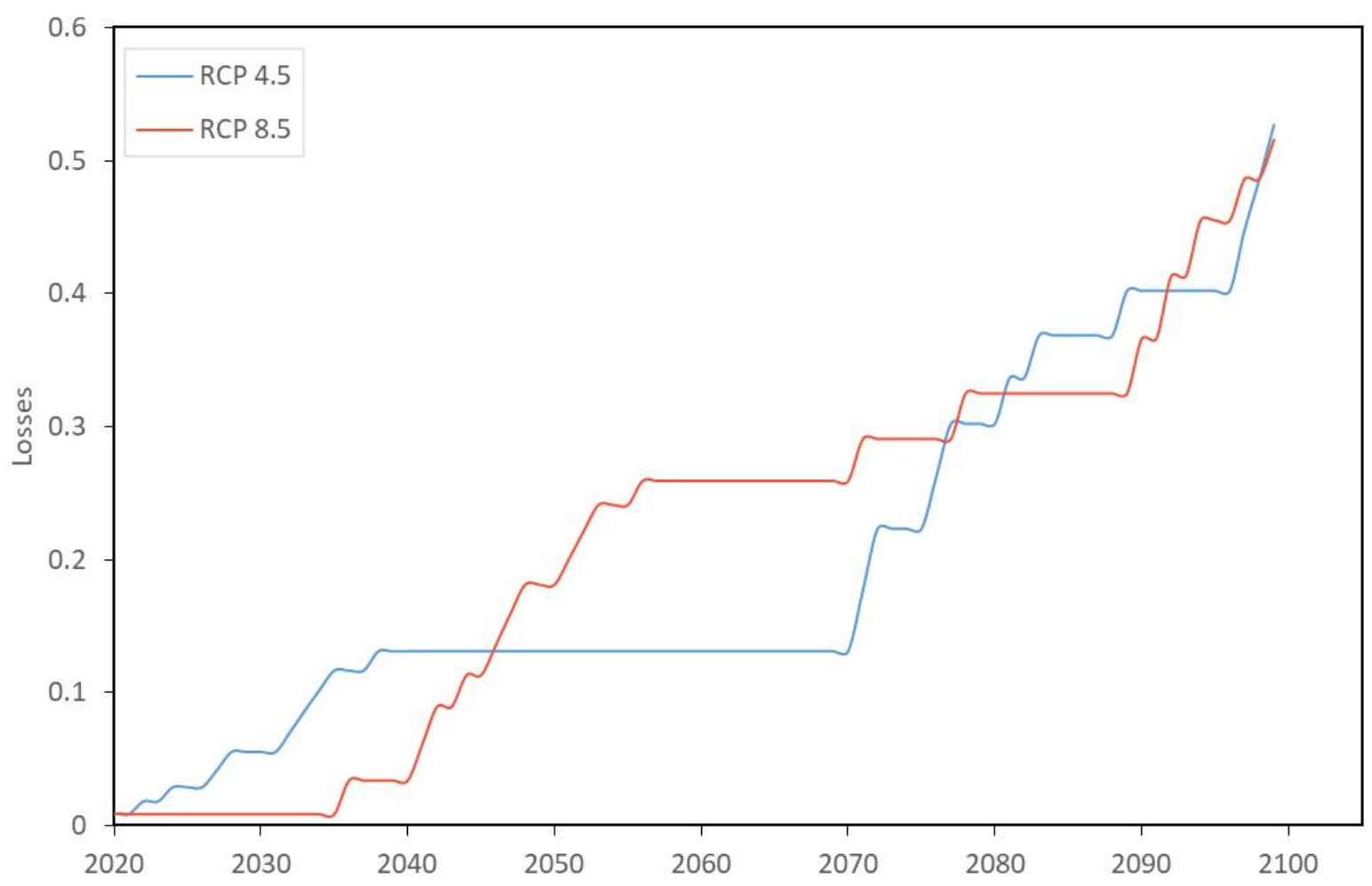

For a better analysis of the impacts of climate change, boxplot graphics were generated for every 20 years of the total period. Analysing moving trend variables of a single length is a method to reduce complexity, while still showing fluctuations in trend direction and magnitude over time (Hennemuth et al., 2013). An increasing trend in relative losses is presented (Figure 21 ), backed by the increasing trend in population density (Figure 22). The flood memory (Figure 23) in the studied area did not show any tendency for growth or decay, as well as the flood risk (Figure 24), when analysed through boxplots. This demonstrates the importance of also analysing events individually, in a reduced time scale, to better understand the influence of memory, since its major impact on flood risk occurs right after the flood events. 
Although some authors assigned possible values of flood memory parameters adopted in Equation (3), future flood risk assessment works should consider alternatives for validate its parameters. Citizen science opportunities have demonstrated that observations, knowledge, and beliefs from locals can provide valuable measures in ungauged basins and outline possible changes in behaviour (Abreu, 2019; Fava et al., 2019; Mondino et al., 2020; Souza et al., submitted). Therefore, citizens' engagement is not only a data source, but it can be a step toward risk reduction and resilience increase as well (Mao et al., 2017).

Figure 21: Boxplot of losses data for each 20-year period.

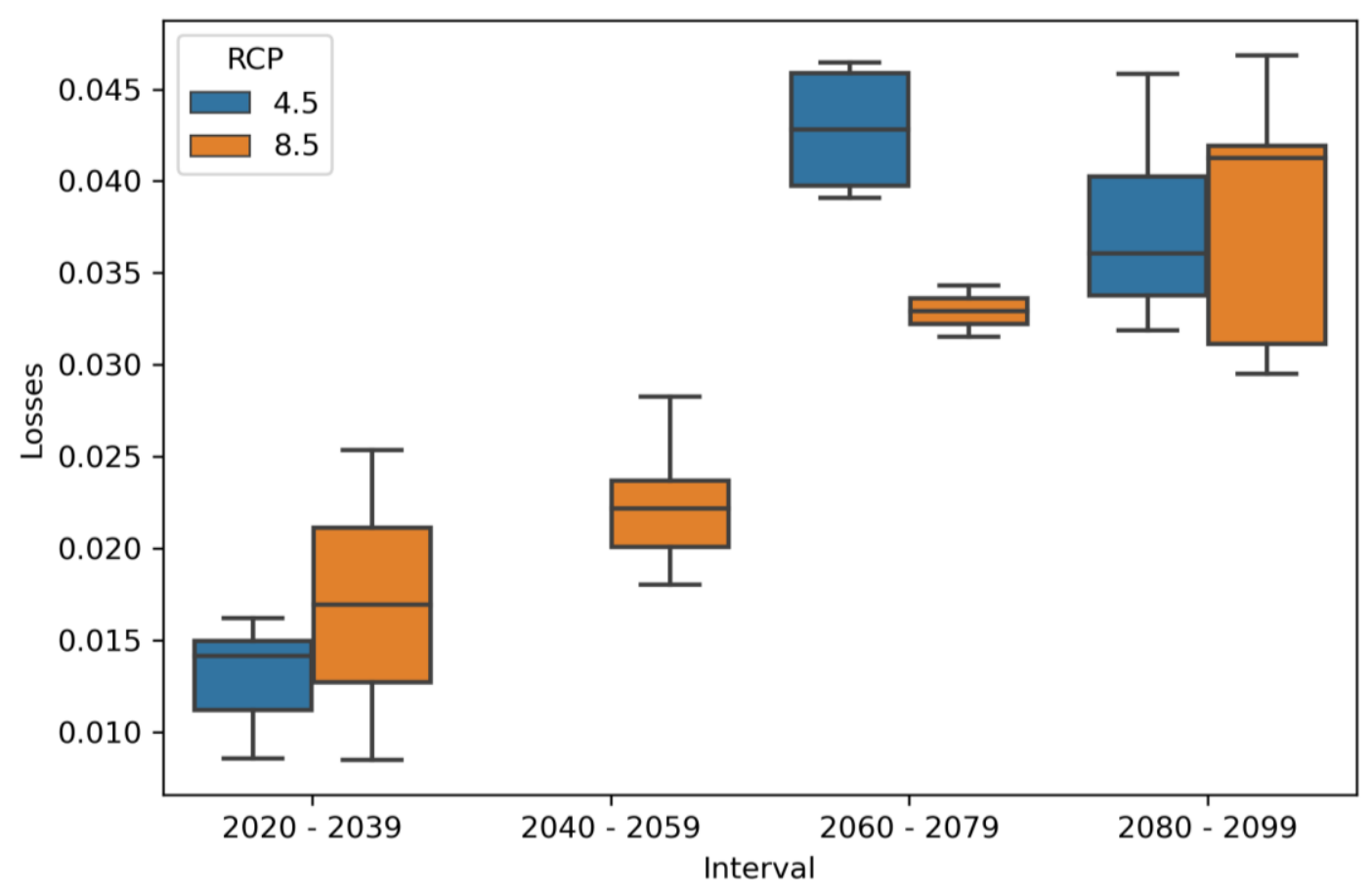


Figure 22: Boxplot of population density data for each 20-year period.

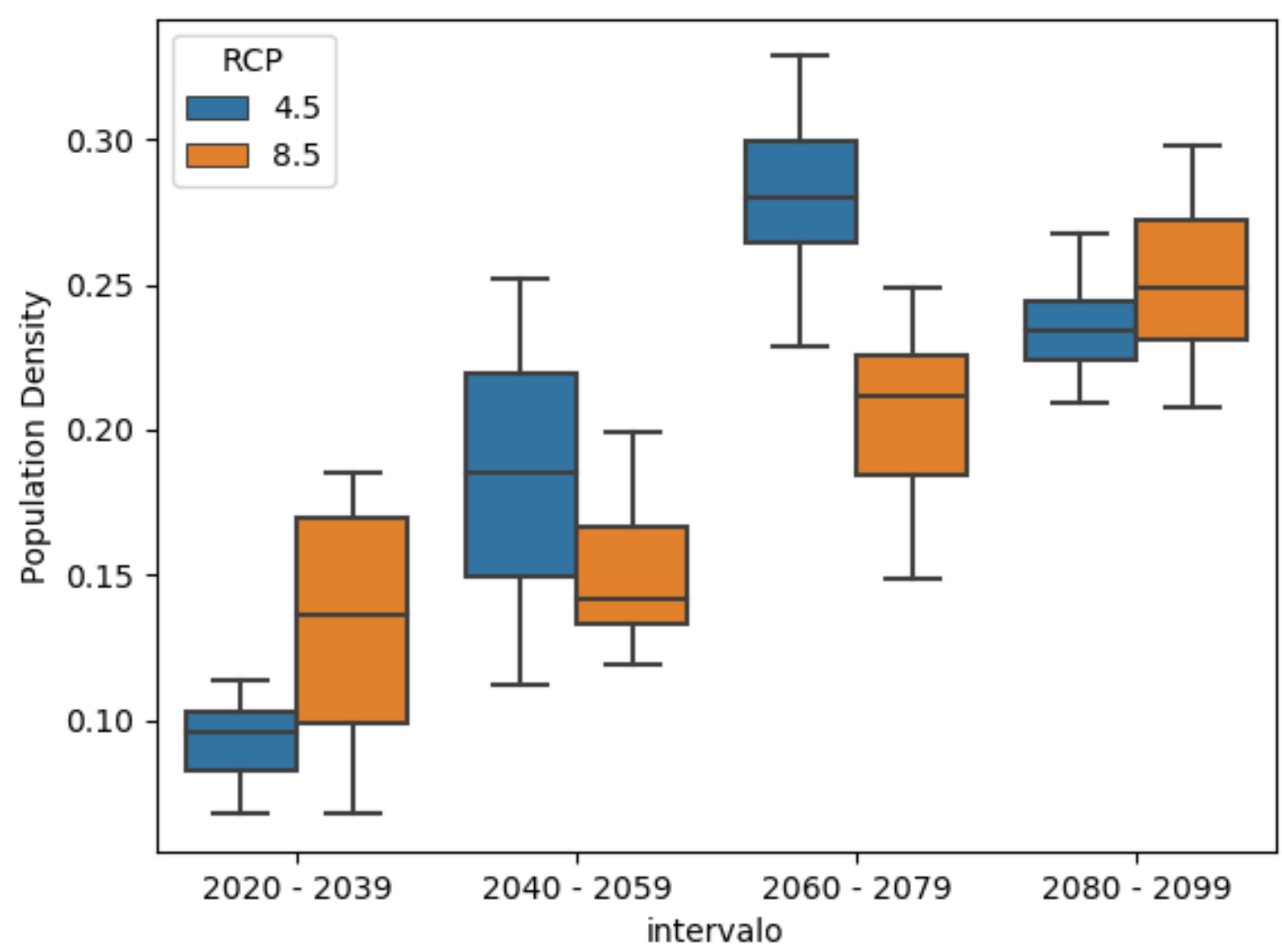

Figure 23: Boxplot of memory data for each 20-year period.

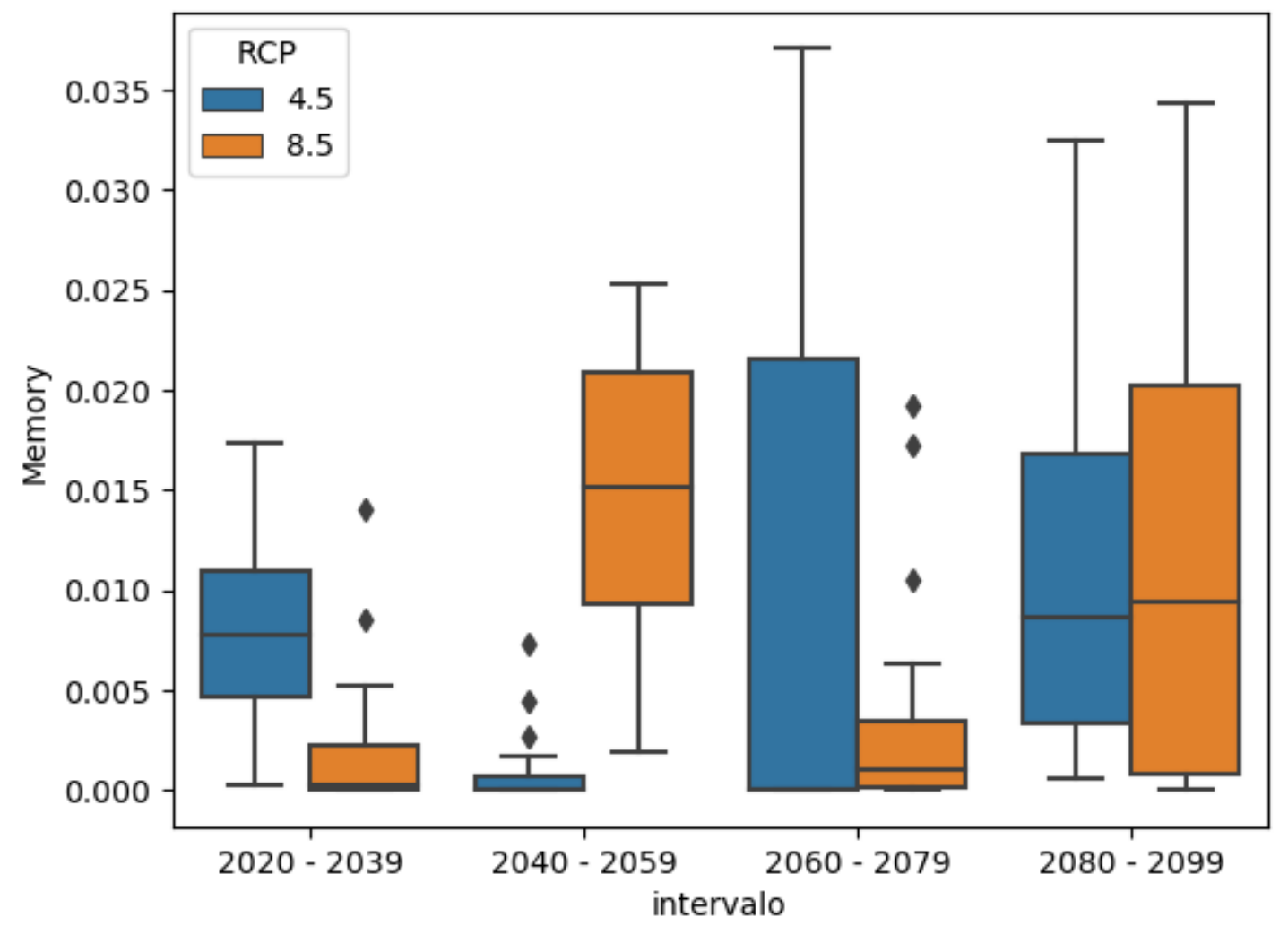


Figure 24: Boxplot of flood risk data for each 20-year period.

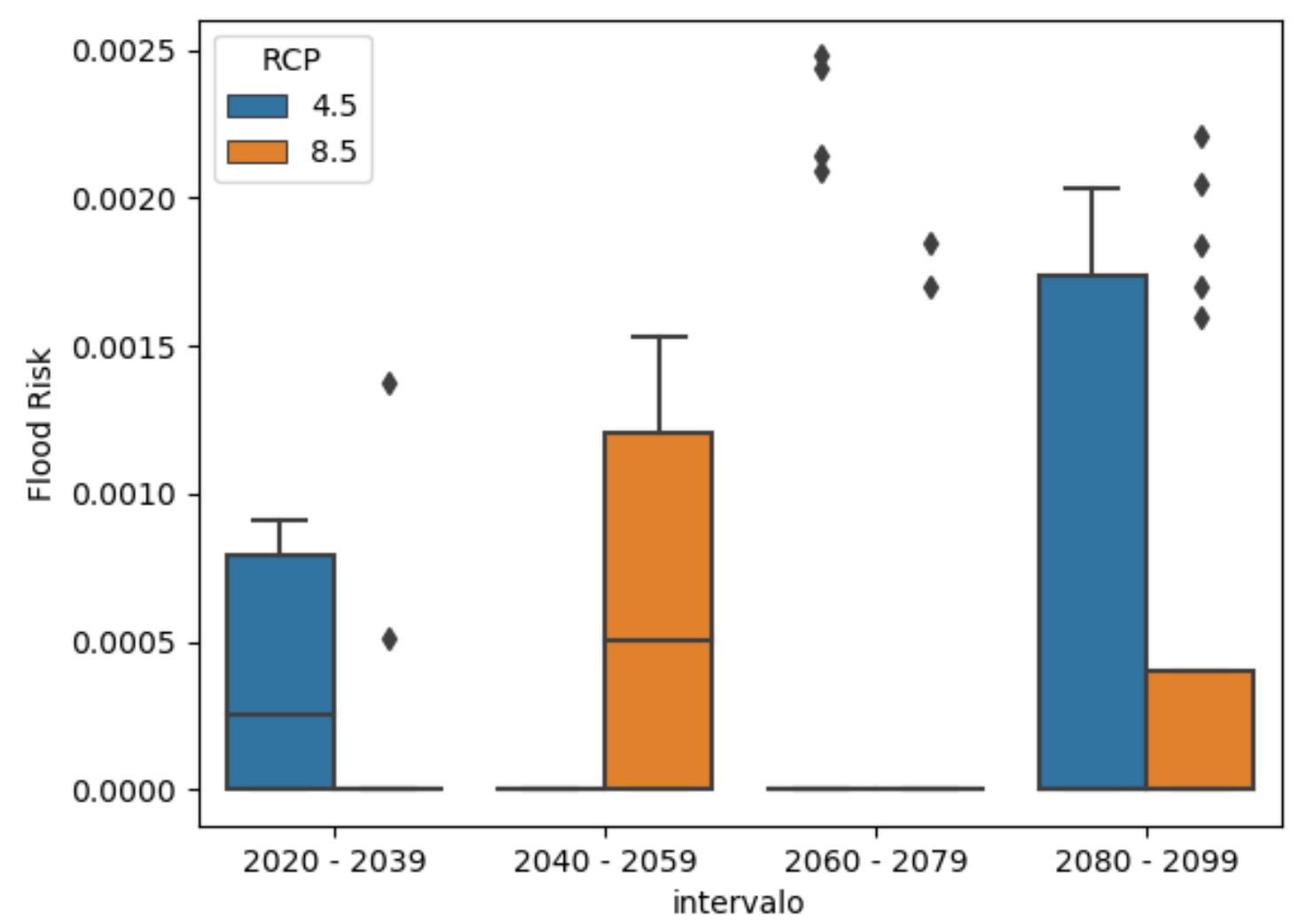

\subsection{CONCLUSIONS AND RECOMMENDATIONS}

In Chapter 3, we proposed a novel approach to assess future flood risk in a changing climate that accounts for human behaviour and socio-hydrological feedbacks. To this end, a cellular automata model was applied using the data from a regional climate to obtain the annual maximum water level for the years between 2020 and 2099. These outputs were used as input to the socio-hydrological model to estimate the flood risk in the study area for the same period. This approach is expected to be a contribution of the state of the art of risk assessment, presenting a holistic alternative to the standard approach.

The specific purpose 2 "Incorporate social and climate change aspects in the flood risk analysis" was investigated in this chapter. To this end, the socio-hydrological model was coupled with the results of a regional climate model to estimate flood risk. The results show that this risk assessment framework can highlight aspects that would not be pointed out through the traditional approach, such as the increased flood risk generated by the decay of the memory of past events. For any climate change scenarios, strategies concerned on maintaining flood memories alive are plausible solutions to reduce risk and damages. 
One of the shortcomings of this study is the absence of data necessary to perform hydrodynamic modelling with greater reliability. A first recommendation for future studies is to carry out a survey of measurements of the micro-drainage network in the area to model the flood events considering the micro-drainage flow, since the floods are not only derived from the creek in the study area. In addition, the authors recommend to perform the flood modelling again using a physically-based model, to investigate the possible underestimation of water level values in the municipal market area due to simplifications of the cellular automata model. Data from different climate models can also be used to run this framework and reduce bias.

\subsection{SUPPLEMENTARY MATERIAL}

Supplementary data related to this article can be found at the Appendix of this work.

\subsection{ACKNOWLEDGMENTS}

The present work was developed using the data provided by CPTEC/INPE and made available on the PROJETA platform (https://projeta.cptec.inpe.br/). The author is grateful for the information provided. This study was financed in part by the Coordenação de Aperfeiçoamento de Pessoal de Nível Superior - Brasil (CAPES) - Finance Code 88882.328899/2019-01, FAPESP 2014/50848-9 INCT-II (Climate Change, Water Security) and FAPESP 2018/03473-0 Understanding risk perception and the enigma of people's memory through social hydrology.

\subsection{REFERENCES}

Abreu, F. G. (2019). Quantification of economic damage to commercial activity from urban flooding. (Tese de doutorado, Escola de Engenharia de São Carlos, Universidade de São Paulo). Recuperado de www.teses.usp.br.

Aerts, J. C., Botzen, W. J., Clarke, K. C., Cutter, S. L., Hall, J. W., Merz, B., ... \& Kunreuther, H. (2018). Integrating human behaviour dynamics into flood disaster risk assessment. Nature Climate Change, 8(3), 193-199.

ANA - Agência Nacional de Águas. Atlas da Vulnerabilidade a Inundações. Brasília, 2014. ANA - Agência Nacional de Águas. Plano Nacional de Segurança Hídrica. Brasília, 2019.

Arnell, N. W., \& Gosling, S. N. (2016). The impacts of climate change on river flood risk at the global scale. Climatic Change, 134(3), 387-401. 
Arora, V. K., Scinocca, J. F., Boer, G. J., Christian, J. R., Denman, K. L., Flato, G. M., ... \& Merryfield, W. J. (2011). Carbon emission limits required to satisfy future representative concentration pathways of greenhouse gases. Geophysical Research Letters, 38(5).

Black, T. L. (1994). The new NMC mesoscale Eta model: Description and forecast examples. Weather and forecasting, 9(2), 265-278.

Blöschl, G., Hall, J., Parajka, J., Perdigão, R. A., Merz, B., Arheimer, B., ... \& Čanjevac, I. (2017). Changing climate shifts timing of European floods. Science, 357(6351), 588590.

Blöschl, G., Hall, J., Viglione, A., Perdigão, R. A., Parajka, J., Merz, B., ... \& Boháč, M. (2019). Changing climate both increases and decreases European river floods. Nature, 573(7772), 108-111.

Chou, S. C., Marengo, J. A., Lyra, A. A., Sueiro, G., Pesquero, J. F., Alves, L. M., ... \& Bustamante, J. F. (2012). Downscaling of South America present climate driven by 4 member HadCM3 runs. Climate dynamics, 38(3-4), 635-653.

Ciullo, A., Viglione, A., Castellarin, A., Crisci, M. \& Di Baldassarre, G. (2017). Sociohydrological modelling of flood-risk dynamics: comparing the resilience of green and technological systems. Hydrological Sciences Journal, v. 62, n. 6, p. 880-891.

Collins, W. J., Bellouin, N., Doutriaux-Boucher, M., Gedney, N., Halloran, P., Hinton, T., ... \& Martin, G. (2011). Development and evaluation of an Earth-System model-HadGEM2. Geosci. Model Dev. Discuss, 4(2), 997-1062.

Di Baldassarre, G.; Viglione, A.; Carr, G.; Kuil, L.; Yan, K.; Brandimarte, L. \& Blöschl, G. (2015). Debates - perspectives on socio-hydrology: Capturing feedbacks between physical and social processes. Water Resources Research, v. 51, n. 6, p. 4770-4781.

Dottori, F., \& Todini, E. (2011). Developments of a flood inundation model based on the cellular automata approach: testing different methods to improve model performance. Physics and Chemistry of the Earth, Parts A/B/C, 36(7-8), 266-280.

Fava, M. C., Abe, N., Restrepo-Estrada, C., Kimura, B. Y., \& Mendiondo, E. M. (2019). Flood modelling using synthesised citizen science urban streamflow observations. Journal of Flood Risk Management, 12(S2), e12498.

Global Assessment Report on Disaster Risk Reduction. (UN Report 2009). (2009). Geneva, Switzerland: United Nations.

Guidolin, M., Duncan, A., Ghimire, B., Gibson, M., Keedwell, E., Chen, A. S., ... \& Savic, D. (2012). CADDIES: a new framework for rapid development of parallel cellular automata algorithms for flood simulation. Paper presented at the 10th International Conference on Hydroinformatics. Hamburg, GERMANY

Guidolin, M., Chen, A. S., Ghimire, B., Keedwell, E. C., Djordjević, S., \& Savić, D. A. (2016). A weighted cellular automata 2D inundation model for rapid flood analysis. Environmental Modelling \& Software, 84, 378-394.

Ghimire, B., Chen, A. S., Guidolin, M., Keedwell, E. C., Djordjević, S., \& Savić, D. A. (2013). Formulation of a fast 2D urban pluvial flood model using a cellular automata approach. Journal of Hydroinformatics, 15(3), 676-686.

Hennemuth, B., Bender, S., Bülow, K., Dreier, N., Keup-Thiel, E., Krüger, O., Mudersbach, C., Radermacher, C., Schoetter, R. (2013). Statistical methods for the analysis of simulated and observed climate data, applied in projects and institutions dealing with climate change impact and adaptation. CSC Report 13, Climate Service Center, Germany.

Hirabayashi, Y., Mahendran, R., Koirala, S., Konoshima, L., Yamazaki, D., Watanabe, S., ... \& Kanae, S. (2013). Global flood risk under climate change. Nature Climate Change, 3(9), 816-821. 
Itami, R. M. (1994). Simulating spatial dynamics: cellular automata theory. Landscape and Urban Planning, 30(1-2), 27-47. doi:10.1016/0169-2046(94)90065-5

Liu, X., Liang, X., Li, X., Xu, X., Ou, J., Chen, Y., ... \& Pei, F. (2017). A future land use simulation model (FLUS) for simulating multiple land use scenarios by coupling human and natural effects. Landscape and Urban Planning, 168, 94-116.

Mao, F., Clark, J., Karpouzoglou, T., Dewulf, A., Buytaert, W., and Hannah, D. (2017). HESS Opinions: A conceptual framework for assessing socio-hydrological resilience under change, Hydrol. Earth Syst. Sci., 21, 3655-3670, https://doi.org/10.5194/hess-21-36552017.

Marengo, J. A., Chou, S. C., Kay, G., Alves, L. M., Pesquero, J. F., Soares, W. R., ... \& Chagas, D. J. (2012). Development of regional future climate change scenarios in South America using the Eta CPTEC/HadCM3 climate change projections: climatology and regional analyses for the Amazon, São Francisco and the Paraná River basins. Climate Dynamics, 38(9-10), 1829-1848.

Macêdo, R. F., Souza, S. A., Andrade, J. P. M., Marco, G., Mendiondo, E. M. Cenários de Políticas de Controle de Impactos devido a Inundações. Anais do I Seminário Latinoamericano de Políticas Públicas em Recursos Hídricos, 23-25 Sep 2004 Brasília.

Mendiondo, E. M., Souza, F. A. A., Taffarello, D., Buarque, A. C. S., Bhattacharya-Mis, N., Estrada, C. R., ... \& Abreu, F. (2019). How to Bridge the Gaps Among DRR, SDG, UPH, MOXXI/CANDHY and Panta Rhei by Volunteered Information of HumanCentered Observatories? Paper presented at the AGU Fall Meeting 2019. San Francisco, CA.

Mesinger, F., Janjić, Z. I., Ničković, S., Gavrilov, D., \& Deaven, D. G. (1988). The stepmountain coordinate: Model description and performance for cases of Alpine lee cyclogenesis and for a case of an Appalachian redevelopment. Monthly Weather Review, 116(7), 1493-1518.

Mondino, E., Scolobig, A., Borga, M., Albrecht, F., Mård, J., Weyrich, Di Baldassarre, P., G. (2020). Exploring changes in hydrogeological risk awareness and preparedness over time: a case study in northeastern Italy. Hydrological Sciences Journal, v. 65, n. 7, p. 1049-1059, DOI: 10.1080/02626667.2020.1729361.

Nobre, C. A.; Young, A.F.; Saldiva, P.; Marengo, J. A.; Nobre, A. D.; Alves Júnior, S.P.; Silva, G. C. M.; Lombardo, M. (2010). Vulnerabilidades das megacidades brasileiras às mudanças climáticas: região metropolitana de São Paulo. (Technical Report). São Paulo - SP.

Palmer, P. I., \& Smith, M. J. (2014). Earth systems: model human adaptation to climate change. Nature News, 512(7515), 365.

Righetto, J. M., \& Mendiondo, E. M. (2004). Avaliação de riscos hidrológicos: principais danos e causas e proposta de seguro contra enchentes. Anais do III Simpósio de Recursos Hídricos do Centro-Oeste, Goiânia, GO.

Righetto, J. M. (2005). Modelo de seguros para riscos hidrológicos no contexto do manejo integrado de bacias. (Dissertação de mestrado, Escola de Engenharia de São Carlos, Universidade de São Paulo). Recuperado de: www.teses.usp.br.

Sendai framework for disaster risk reduction 2015-2030. (UNISDR Report 2015). (2015). Geneva, Switzerland: United Nations Office for Disaster Risk Reduction.

Souza, F. A. A.; Degrossi, L.C.; Albuquerque, J. P.; Delbem, A. C. B.; Buarque, A. C. S.; Fava, M. C.; Bhattacharya-Mis, N.; Taffarello, D.; Mendiondo, E. M. (submitted). Egalitarian Citizens' Storylines Unravelled Through A Socio-Hydrological Observatory for Water Security: From conceptualization to a Brazilian case study. Science of Total Environment. 
Sun, G. Q., Jusup, M., Jin, Z., Wang, Y., \& Wang, Z. (2016). Pattern transitions in spatial epidemics: Mechanisms and emergent properties. Physics of life reviews, 19, 43-73.

Tariq, J., \& Kumaravel, A. (2016). Construction of cellular automata over hexagonal and triangular tessellations for path planning of multi-robots. Paper presented at the 2016 IEEE International Conference on Computational Intelligence and Computing Research (ICCIC) (pp. 1-6). Tamil Nadu, India.

Torres, R. R., Lapola, D. M., Marengo, J. A., \& Lombardo, M. A. (2012). Socio-climatic hotspots in Brazil. Climatic change, 115(3-4), 597-609.

UNISDR terminology on disaster risk reduction. (ISDR Report 2009). (2009). Geneva, Switzerland: United Nations.

Valeriano, M. M., \& Rossetti, D. F. (2012). Topodata: Brazilian full coverage refinement of SRTM data. Applied Geography, 32(2), 300-309.

Viglione, A., Di Baldassarre, G., Brandimarte, L., Kuil, L., Carr, G., Salinas, J. L., ... \& Blöschl, G. (2014). Insights from socio-hydrology modelling on dealing with flood risk-roles of collective memory, risk-taking attitude and trust. Journal of Hydrology, 518, 71-82.

Watanabe, M., Suzuki, T., O'ishi, R., Komuro, Y., Watanabe, S., Emori, S., ... \& Takata, K. (2010). Improved climate simulation by MIROC5: mean states, variability, and climate sensitivity. Journal of Climate, 23(23), 6312-6335.

Wing, O. E., Pinter, N., Bates, P. D., \& Kousky, C. (2020). New insights into US flood vulnerability revealed from flood insurance big data. Nature communications, 11(1), 110. 


\section{SOCIO-HYDROLOGY OBSERVATORY FOR WATER SECURITY UNDER CLIMATE CHANGE}

The International Association of Hydrological Sciences (IAHS) Scientific Decade 2013-2022 (Montanari et al. 2013) brings as one of its concepts that advances in hydrology are currently limited by the available measurement techniques and that the community should therefore be proactive in devising innovative monitoring strategies by taking advantage of new technologies and new generations of data. In this context, citizen observatories emerges as an alternative data source. A citizen observatory is software platform that obtain volunteered information about a specific topic through different devices (e.g. web browser, mobile application and SMS), and allow their visualization (Degrossi et al., 2014).

The engagement of citizens through the provision of data can be a useful tool to overcome the problem of the absence of data related to urban flood extension. In this context, the conceptual framework of the SHOWS for urban flood was developed. The structure of SHOWS, represented in Figure 25, which was partially tested and applied in Chapter 3, consists in three code modules, a database and a graphic interface that communicates with the user. The 'Data Gathering and Processing' collects the data required for the operation of the observatory that are available on the web. In this scheme, these data are digital elevation models of the area of interest, climate projections of rainfall and rainfall series from observational networks.

These data are processed to provide the inputs to the Flood Estimation module. This module consists in a Cellular Automata model that propagates the rainfall volume over the DEM cells. For this, it uses as input the rainfall intensity and the duration of the event. The observed data can be used to calibrate and validate the model, improving its accuracy. The output of Flood Estimation module is the annual maximum water level, which is used as input in the Socio-Hydrological module. This module performs the model developed by Di Baldassarre et al. (2015) and improved by Ciullo et al. (2017) to estimate the flood risk in the area over time. This risk is stored in the database and can be presented in the form of graphics in the user interface.

This interface will also be used to collect data provided by society. The information collected through SHOWS will be related to water level in the streets during flood extremes events and can be provided through the insertion of measured values or photographs. This 
information will be saved in the database and can be used for calibration and validation of the model, together with data from observational networks.

Figure 25: Conceptual Framework of the Socio-Hydrological Observatory for Water Security under Climate Change (SHOWS).

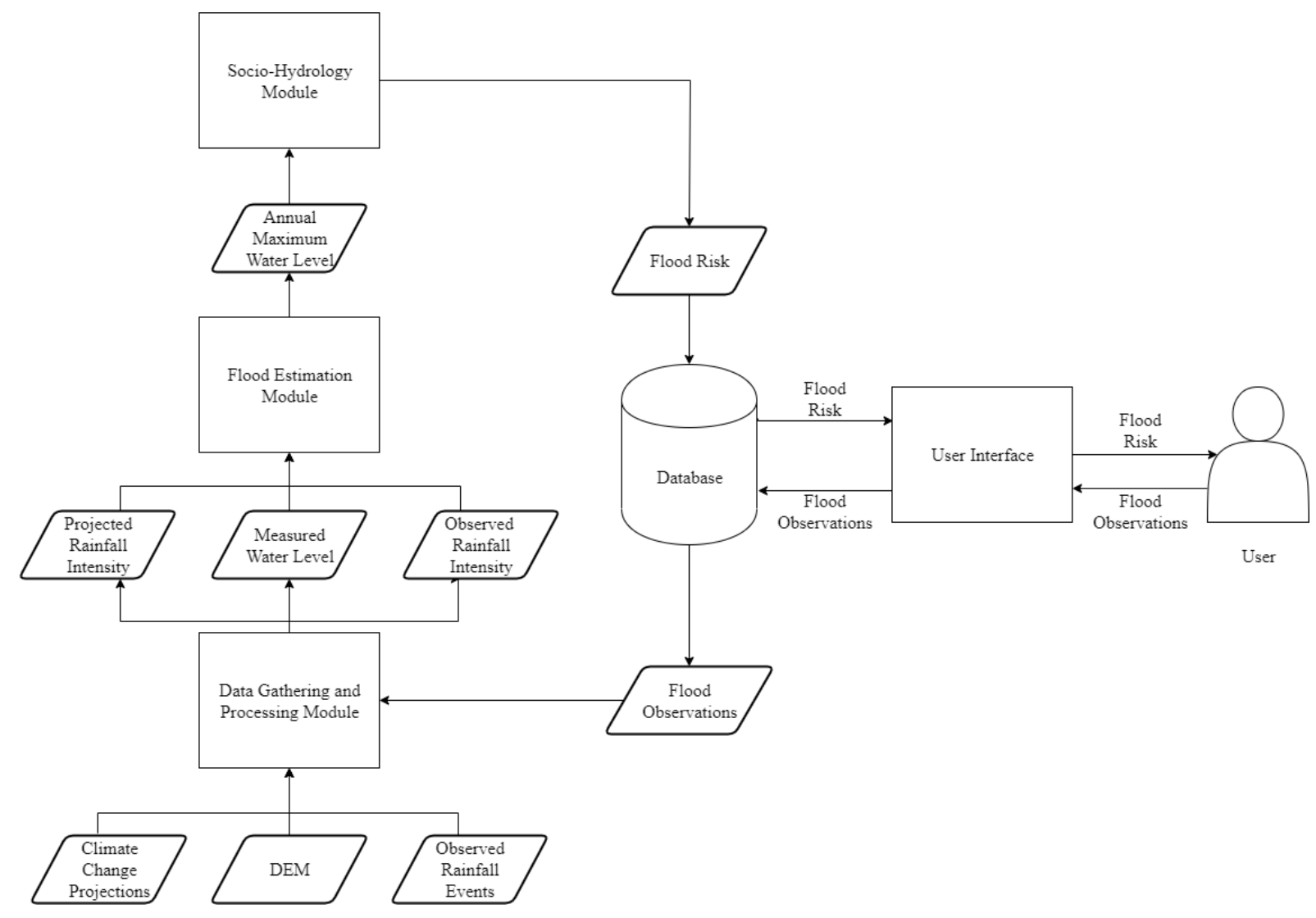

\subsection{REFERENCES}

Ciullo, A., Viglione, A., Castellarin, A., Crisci, M. \& Di Baldassarre, G. (2017). Sociohydrological modelling of flood-risk dynamics: comparing the resilience of green and technological systems. Hydrological Sciences Journal, v. 62, n. 6, p. 880-891.

Degrossi, L. C., de Albuquerque, J. P., Fava, M. C., \& Mendiondo, E. M. (2014). Flood Citizen Observatory: a crowdsourcing-based approach for flood risk management in Brazil. Paper presented at the 26th International Conference on Software Engineering and Knowledge Engineering (SEKE) (pp. 570-575). Vancouver, Canada.

Di Baldassarre, G.; Viglione, A.; Carr, G.; Kuil, L.; Yan, K.; Brandimarte, L. \& Blöschl, G. (2015). Debates - perspectives on socio-hydrology: Capturing feedbacks between physical and social processes. Water Resources Research, v. 51, n. 6, p. 4770-4781, 2015.

Montanari, A., Young, G., Savenije, H. H. G., Hughes, D., Wagener, T., Ren, L. L., ... \& Blöschl, G. (2013). "Panta Rhei-everything flows": change in hydrology and societythe IAHS scientific decade 2013-2022. Hydrological Sciences Journal, 58(6), 12561275. 


\section{GENERAL CONCLUSIONS}

The general conclusions of this work will be presented as answers to the objectives and the recommendations for future work are presented in the next topic.

\subsection{CONCLUSIONS}

The first objective is "Analyse flood risk reduction measures related to social aspects" and it was discussed in Chapter 2. In this chapter, historical data was used as input to the sociohydrological model to estimate the past flood risk in the study area and scenarios of environmental and social interventions were performed. This step was fundamental to verify the applicability of the socio-hydrological model to the study area and understand the impact of the memory in the flood risk.

The history of the Gregório Creek Basin were confronted with the model results and it was possible to perceive that the model captured some important feedbacks between human and floods in the area. The measures related to social aspects analysed in this chapter reduced the risk of flooding, but the environmental measures generated more significant reductions. However, as the measures that focus on memory maintenance have a lower cost, they can be adopted more easily, even in conjunction with environmental measures.

The second objective is "Incorporate social and climate change aspects in the flood risk analysis" and it was discussed in Chapter 3. In this chapter, data from a regional climate model was processed by a cellular automata model, which produced the annual maximum water level, used as input to the socio-hydrological model. The results of this chapter show that the coupling of these models serves as a risk assessment tool, which can highlight aspects that would not be pointed out through the traditional approach, such as the increased flood risk generated by the decay of the memory of past events.

The main goal of the study is to "Develop conceptually a platform cooperative to acquire and provide information about urban flood risk coevolution under climate change scenarios, using the Socio-Hydrology Observatory for Water Security (SHOWS)" and it was discussed in Chapter 4. This chapter gathered the analysis performed in Chapter 2 and 3 to develop a framework to communicate flood risk and acquire data to improve flood assessment. 
Thus, the conceptual model of the SHOWS was developed coupling climate, hydrodynamic and socio-hydrological models in a web platform that communicates with the user.

\subsection{RECOMMENDATIONS FOR FUTURE WORKS}

In order to continue the study developed here and improve its results, the following suggestions are recommended for future works:

a. Conduct field micro-drainage data collection to improve modelling of annual maximum water levels;

b. Conduct periodic interviews with the population to identify the decay of flood memory and, thus, calibrate the parameter that represents it in the sociohydrological model;

c. Improve the socio-hydrological model so that it can consider other structural measures besides levees;

d. Develop a prototype of the Socio-Hydrology Observatory for Water Security and test its applicability in the region;

e. Include changes in land use in the catchment in the flood risk assessment. 


\section{APPENDIX: SUPPLEMENTARY MATERIAL}

a) FLOOD MAPS

- $\quad$ RCP 4.5

Flood extension map for the flood event with the highest daily rainfall intensity of 2020 for the RCP 4.5.

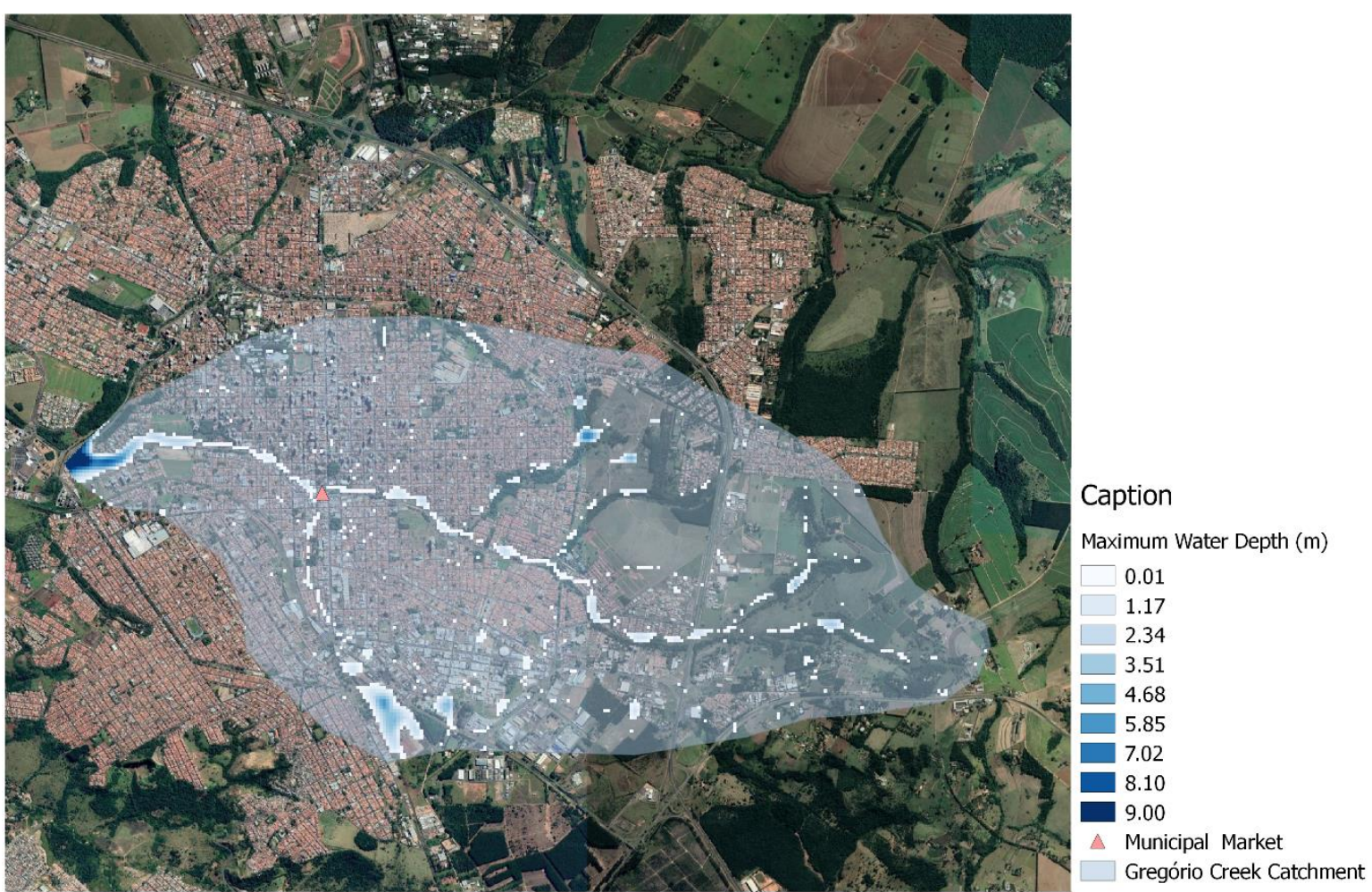


Flood extension map for the flood event with the highest daily rainfall intensity of 2022 for the RCP 4.5.

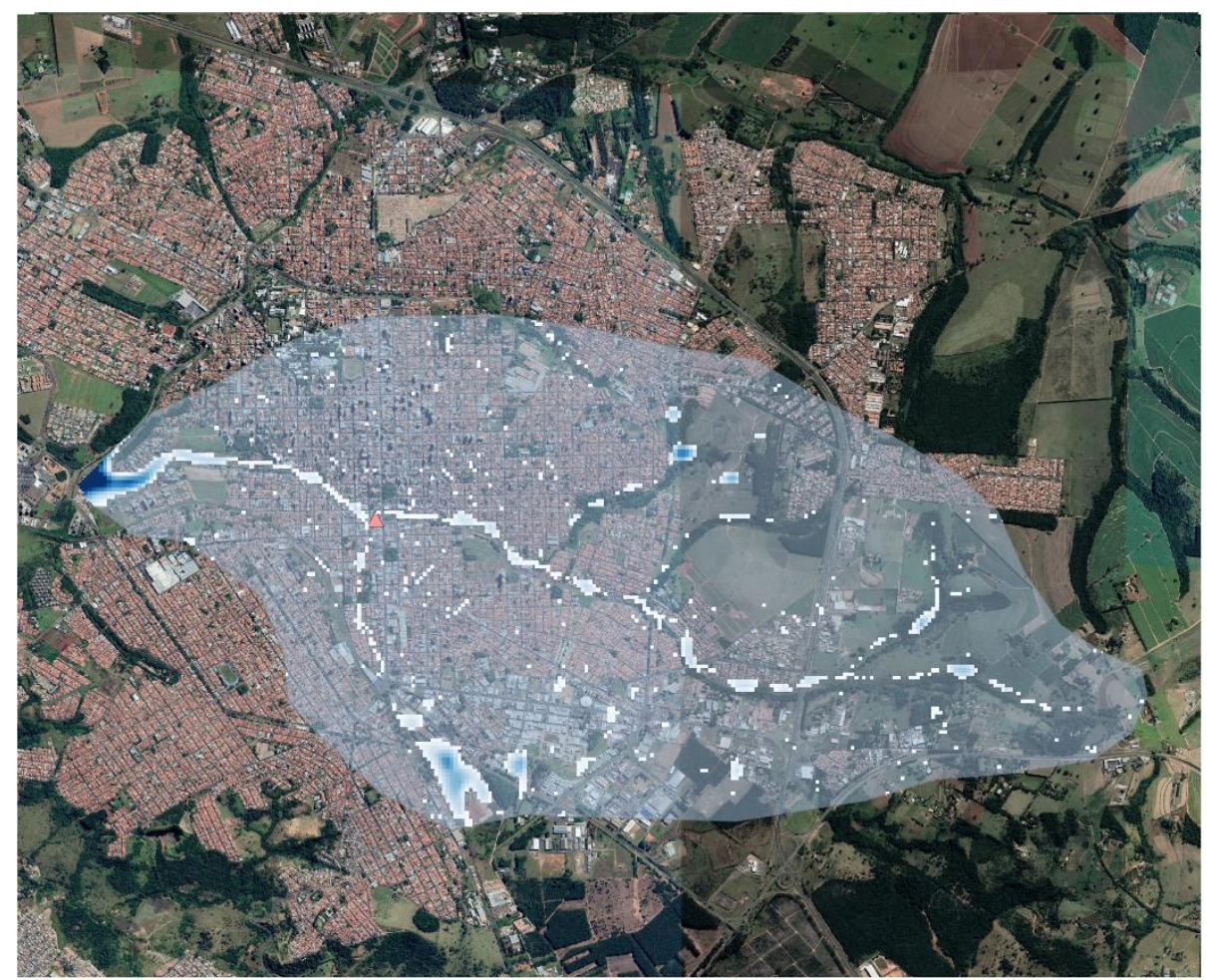

\section{Caption}

Maximum Water Depth $(\mathrm{m})$

$\square 0.01$

$\square 1.11$

2.22
3.33

$\square 4.44$

5.55

7.68

8.53

$\triangle$ Municipal Market

Gregório Creek Catchment

Flood extension map for the flood event with the highest daily rainfall intensity of 2024 for the RCP 4.5.

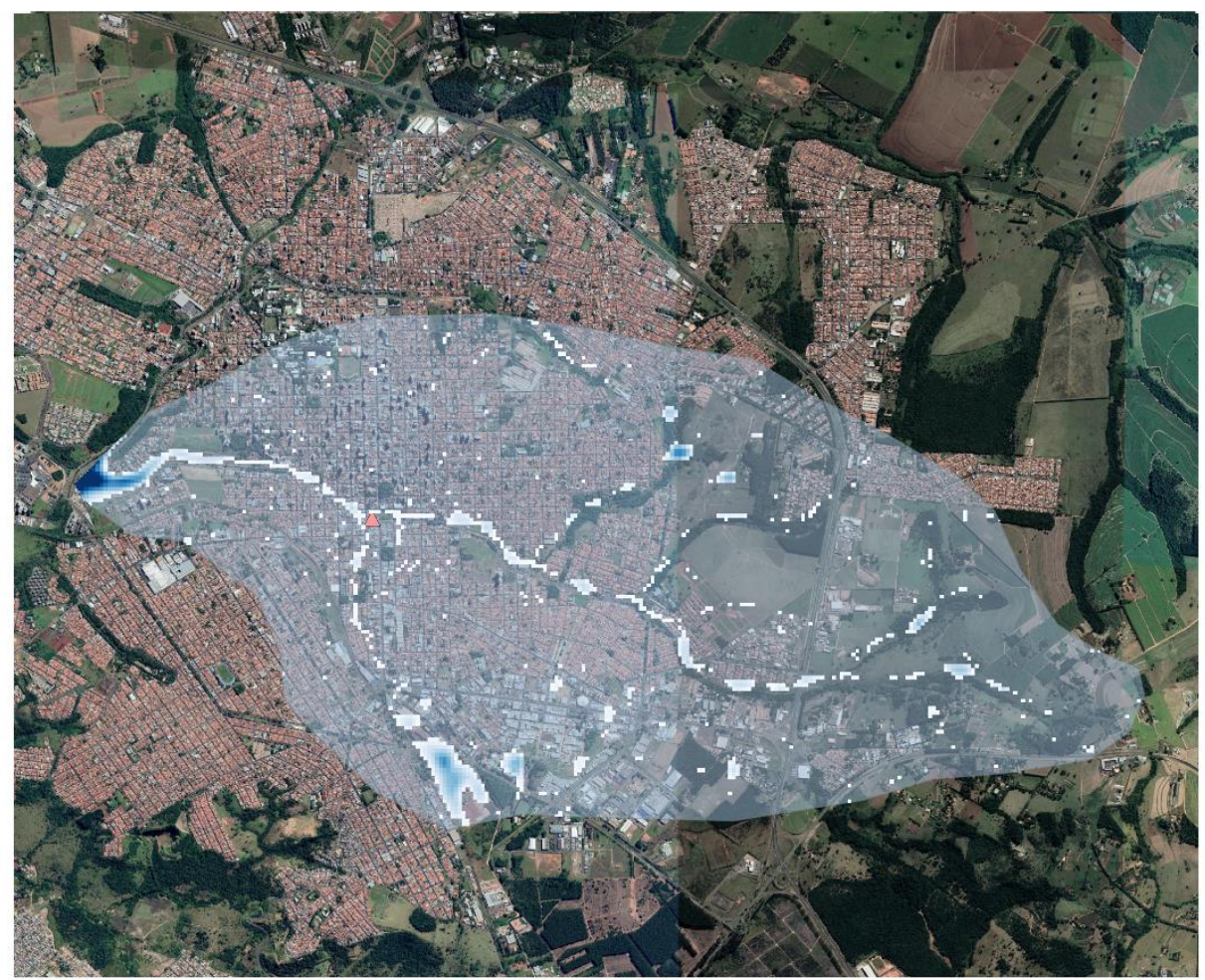

\section{Caption}

Maximum Water Depth $(\mathrm{m})$

$\square 0.01$

1.11

2.22
3.33

3.44
$\square$

5.55

6.66

7.68

8.53

$\triangle$ Municipal Market

Gregório Creek Catchment 
Flood extension map for the flood event with the highest daily rainfall intensity of 2027 for the RCP 4.5.

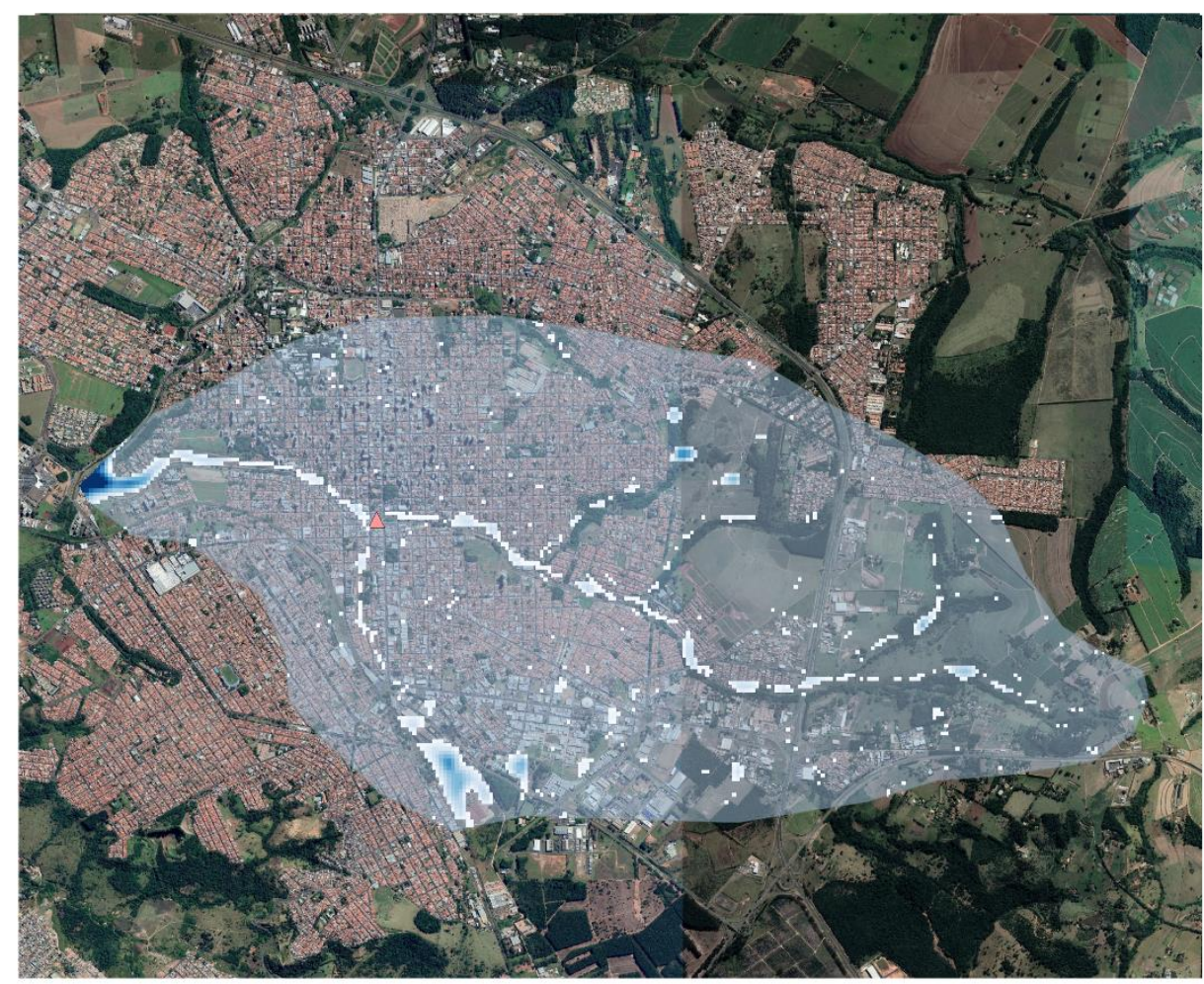

\section{Caption}

Maximum Water Depth ( $\mathrm{m}$ )

$\square 0.01$

$\square 1.11$

$\square .22$
$\square$
$\square .33$

$\square 4.44$

5.55

$\square .66$

7.68

$\triangle$ Municipal Market

Gregório Creek Catchment

Flood extension map for the flood event with the highest daily rainfall intensity of 2028 for the RCP 4.5.

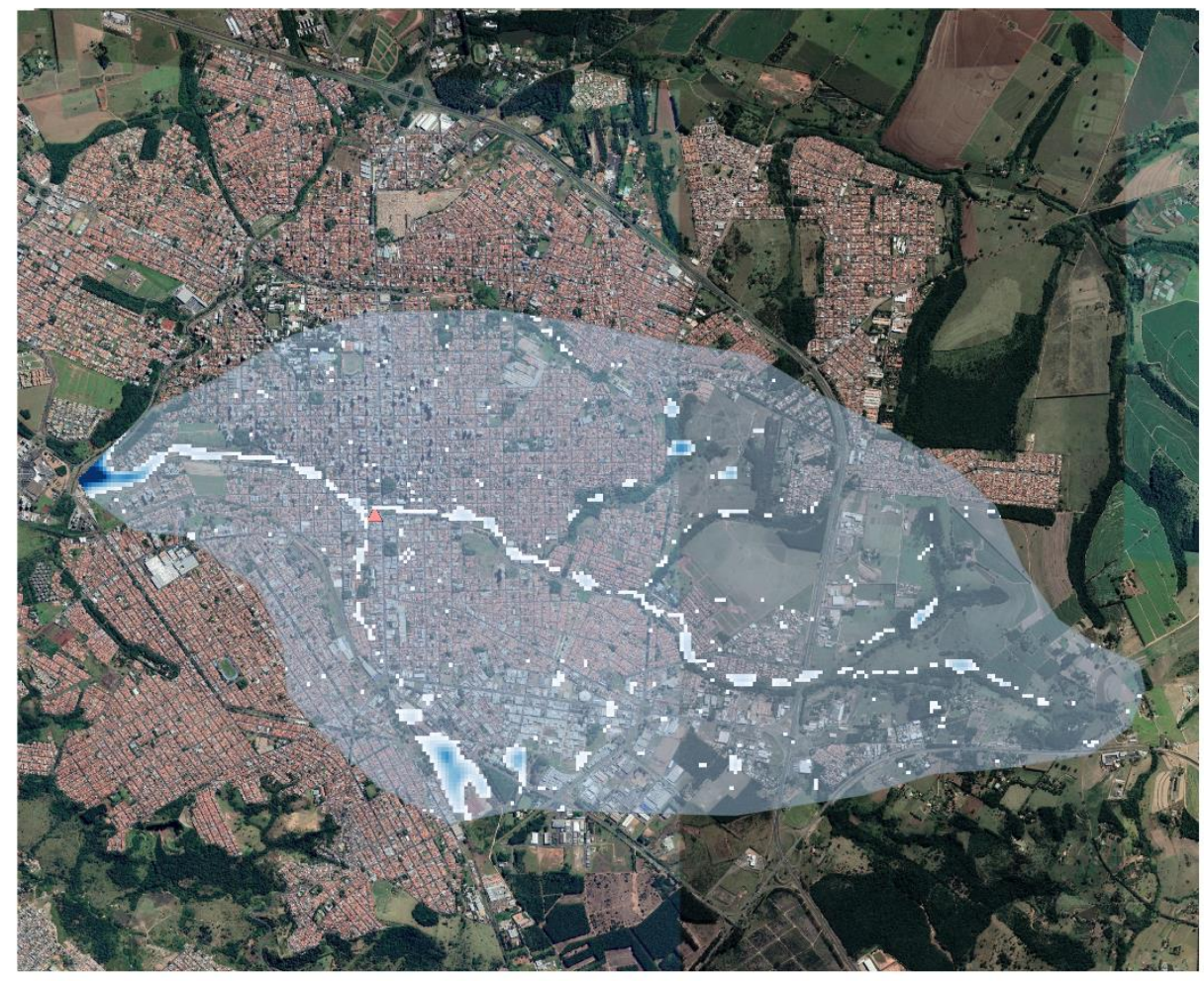

\section{Caption}

Maximum Water Depth (m)

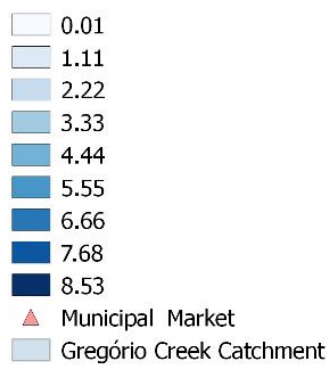


Flood extension map for the flood event with the highest daily rainfall intensity of 2034 for the RCP 4.5.

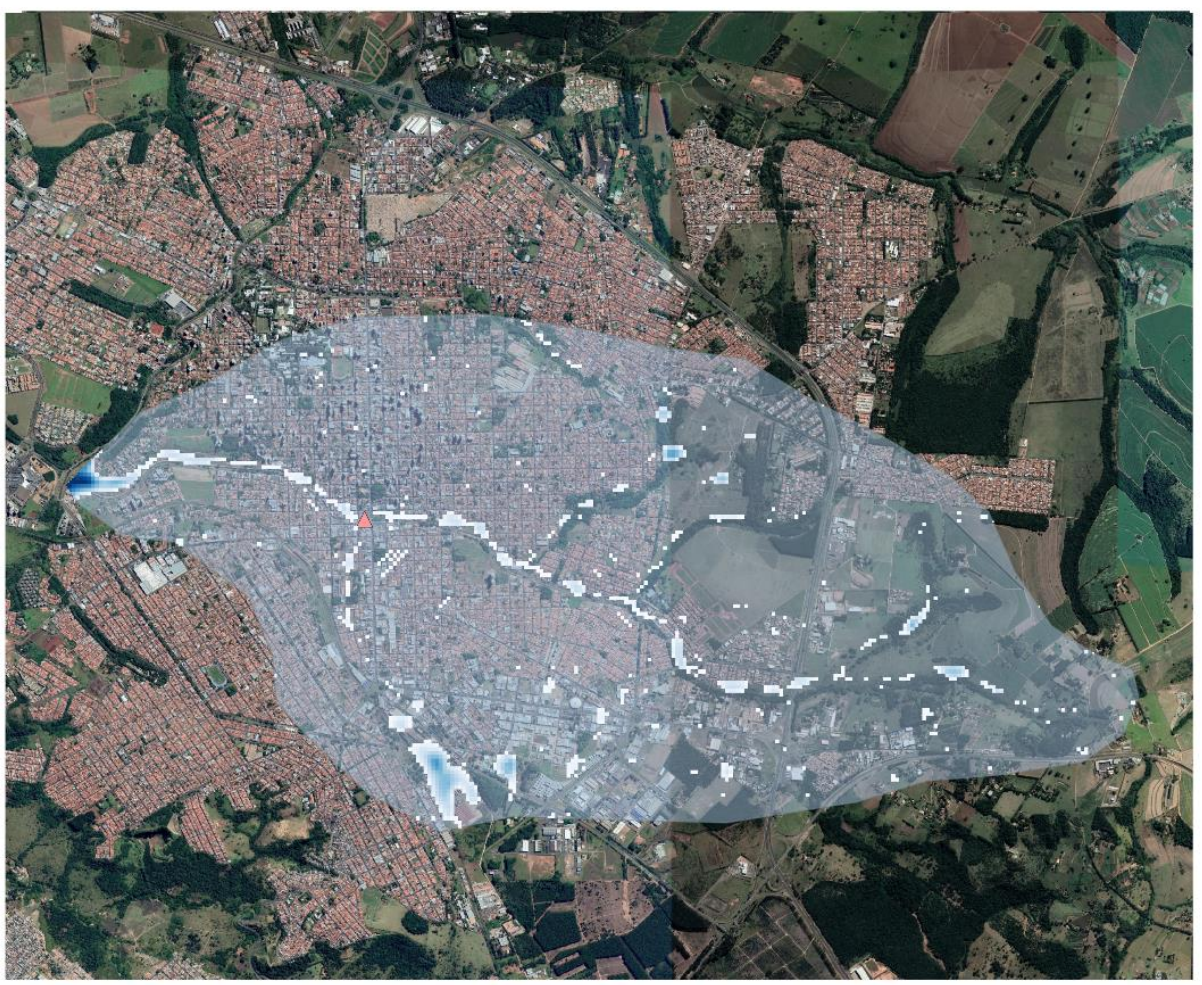

\section{Caption}

Maximum Water Depth (m)

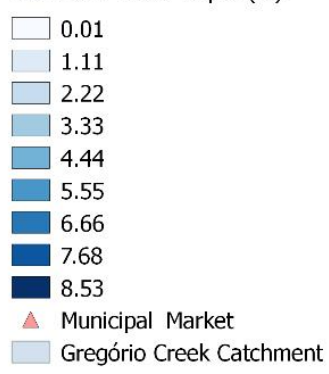

Flood extension map for the flood event with the highest daily rainfall intensity of 2035 for the RCP 4.5.

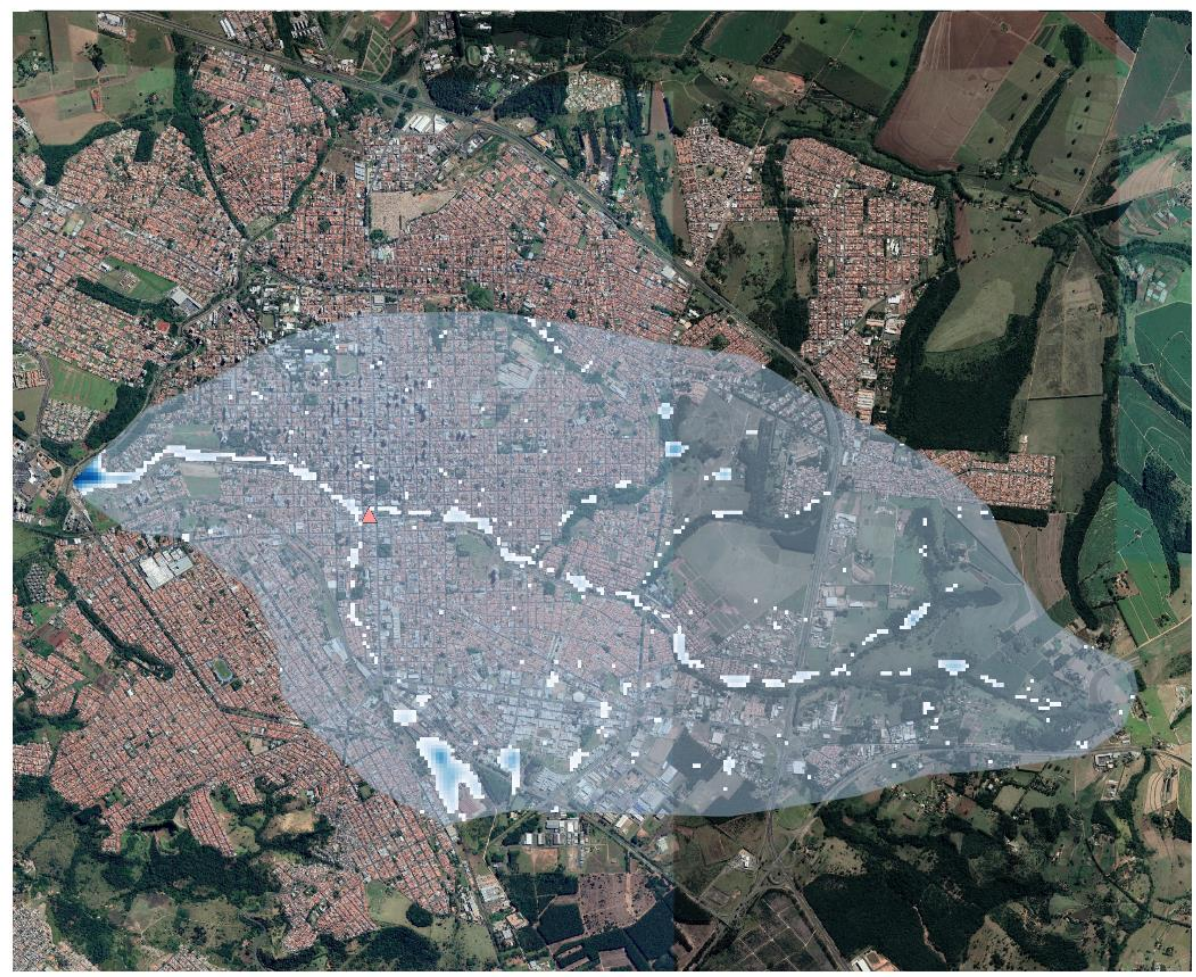

\section{Caption}

Maximum Water Depth (m)

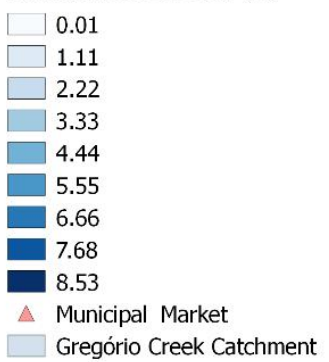


Flood extension map for the flood event with the highest daily rainfall intensity of 2038 for the RCP 4.5.

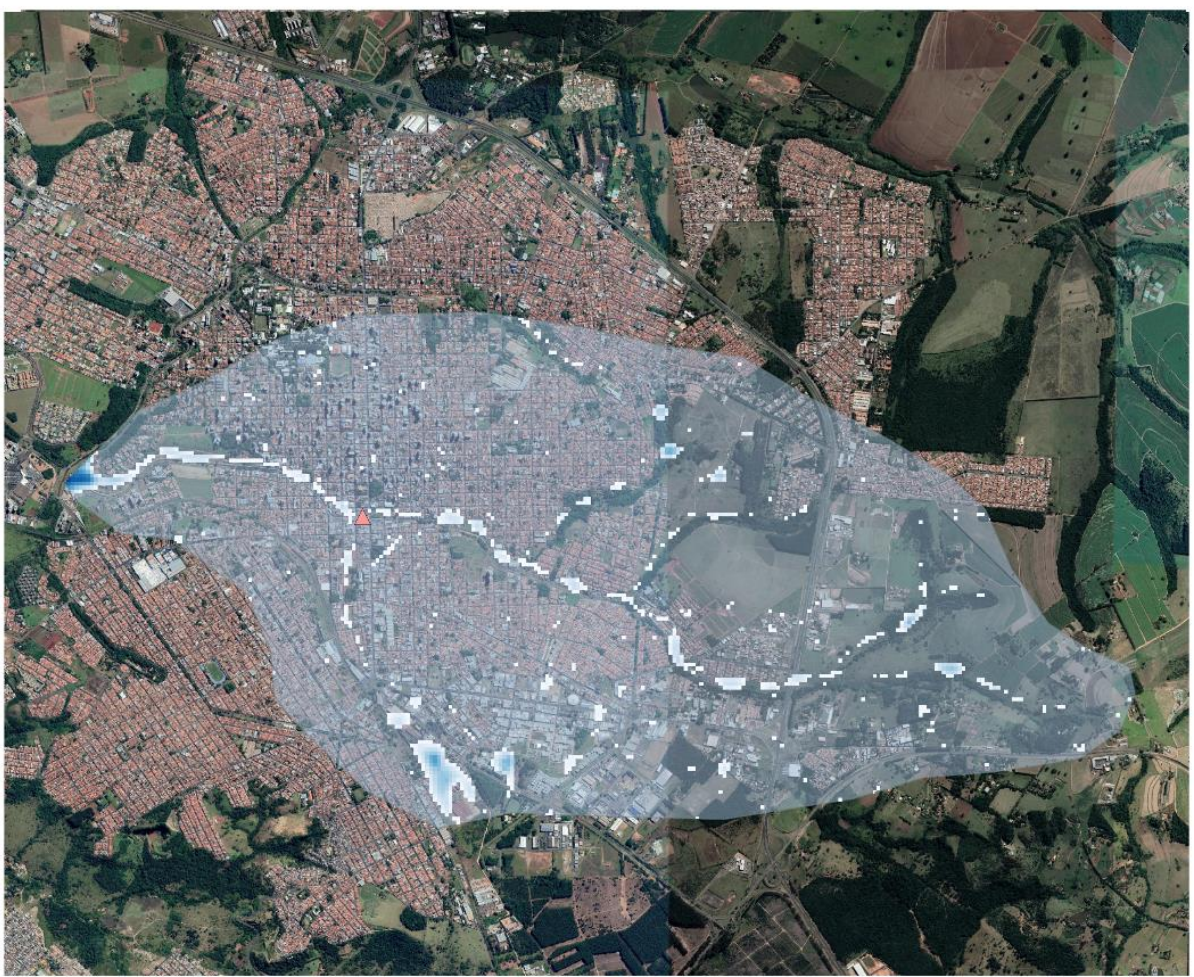

\section{Caption}

Maximum Water Depth (m)
0.01
$\square 1.11$
$\square .33$
$\square .44$
5.55
6.66
7.68
A Municipal Market
Gregório Creek Catchment

Flood extension map for the flood event with the highest daily rainfall intensity of 2071 for the RCP 4.5.

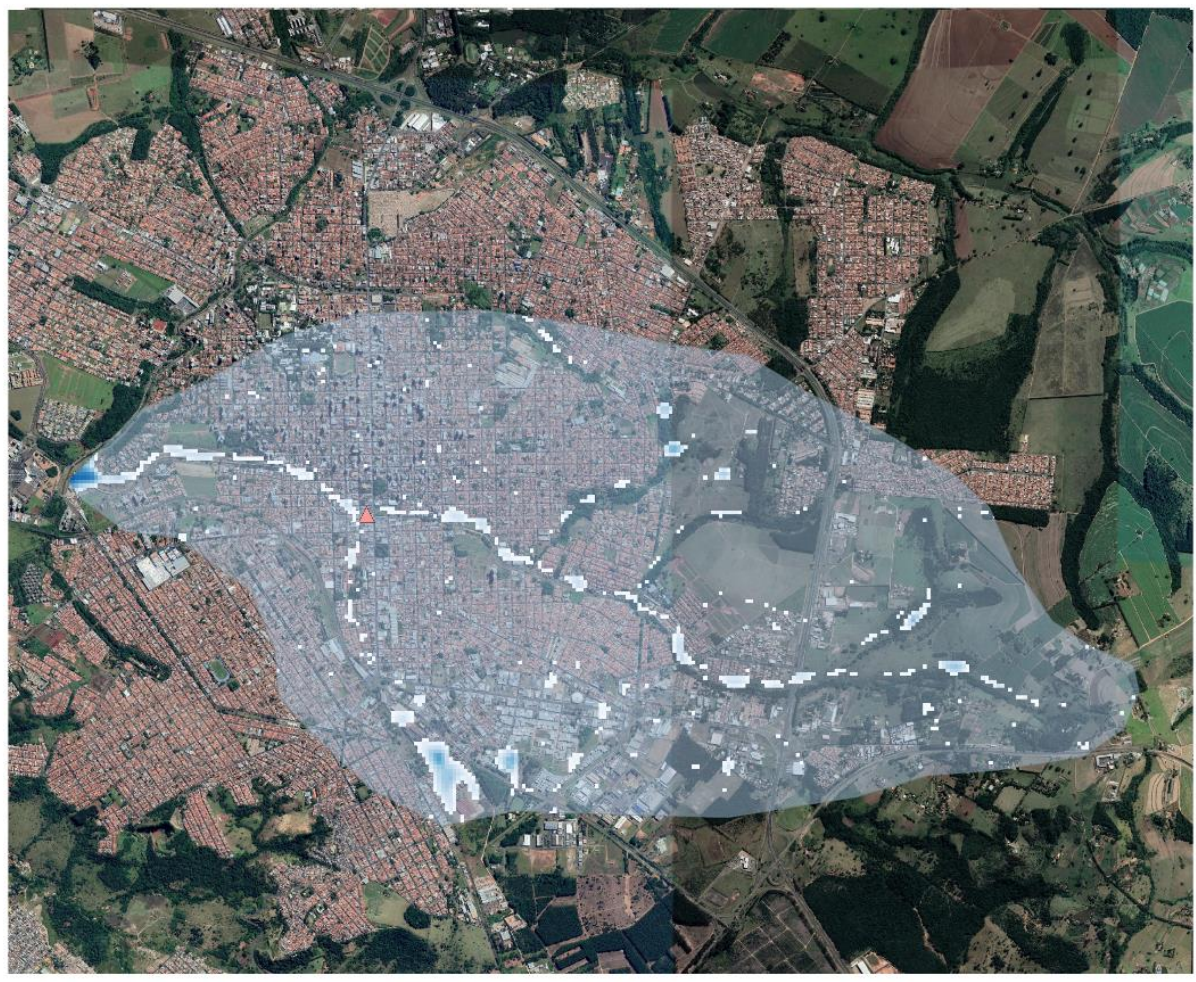

\section{Caption}

Maximum Water Depth ( $\mathrm{m}$ )

\begin{tabular}{|l|l}
$\square$ & 0.01 \\
$\square$ & 1.11 \\
$\square$ & 2.22 \\
$\square$ & 3.33 \\
$\square$ & 4.44 \\
5.55 \\
6.66 \\
7.68 \\
& 8.53 \\
$\Delta \quad$ Municipal Market \\
$\square \quad$ Gregório Creek Catchment
\end{tabular}


Flood extension map for the flood event with the highest daily rainfall intensity of 2072 for the RCP 4.5.

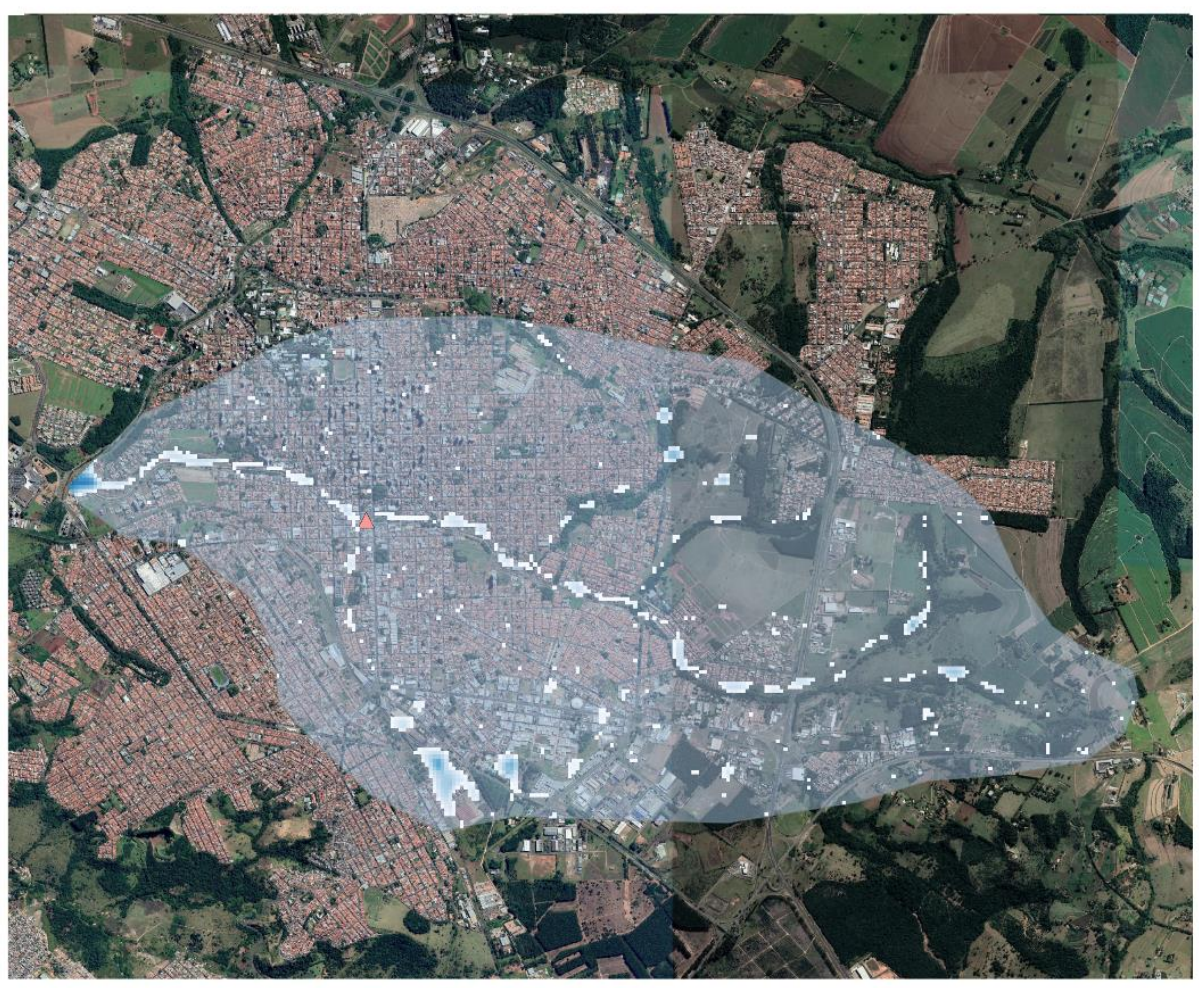

\section{Caption}

Maximum Water Depth (m)

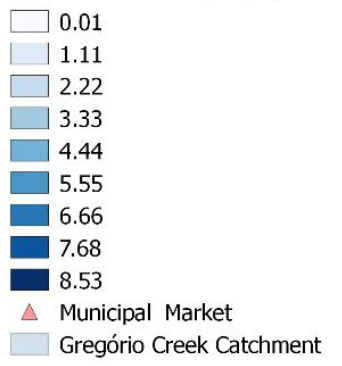

Flood extension map for the flood event with the highest daily rainfall intensity of 2076 for the RCP 4.5.

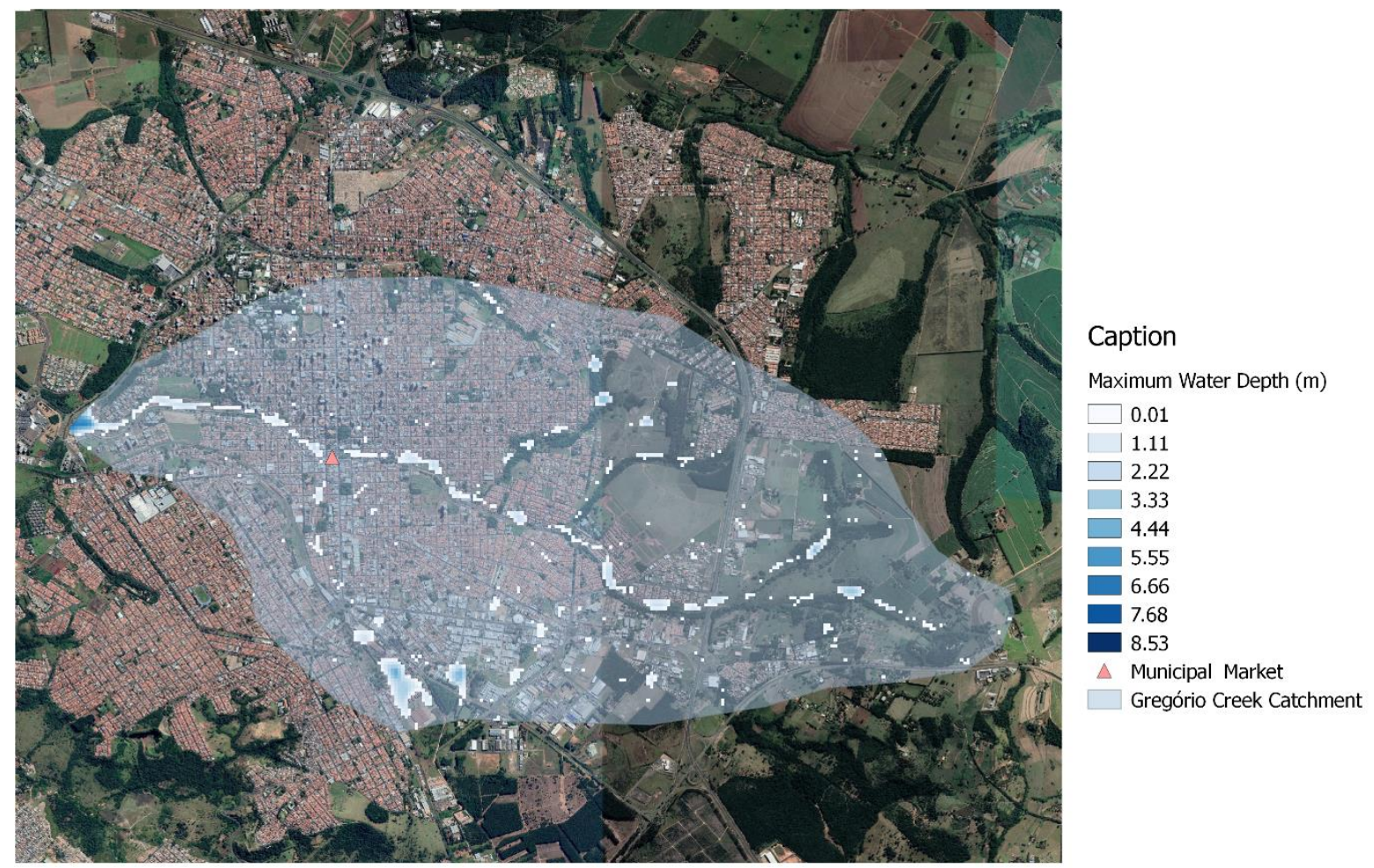


Flood extension map for the flood event with the highest daily rainfall intensity of 2077 for the RCP 4.5.

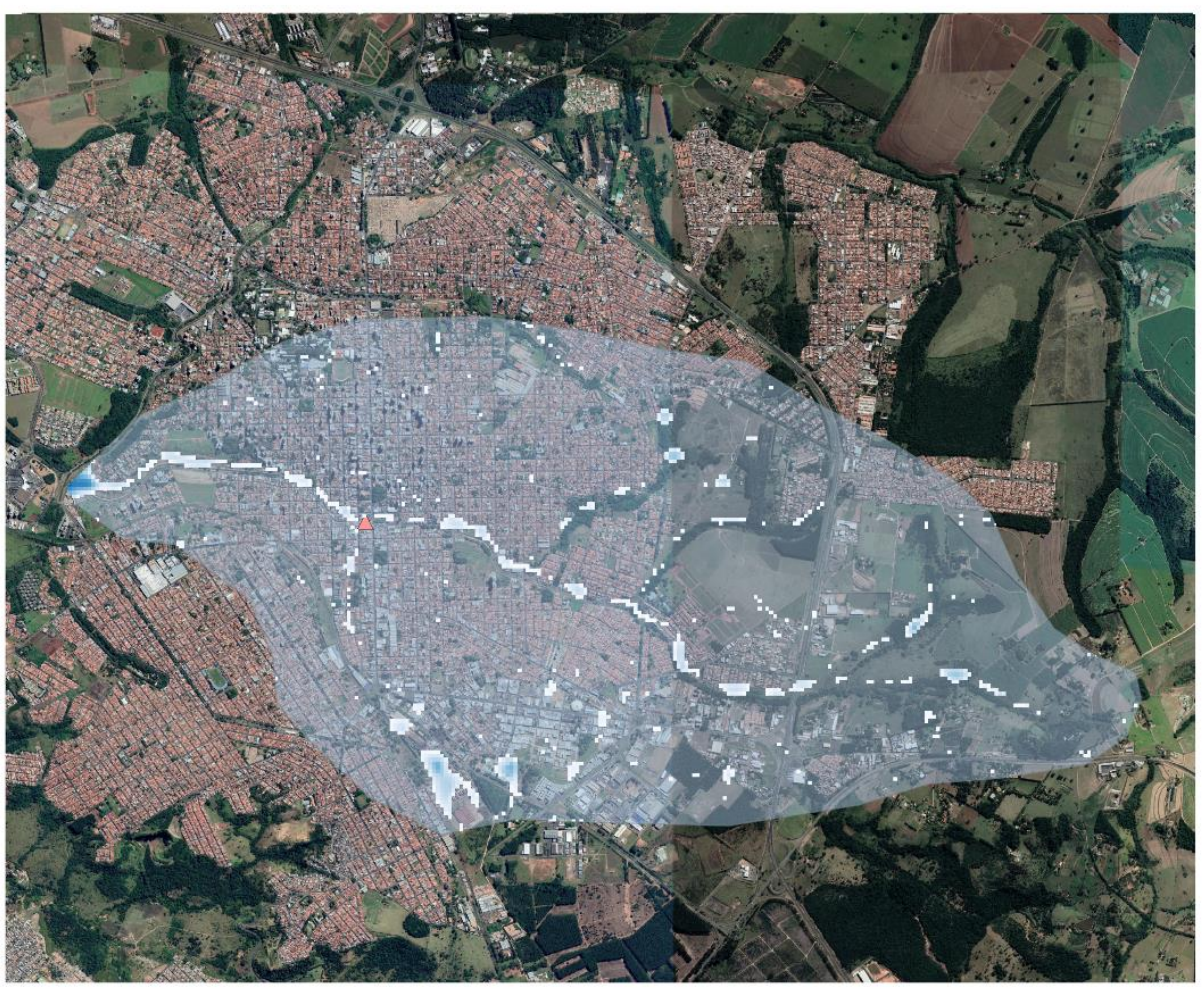

\section{Caption}

Maximum Water Depth (m)

$\square$
$\square .01$
$\square .11$
2.22
3.33
4.44
5.55
6.66
7.68
8.53
$\Delta \quad$ Municipal Market
$\square$ Gregório Creek Catchment

Flood extension map for the flood event with the highest daily rainfall intensity of 2081 for the RCP 4.5.

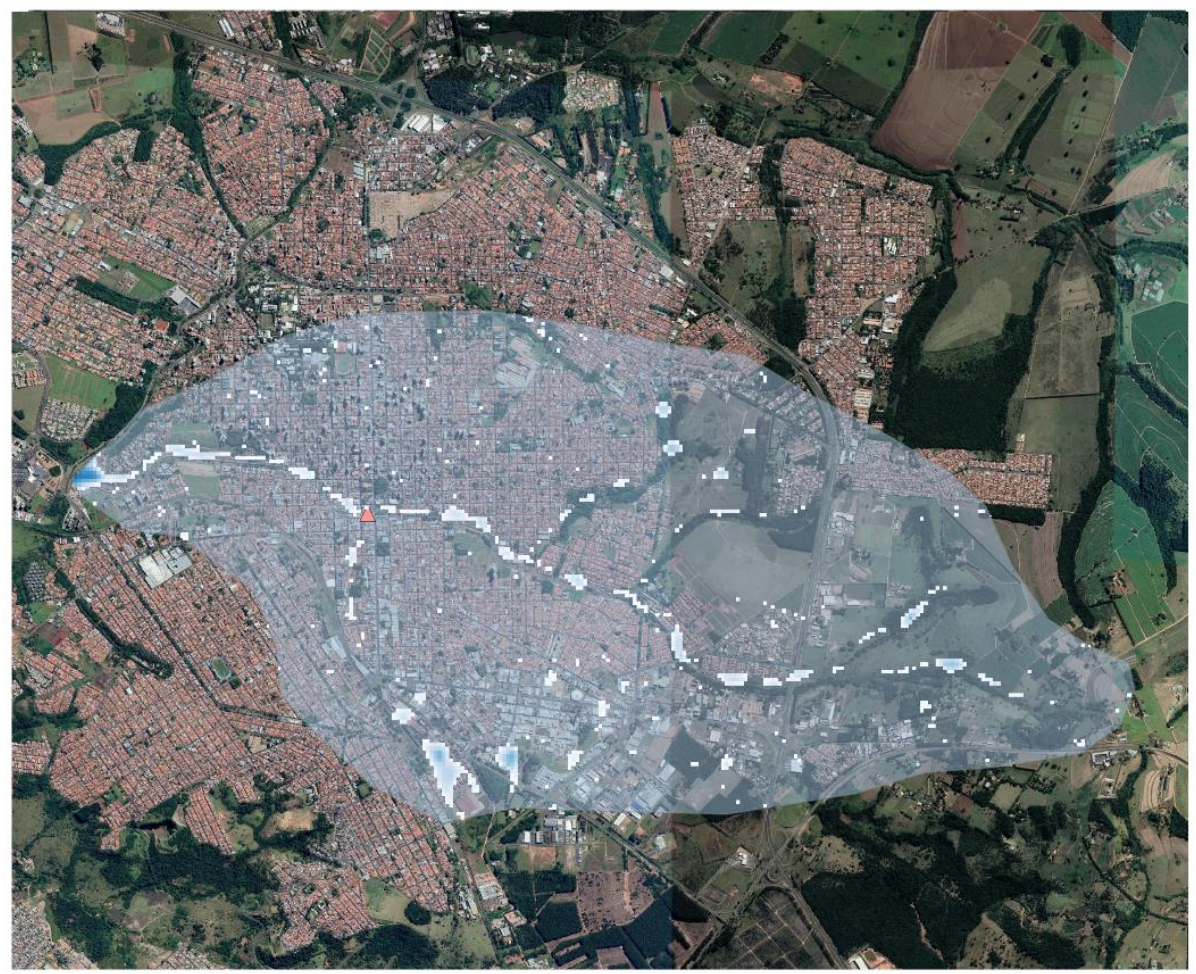

Caption

Maximum Water Depth (m)

$\square 0.01$

$\square 1.11$

$\square .33$

4.44

5.55

6.66

7.68
8.53

$\triangle$ Municipal Market

Gregório Creek Catchment 
Flood extension map for the flood event with the highest daily rainfall intensity of 2083 for the RCP 4.5.

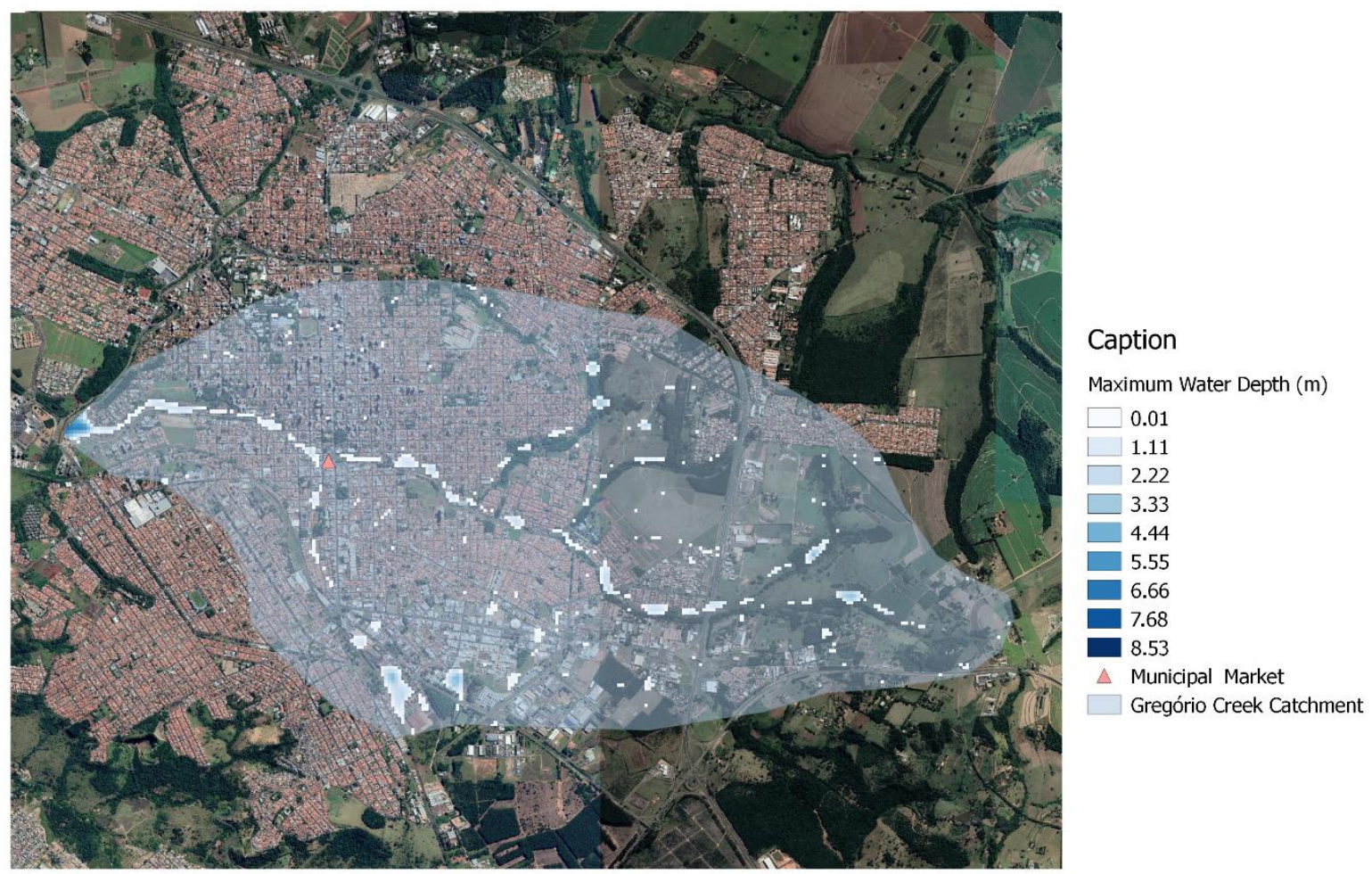

Flood extension map for the flood event with the highest daily rainfall intensity of 2089 for the RCP 4.5.

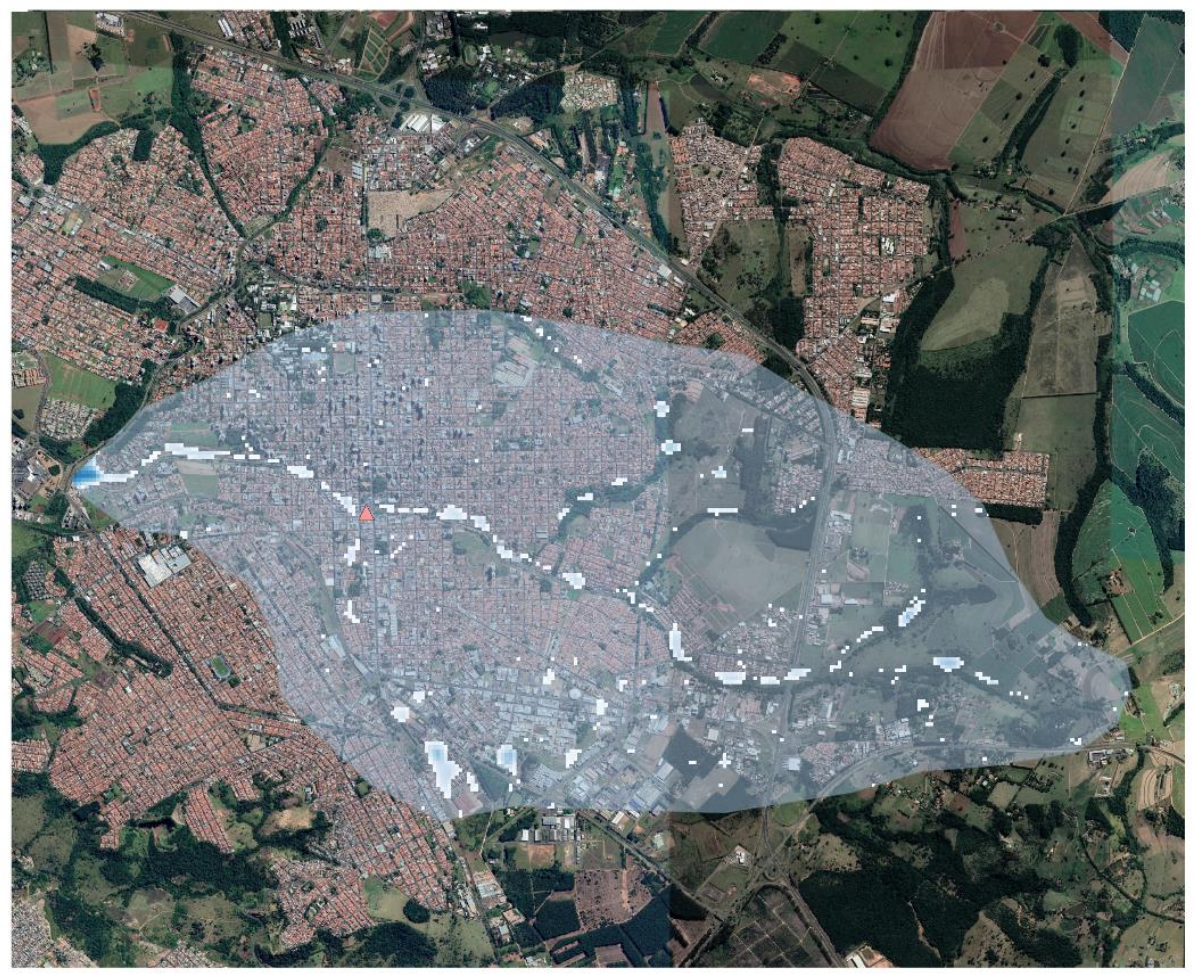

\section{Caption}

Maximum Water Depth $(\mathrm{m})$ $\square 0.01$

$\square 1.11$

$\square 2.22$

$\square 3.33$

$\square .44$

5.55
-6.66

$\begin{array}{r}6.66 \\ 7.68 \\ \hline\end{array}$

8.53

$\triangle$ Municipal Market

- Gregório Creek Catchment 
Flood extension map for the flood event with the highest daily rainfall intensity of 2097 for the RCP 4.5.

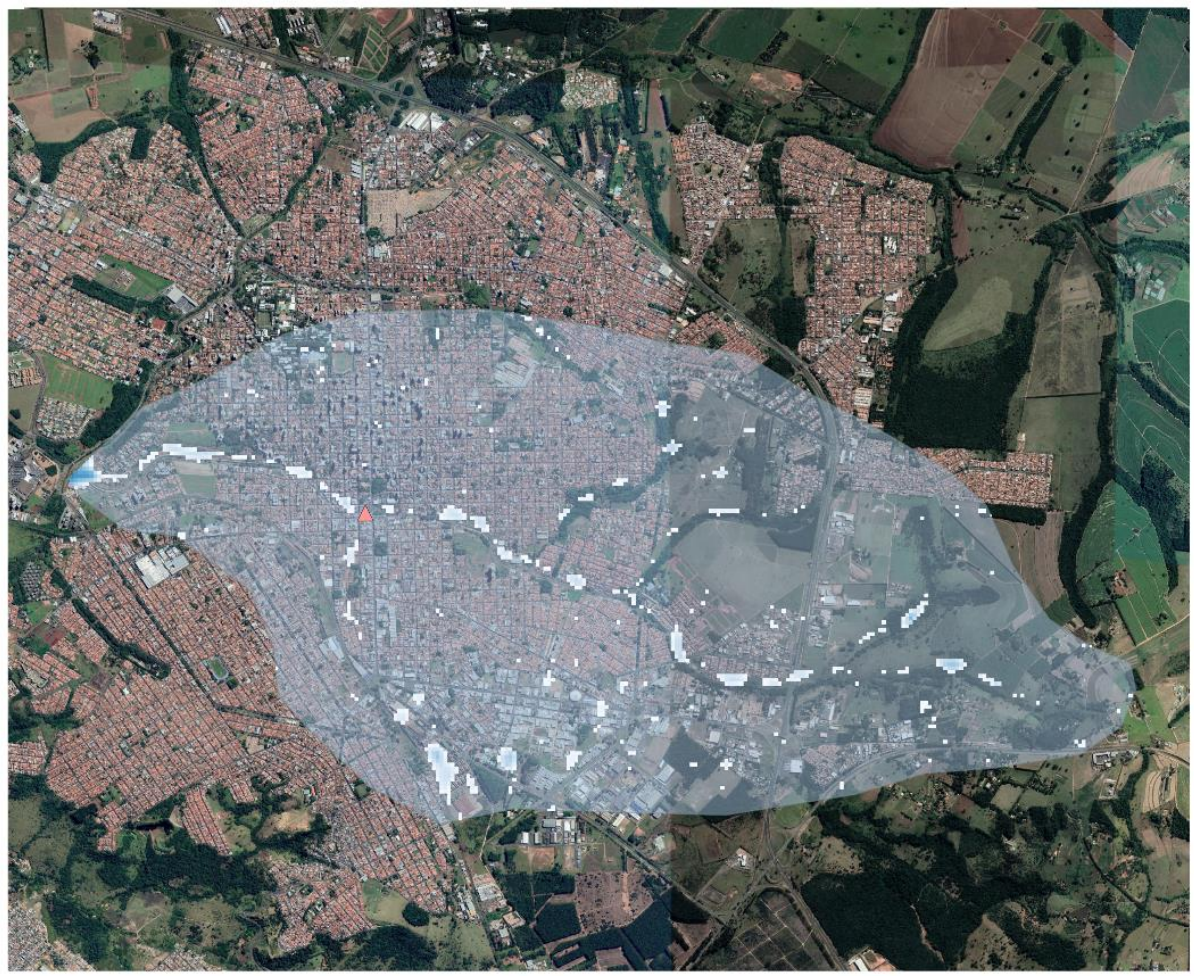

\section{Caption}

Maximum Water Depth (m)

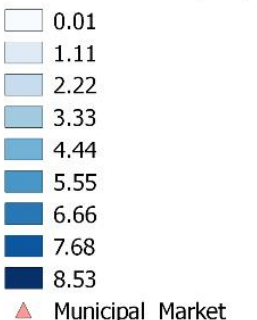

Municipal Market

Gregório Creek Catchment

Flood extension map for the flood event with the highest daily rainfall intensity of 2098 for the RCP 4.5.

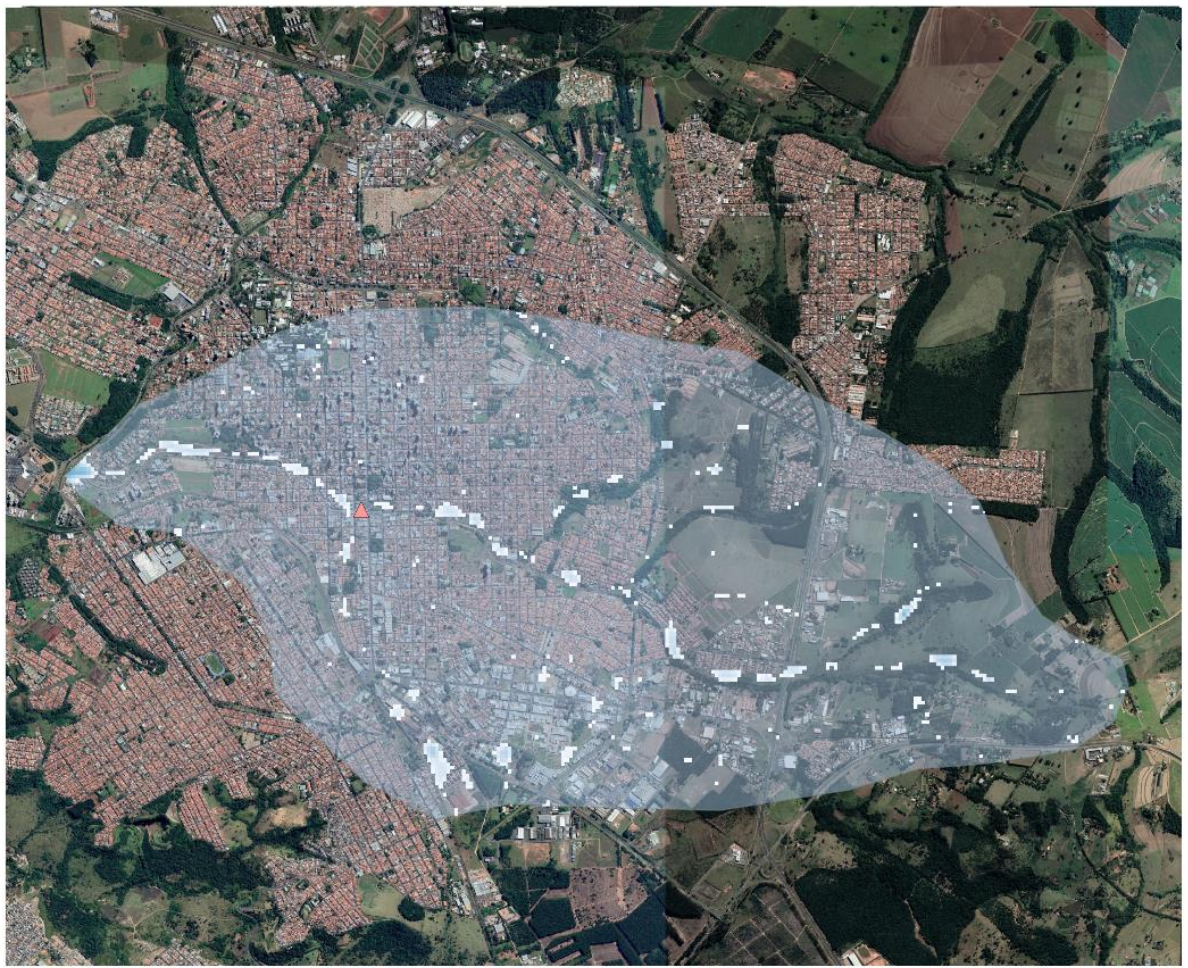

\section{Caption}

Maximum Water Depth (m)

$\square 0.01$

$\square 1.11$

$\square 3.33$

$\square 4.44$

5.55

6.66

7.68

8.53

$\triangle$ Municipal Market

Gregório Creek Catchment 
Flood extension map for the flood event with the highest daily rainfall intensity of 2099 for the RCP 4.5.

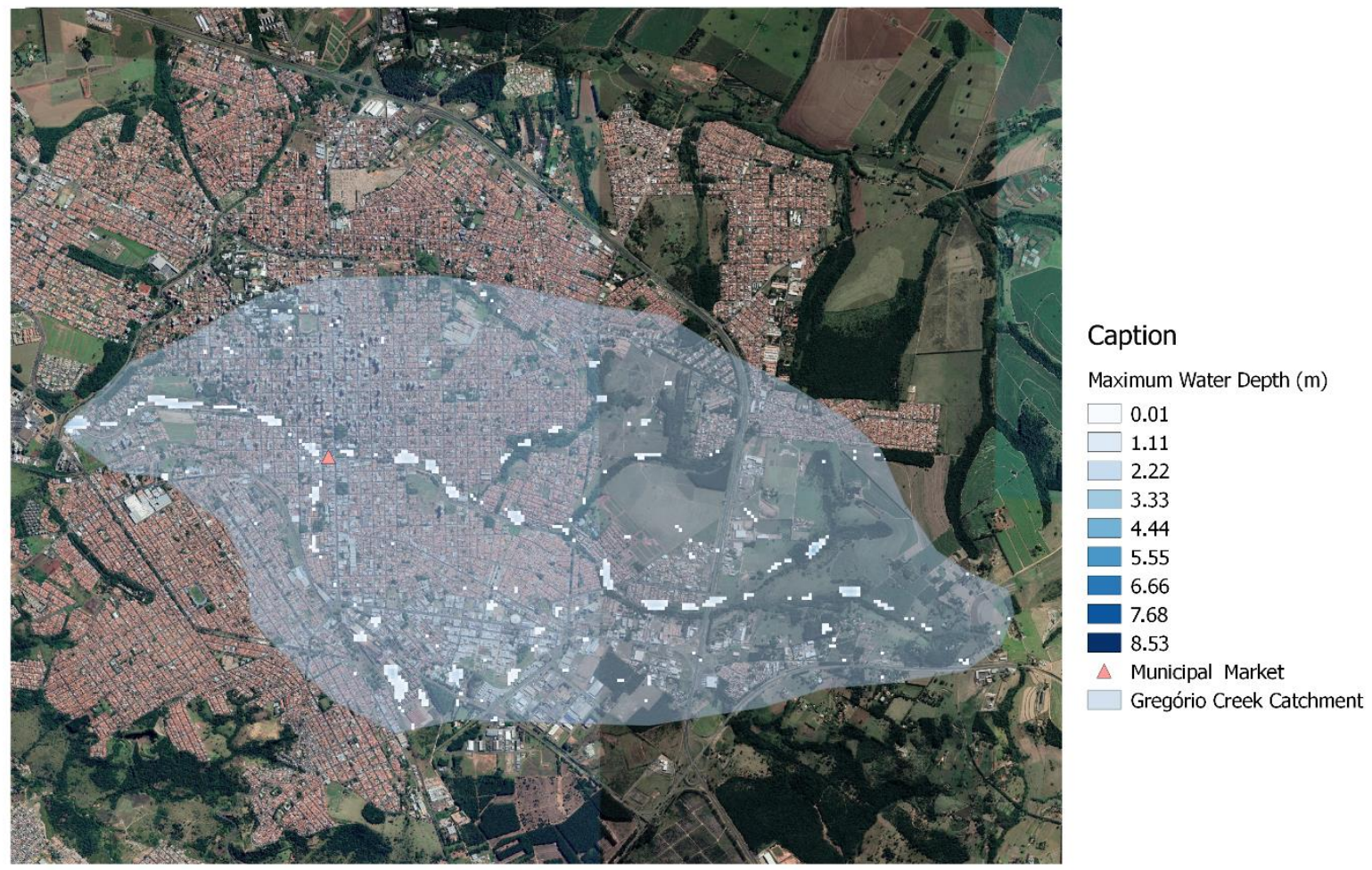




\section{- $\quad$ RCP 8.5}

Flood extension map for the flood event with the highest daily rainfall intensity of 2020 for the RCP 8.5.

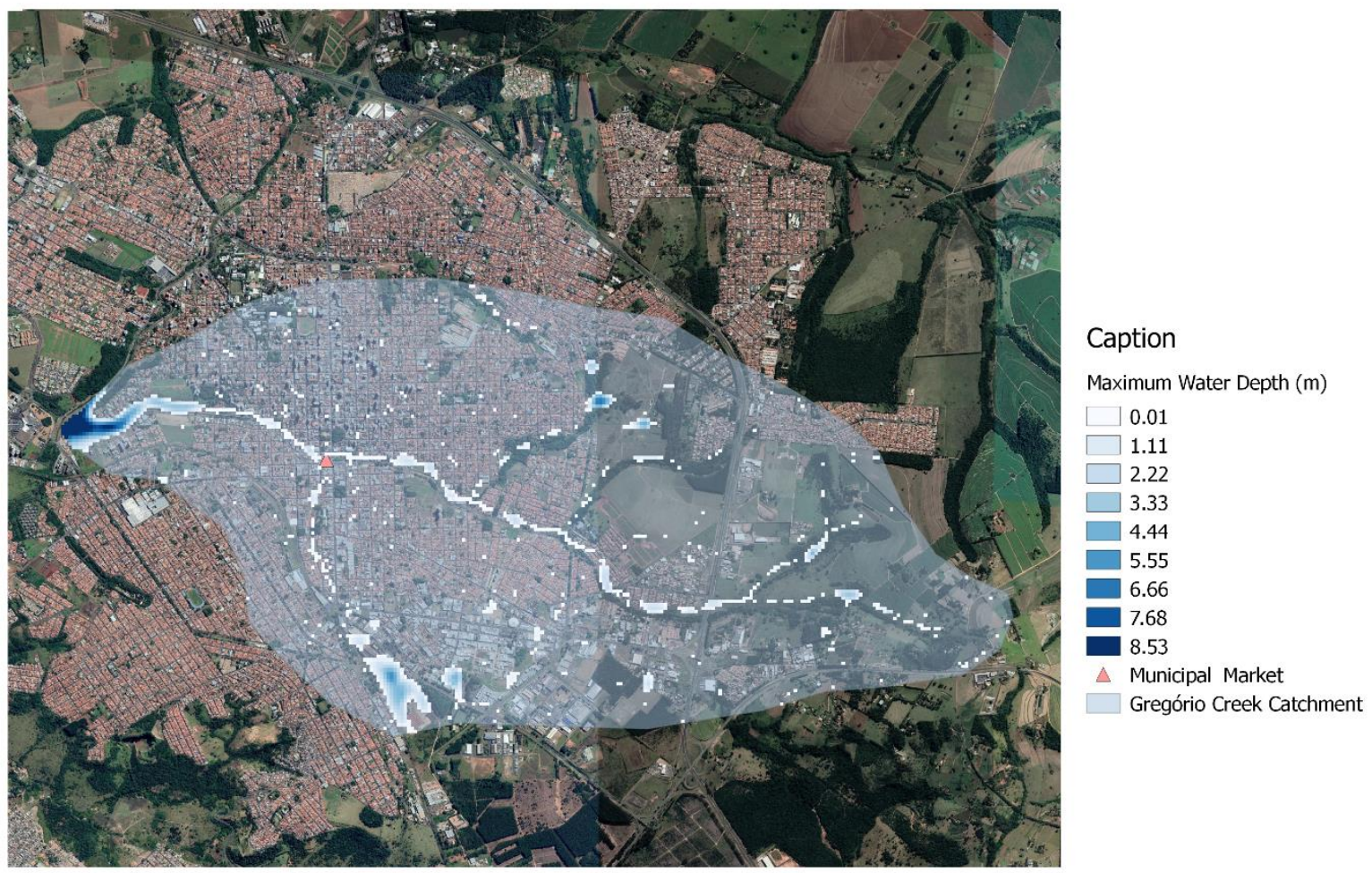

Flood extension map for the flood event with the highest daily rainfall intensity of 2036 for the RCP 8.5.

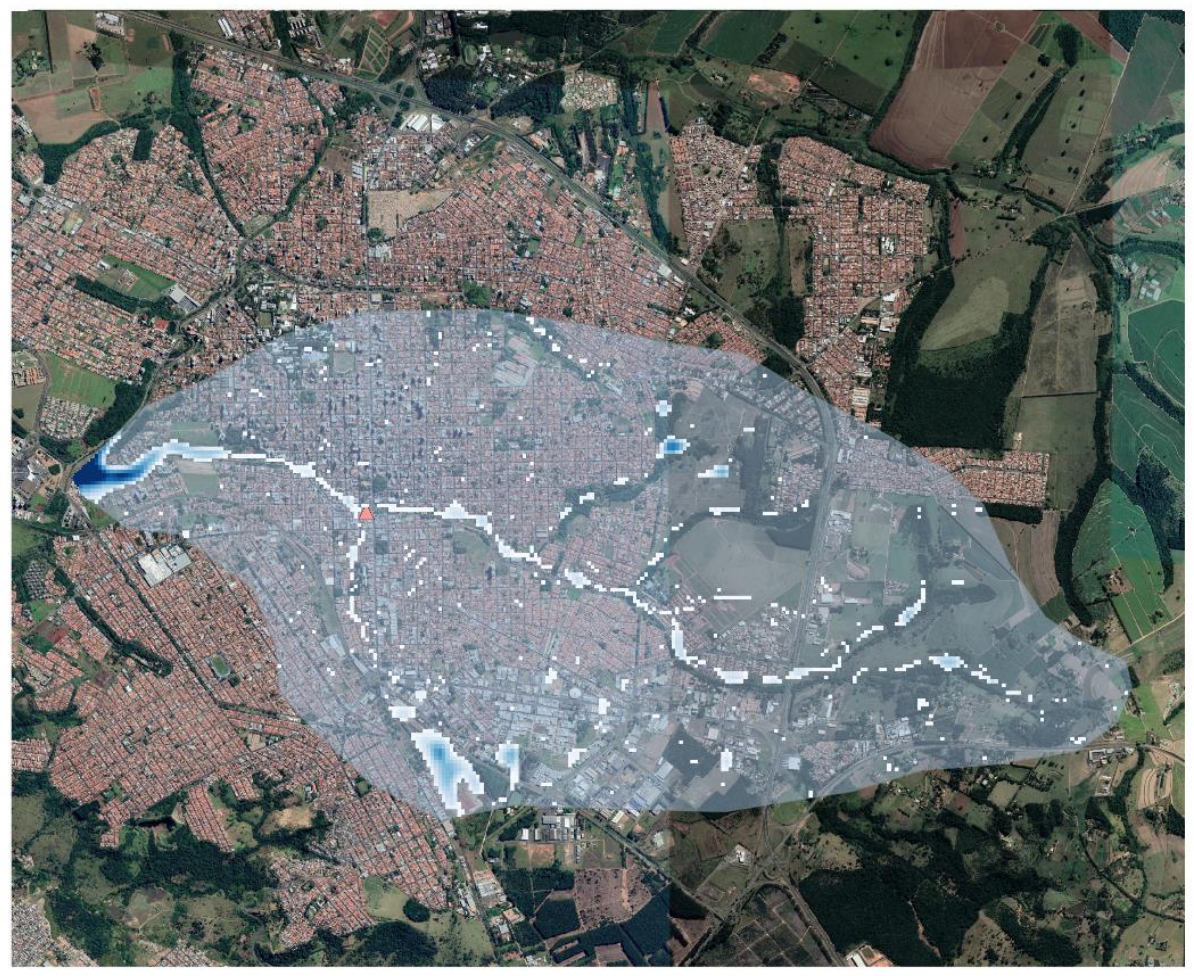

\section{Caption}

Maximum Water Depth $(\mathrm{m})$

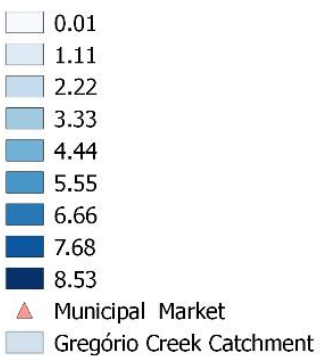


Flood extension map for the flood event with the highest daily rainfall intensity of 2041 for the RCP 8.5.

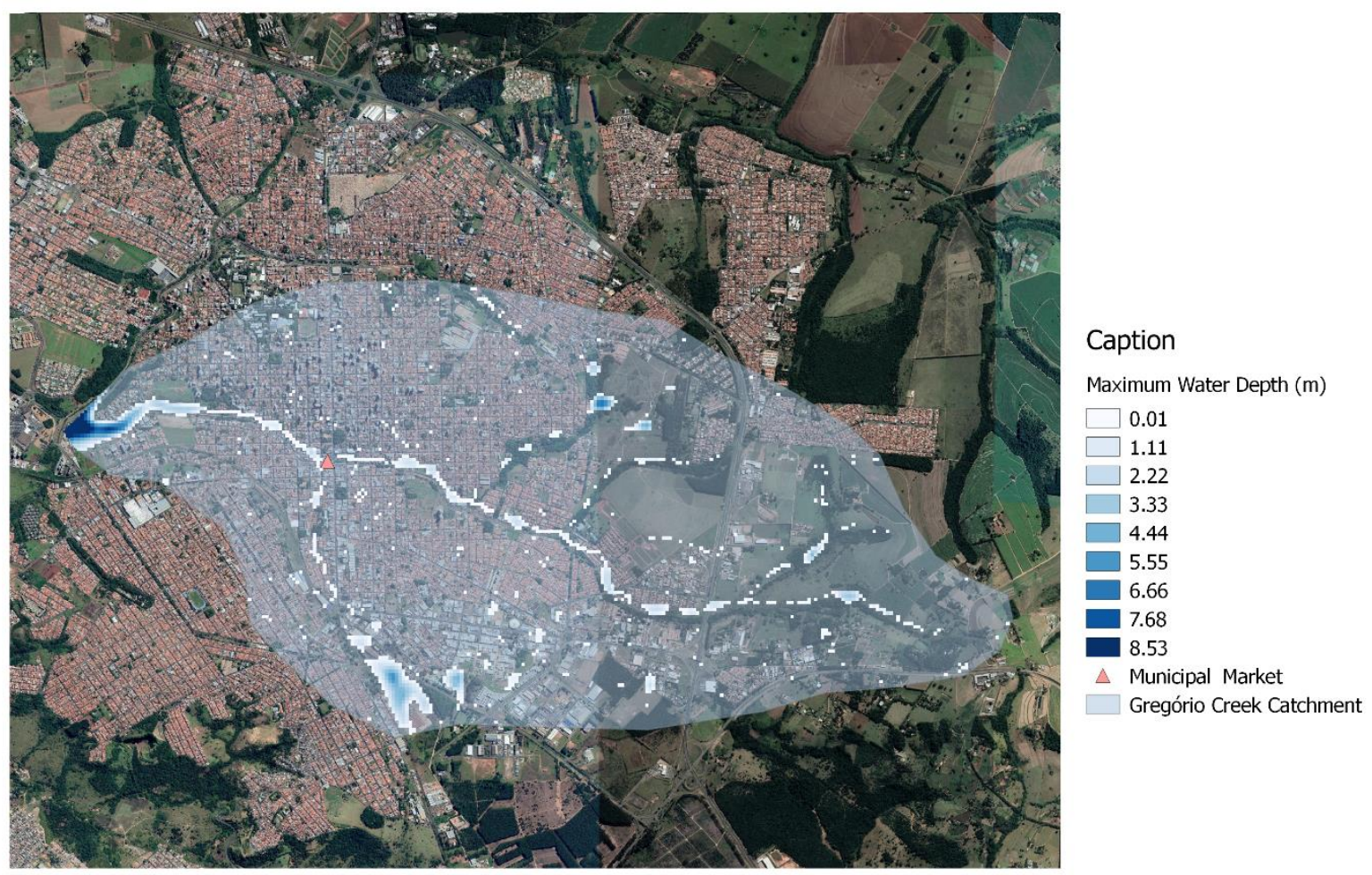

Flood extension map for the flood event with the highest daily rainfall intensity of 2042 for the RCP 8.5.

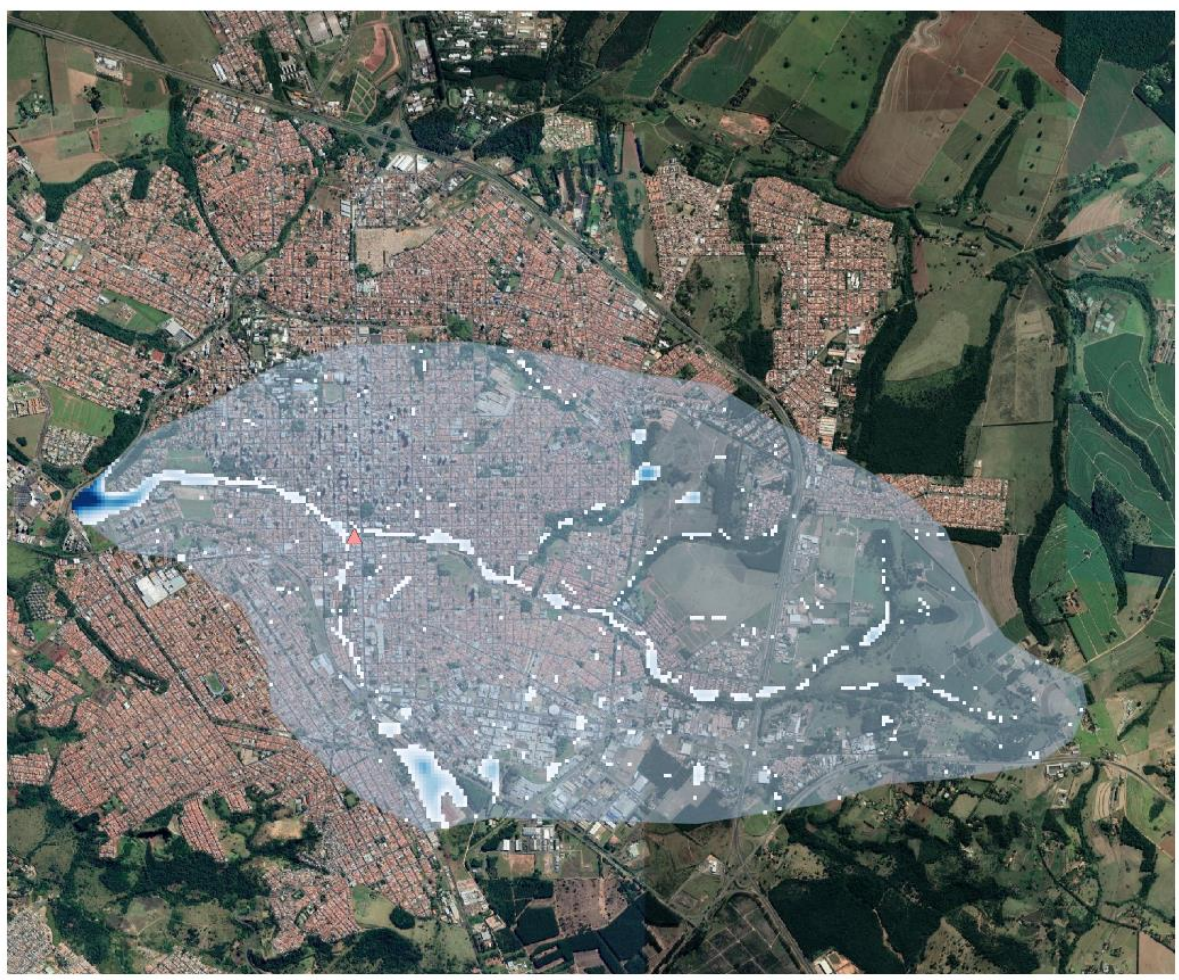

\section{Caption}

A Municipal Market Maximum Water Depth (m)

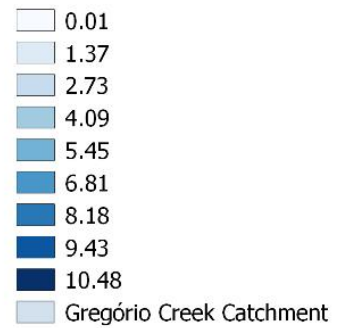


Flood extension map for the flood event with the highest daily rainfall intensity of 2044 for the RCP 8.5.

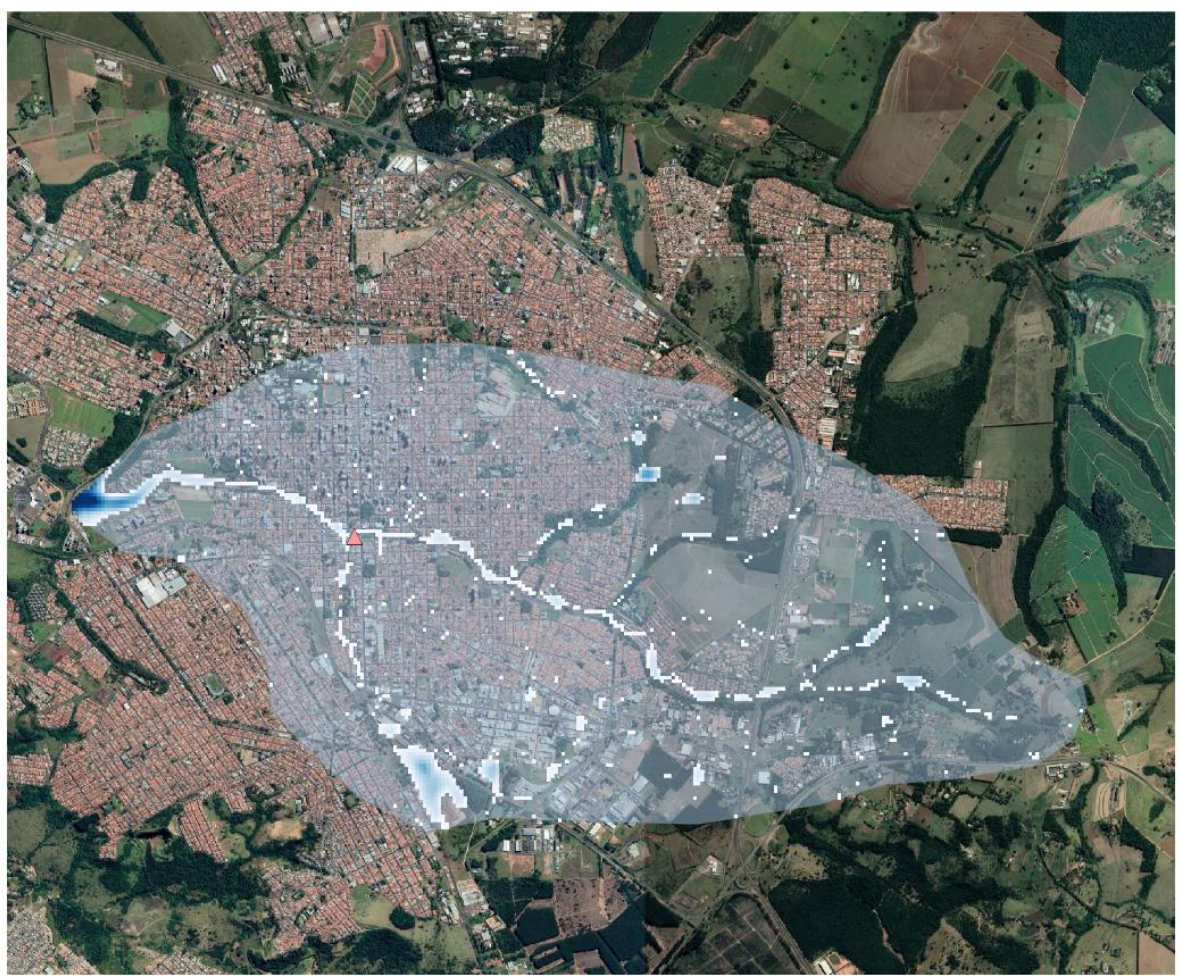

\section{Caption}

$\triangle$ Municipal Market Maximum Water Depth ( $\mathrm{m}$ )

$\square$
$\square .01$
$\square$
$\square .37$
$\square .73$
4.09
5.45
6.81
8.18
9.43
10.48
$\square$ Gregório Creek Catchment

Flood extension map for the flood event with the highest daily rainfall intensity of 2046 for the RCP 8.5.

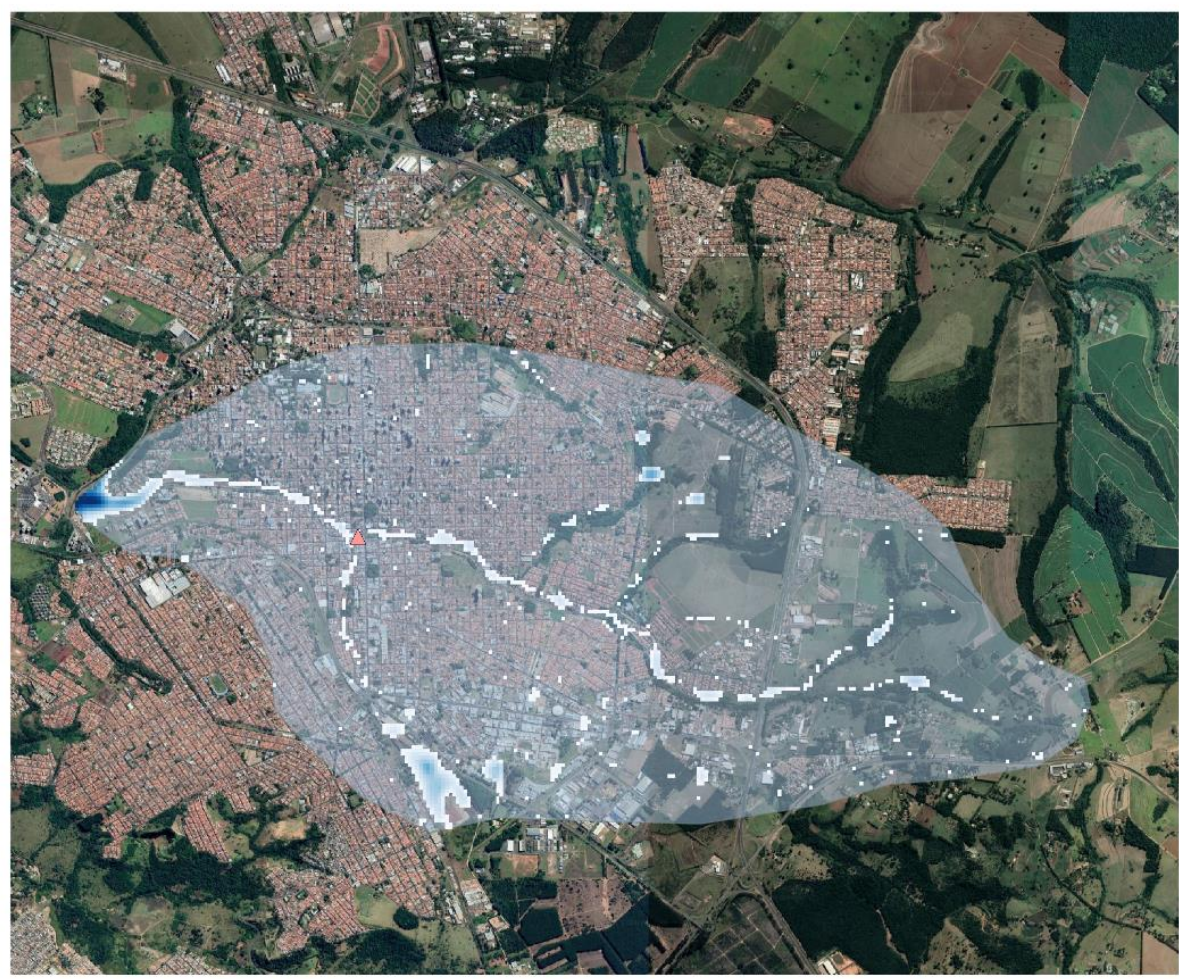

\section{Caption}

$\triangle$ Municipal Market Maximum Water Depth (m)

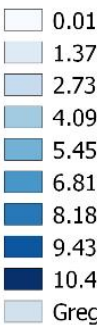

Gregório Creek Catchment 
Flood extension map for the flood event with the highest daily rainfall intensity of 2047 for the RCP 8.5.

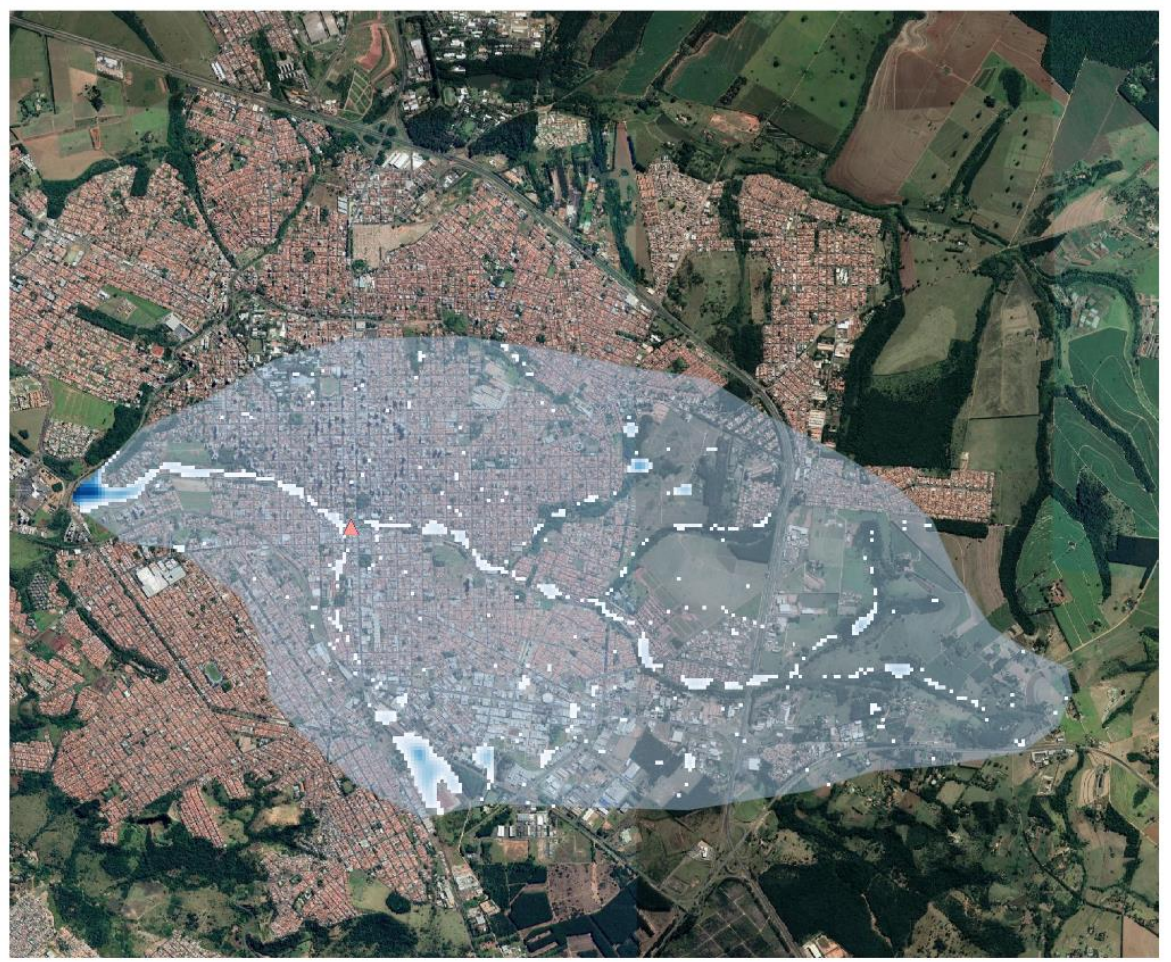

\section{Caption}

$\triangle$ Municipal Market

Maximum Water Depth (m)

$\square$
$\square .01$
1.37
2.73
4.09
5.45
6.81
8.18
9.43
10.48
Gregório Creek Catchment

Flood extension map for the flood event with the highest daily rainfall intensity of 2048 for the RCP 8.5.

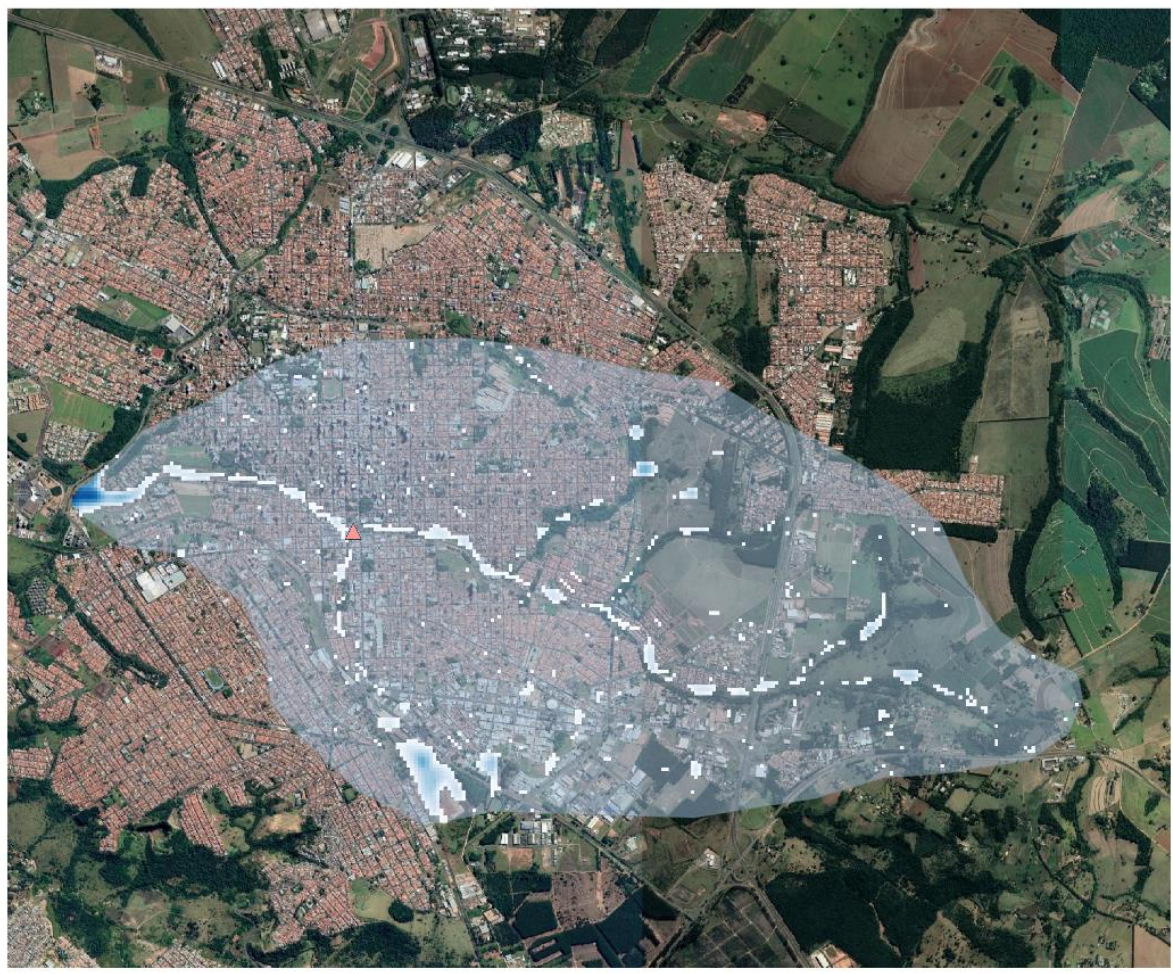

\section{Caption}

$\triangle$ Municipal Market

Maximum Water Depth $(\mathrm{m})$

\begin{tabular}{|c|c|}
\hline$\square 0.01$ & \\
\hline $\mid$ & \\
\hline$\square 2.73$ & \\
\hline$\square \quad 4.09$ & \\
\hline 5.45 & \\
\hline 6.81 & \\
\hline | 8.18 & \\
\hline 9.43 & \\
\hline $\begin{array}{l}10.48 \\
\text { Gregório }\end{array}$ & \\
\hline
\end{tabular}


Flood extension map for the flood event with the highest daily rainfall intensity of 2051 for the RCP 8.5.

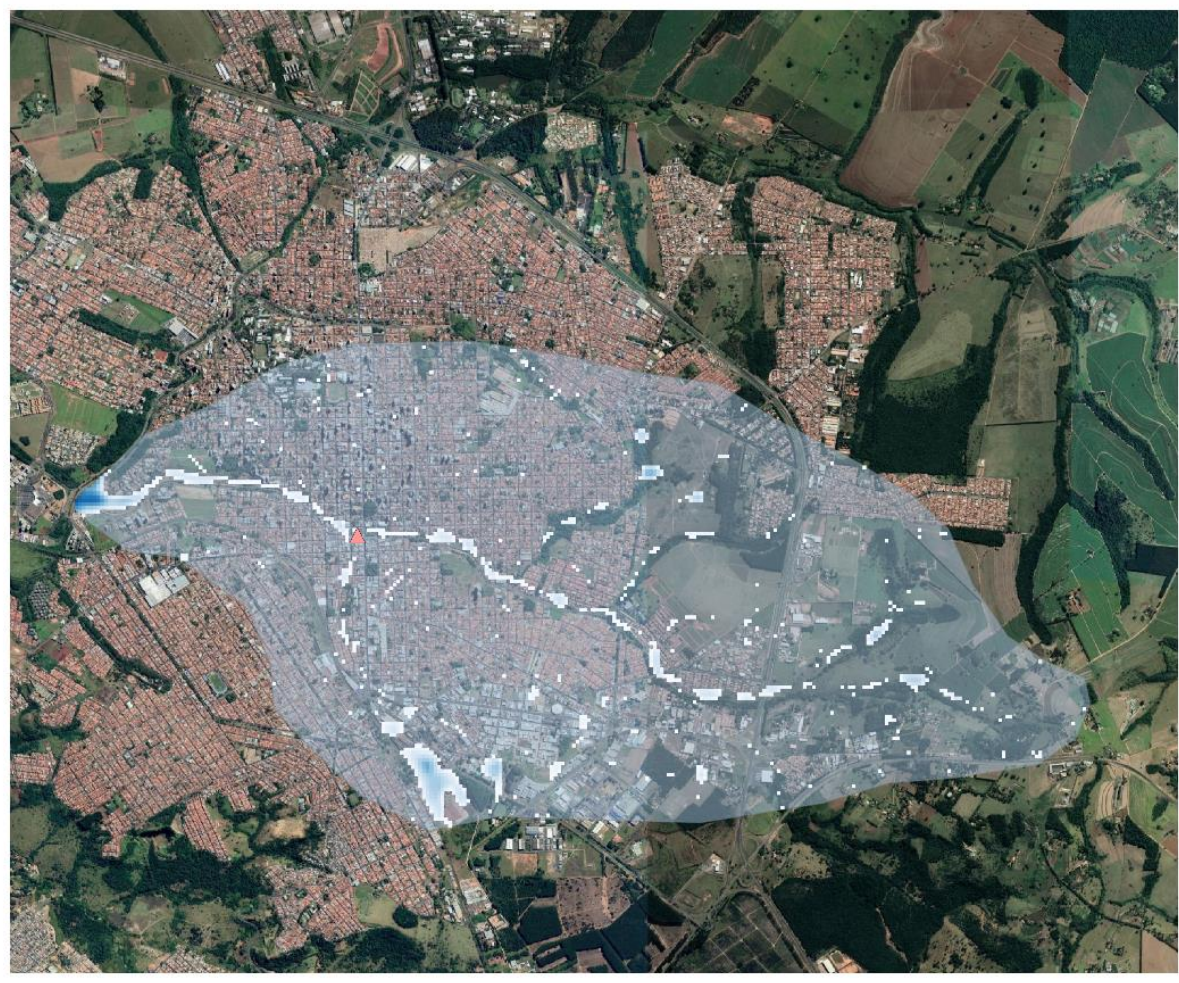

\section{Caption}

A Municipal Market

Maximum Water Depth $(\mathrm{m})$

$\square$
$\square .01$
$\square$
$\square .37$
2.73
4.09
5.45
6.81
8.18
9.43
10.48
Gregório Creek Catchment

Flood extension map for the flood event with the highest daily rainfall intensity of 2052 for the RCP 8.5.

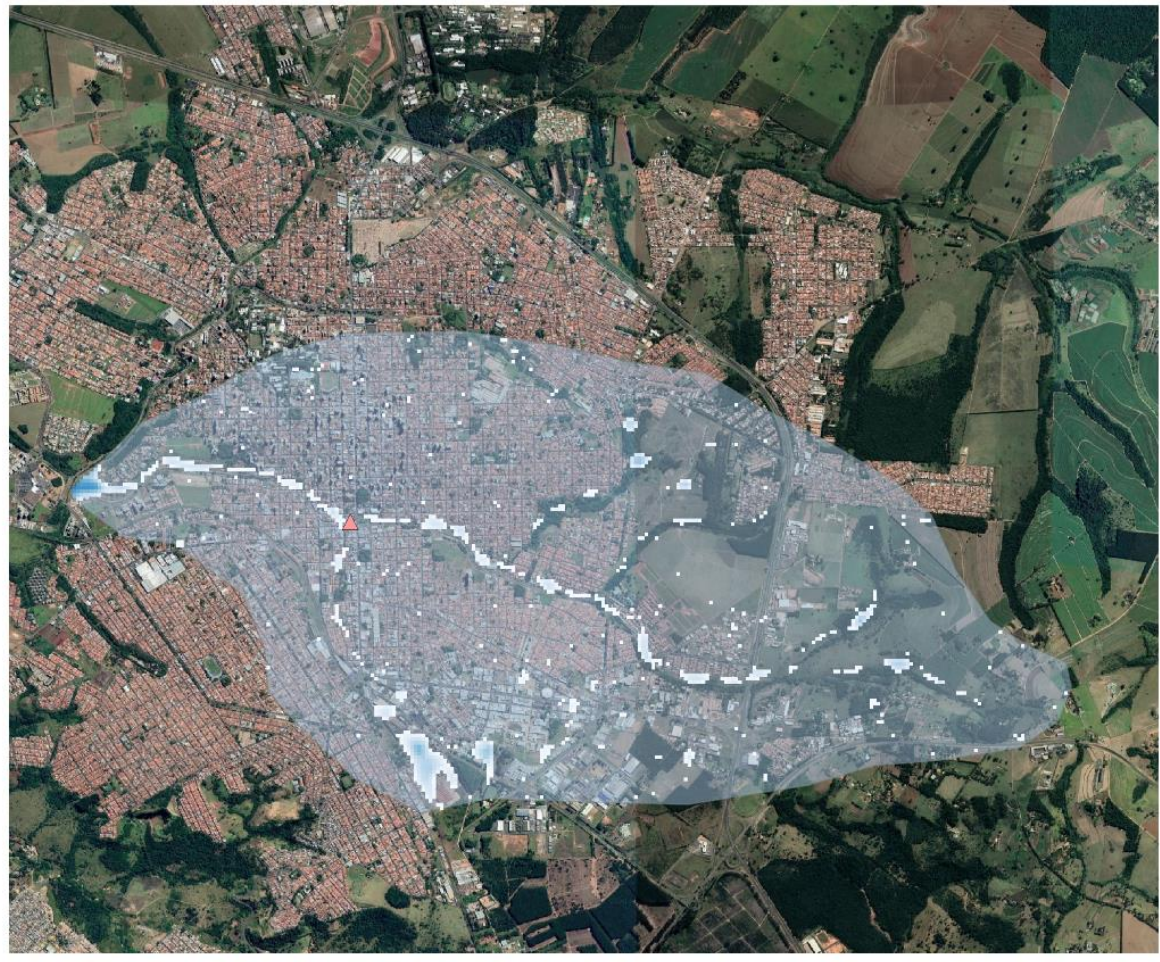

\section{Caption}

$\triangle$ Municipal Market

Maximum Water Depth ( $\mathrm{m}$ )

$\square .01$
$\square$
1.37
2.73
4.09
5.45
6.81
8.18
9.43
10.48

Gregório Creek Catchment 
Flood extension map for the flood event with the highest daily rainfall intensity of 2053 for the RCP 8.5.

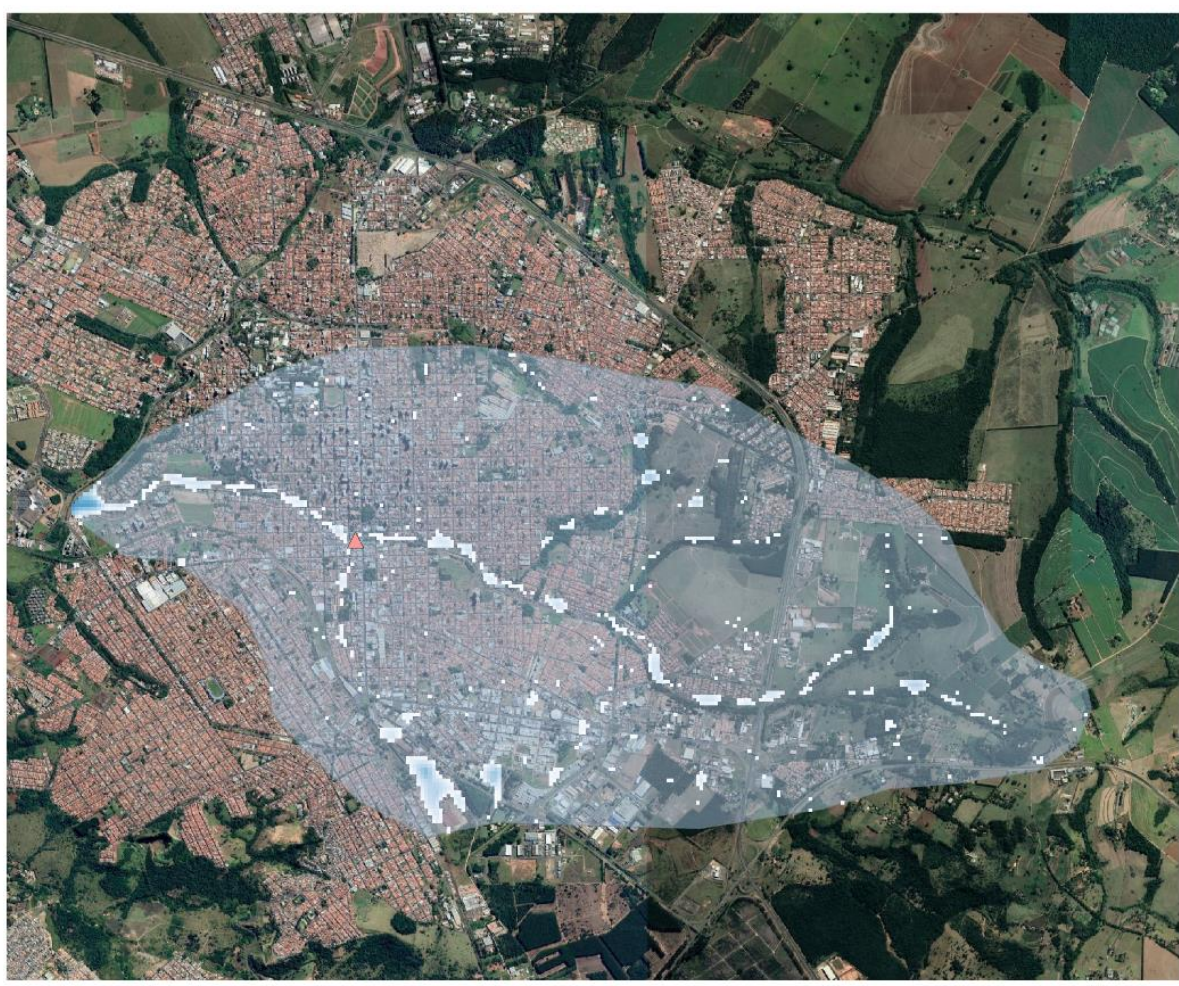

\section{Caption}

$\triangle$ Municipal Market

Maximum Water Depth (m)

\begin{tabular}{|l|l}
$\square$ & 0.01 \\
$\square$ & 1.37 \\
$\square$ & 2.73 \\
$\square$ & 4.09 \\
$\square$ & 5.45 \\
& 6.81 \\
8.18 \\
9.43 \\
10.48 \\
$\square$ \\
Gregório Creek Catchment
\end{tabular}

Flood extension map for the flood event with the highest daily rainfall intensity of 2056 for the RCP 8.5.

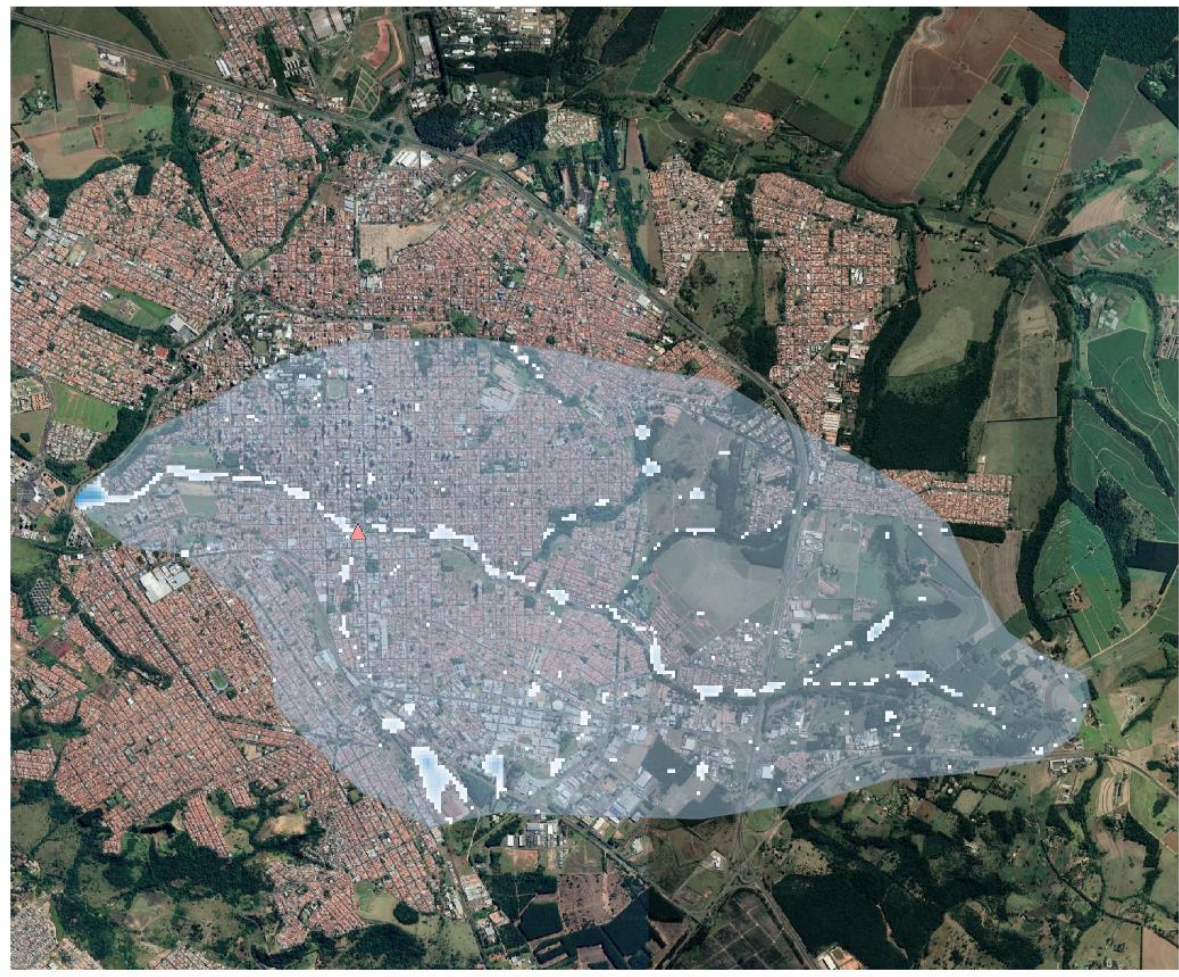

\section{Caption}

$\triangle$ Municipal Market

Maximum Water Depth (m)

\begin{tabular}{l}
$\square$ \\
$\square$ \\
$\square .01$ \\
$\square$ \\
$\square .37$ \\
\hline$\square .09$ \\
$\square .45$ \\
5.81 \\
6.11 \\
8.18 \\
9.43 \\
10.48 \\
Gregório Creek Catchment
\end{tabular}


Flood extension map for the flood event with the highest daily rainfall intensity of 2071 for the RCP 8.5.

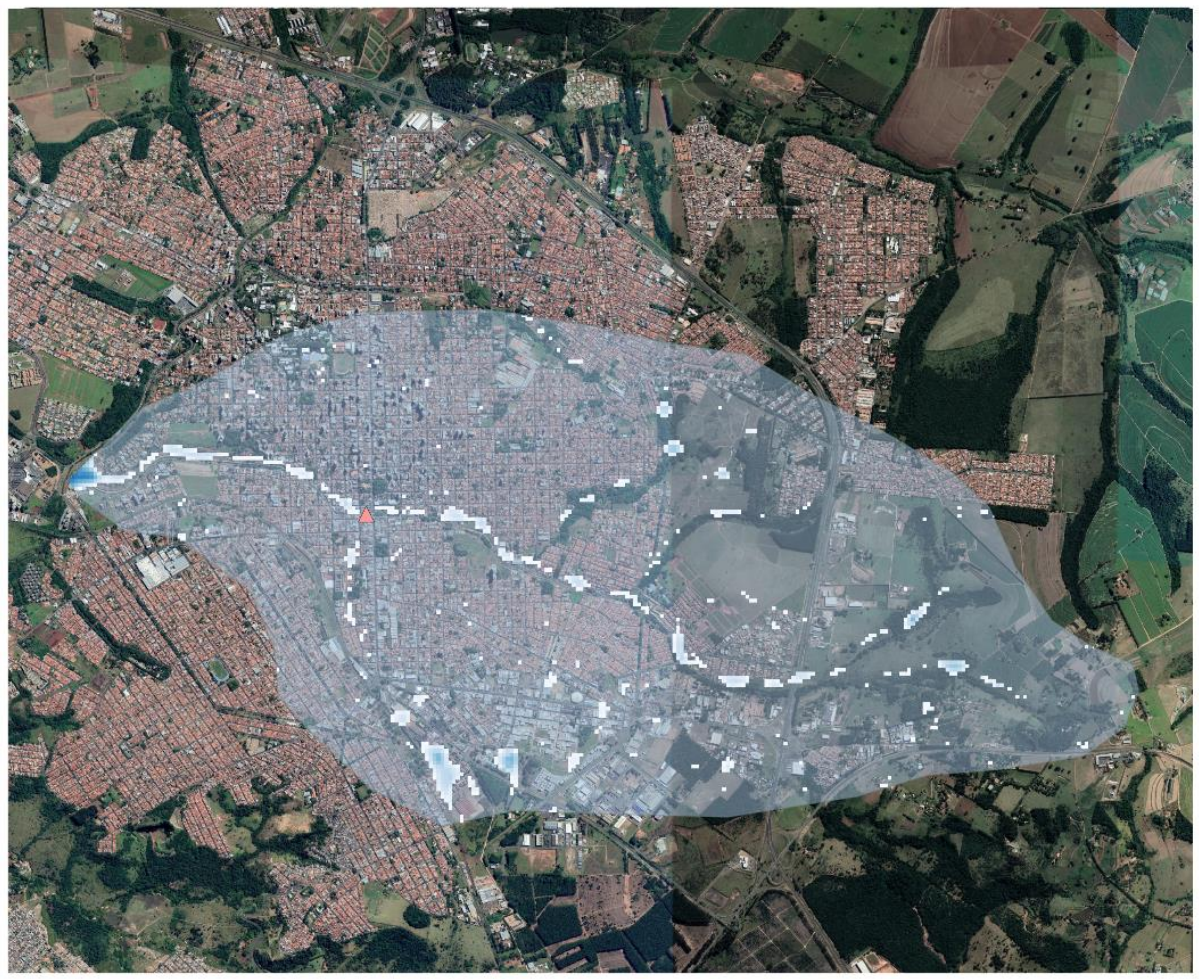

\section{Caption}

Maximum Water Depth (m)

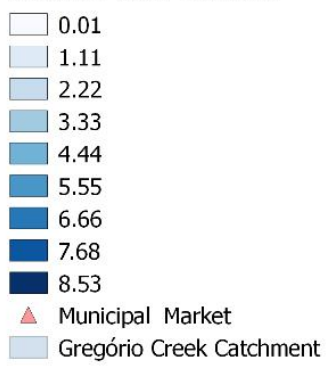

Flood extension map for the flood event with the highest daily rainfall intensity of 2075 for the RCP 8.5.

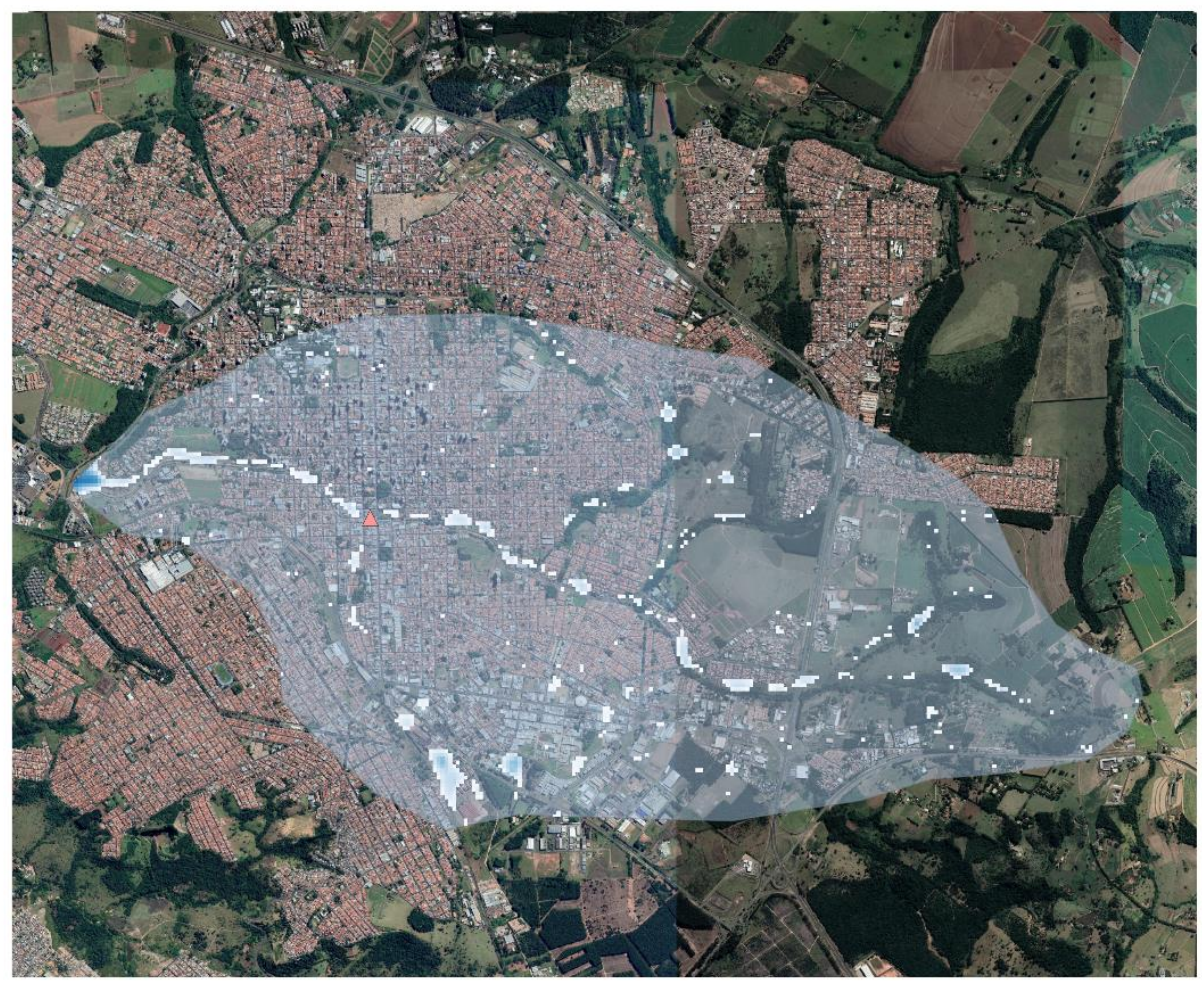

\section{Caption}

Maximum Water Depth (m)

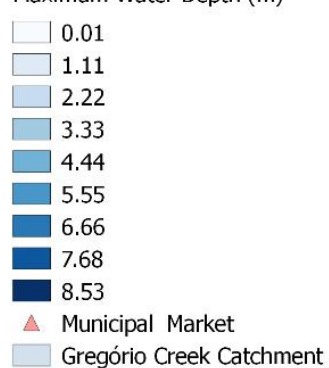


Flood extension map for the flood event with the highest daily rainfall intensity of 2078 for the RCP 8.5.

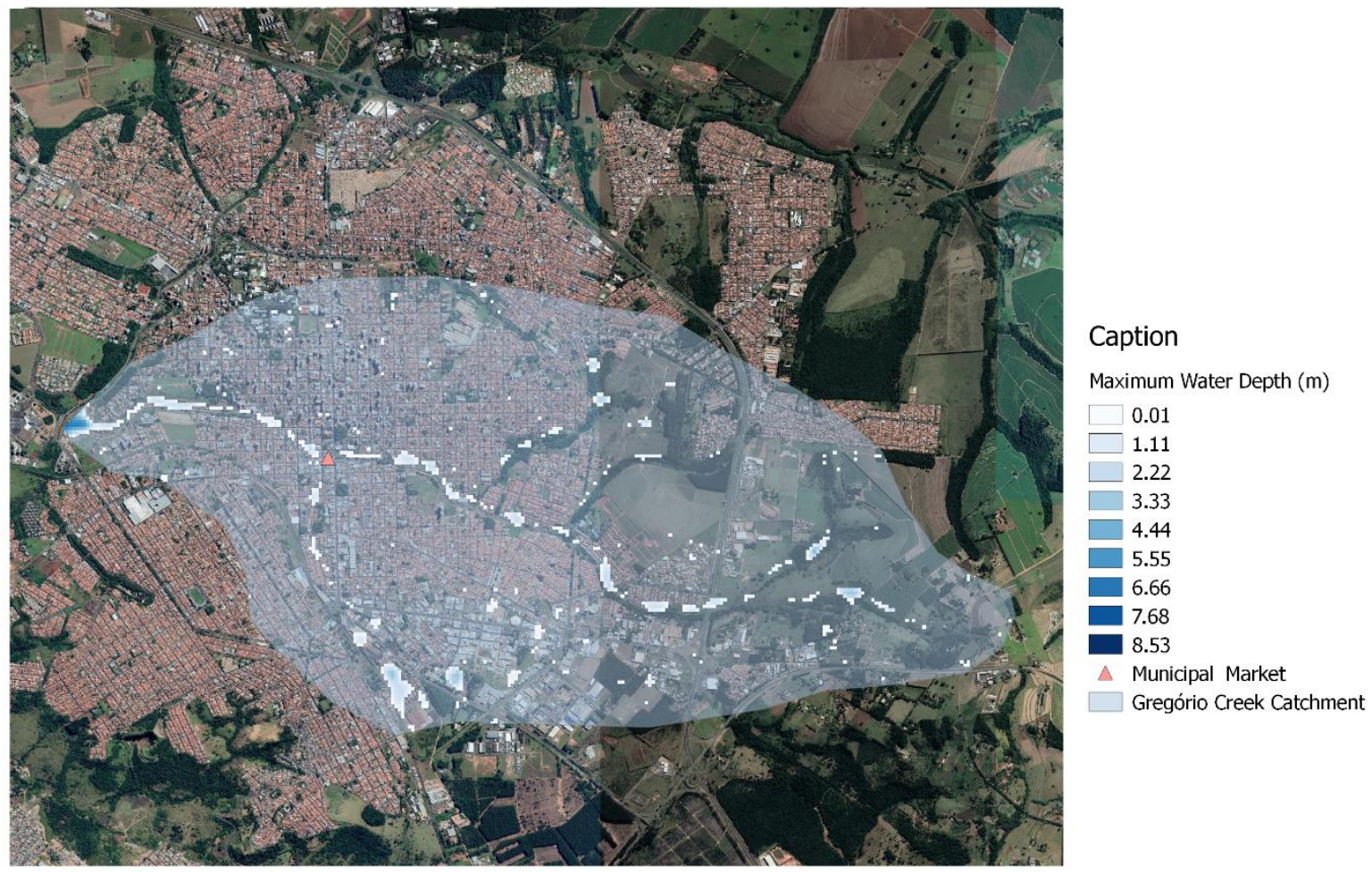

Flood extension map for the flood event with the highest daily rainfall intensity of 2090 for the RCP 8.5.

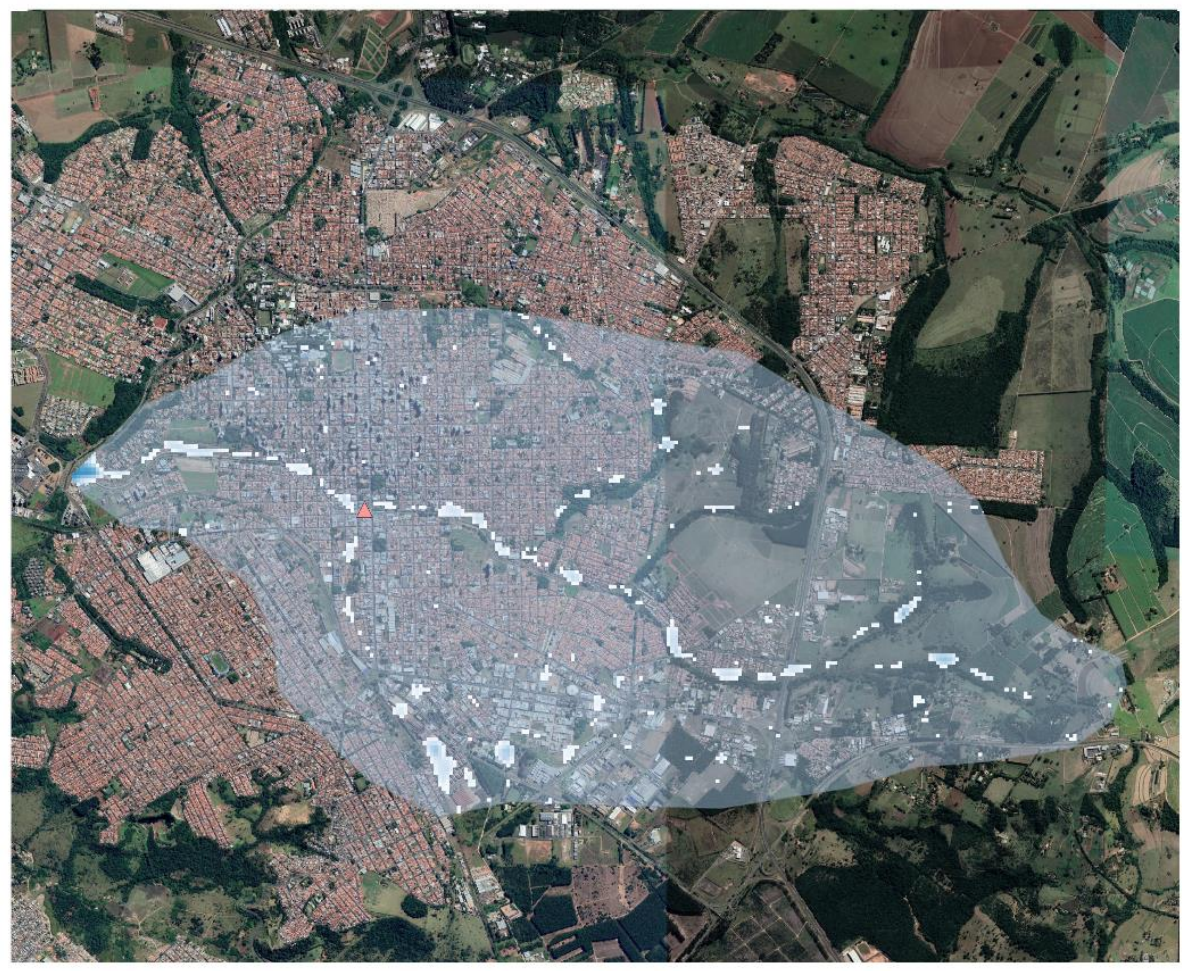

\section{Caption}

Maximum Water Depth (m)

$\square 0.01$

$\square 1.11$

$\square .22$

ए 3.33

$\square 4.44$

5.55

6.66

7.68
8.53

$\triangle$ Municipal Market

Gregório Creek Catchment 
Flood extension map for the flood event with the highest daily rainfall intensity of 2092 for the RCP 8.5.

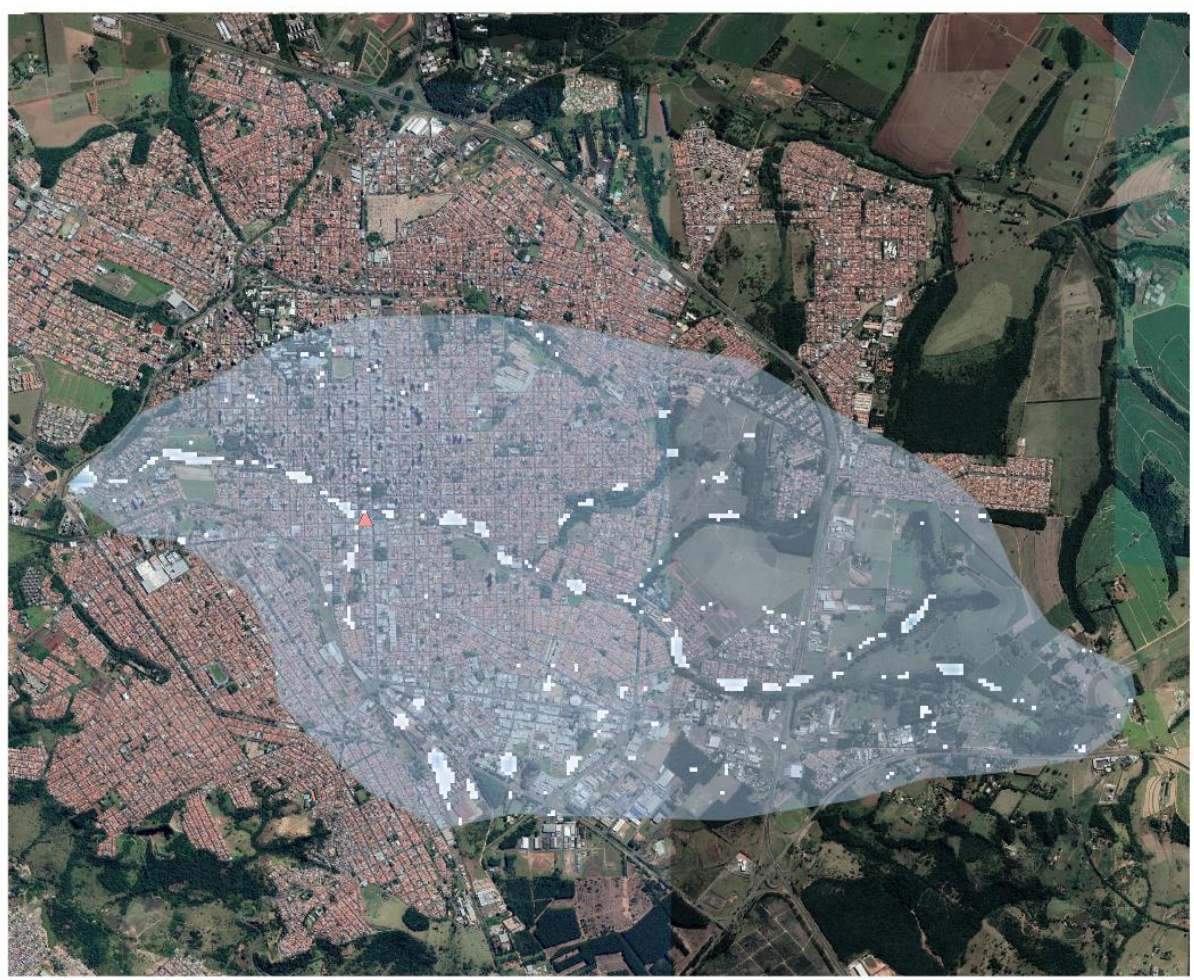

\section{Caption}

Maximum Water Depth (m)

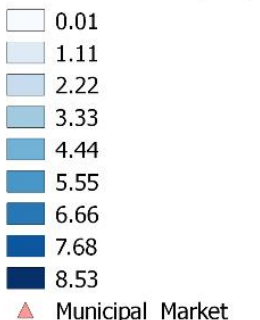

$\triangle$ Municipal Market

Gregório Creek Catchment

Flood extension map for the flood event with the highest daily rainfall intensity of 2094 for the RCP 8.5.

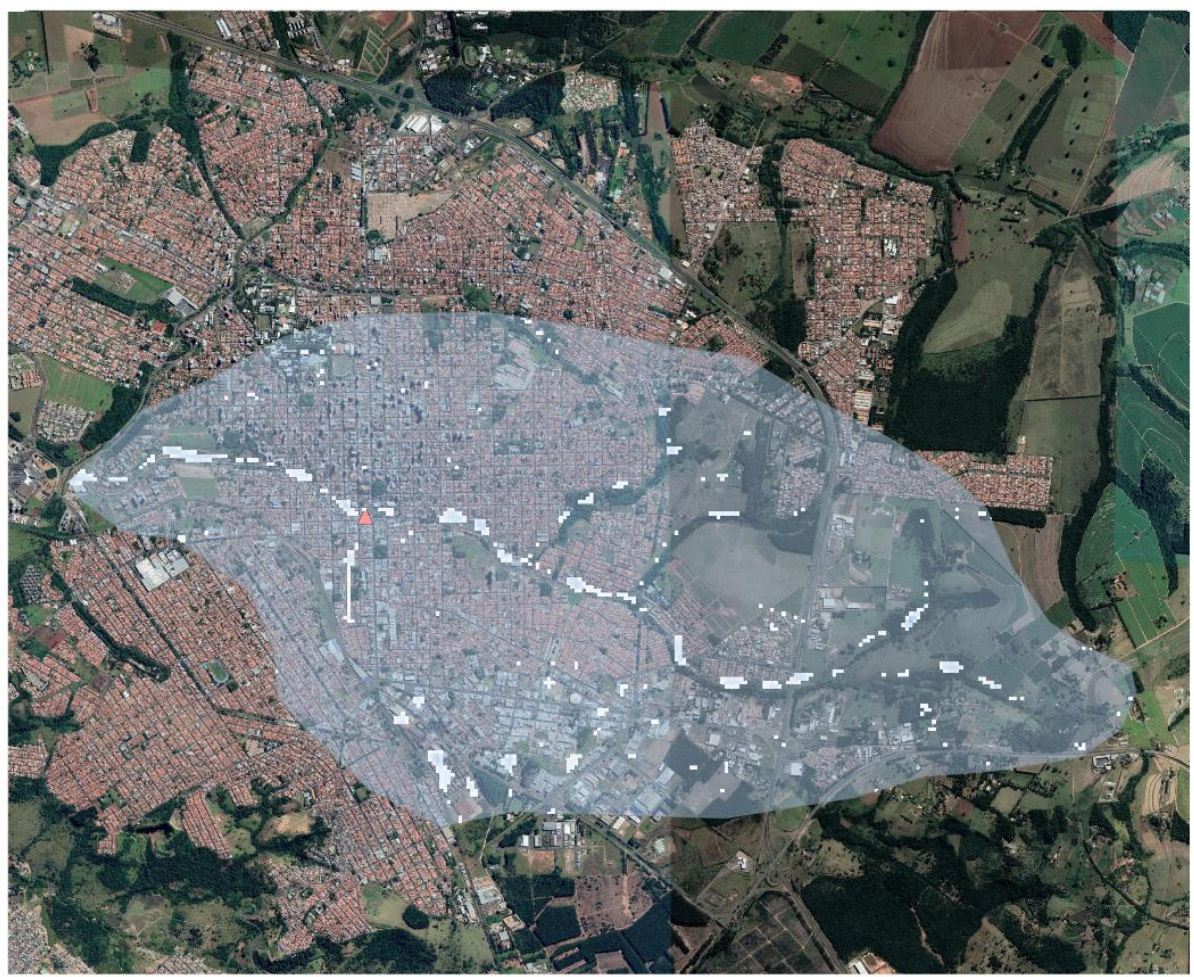

\section{Caption}

Maximum Water Depth (m)
$\square 0.01$
$\square \quad 2.22$
$\square .33$
4.44
5.55
6.66
7.68
8.53
$\triangle$ Municipal Market

Gregório Creek Catchment 
Flood extension map for the flood event with the highest daily rainfall intensity of 2097 for the RCP 8.5.

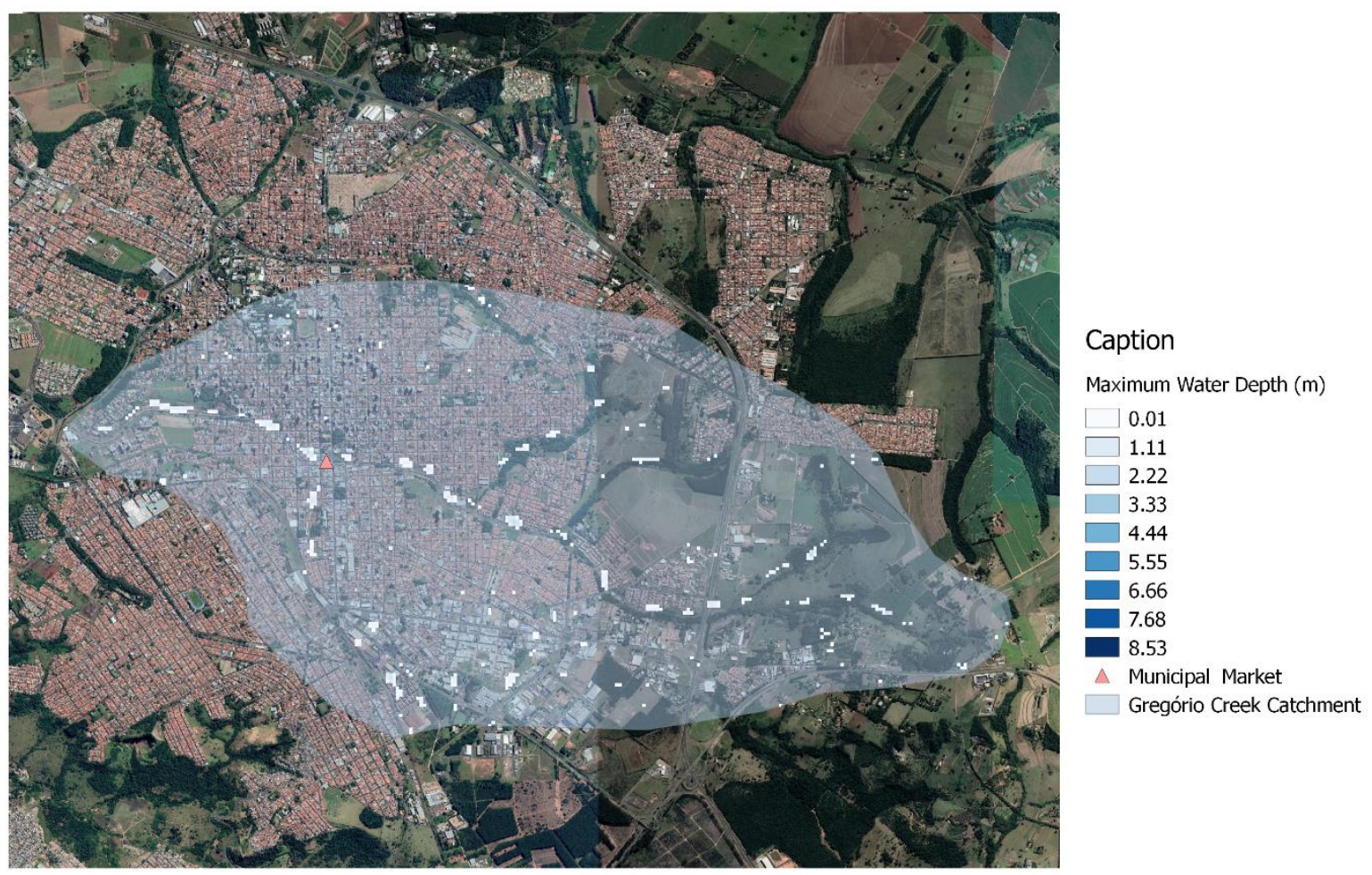

Flood extension map for the flood event with the highest daily rainfall intensity of 2099 for the RCP 8.5.

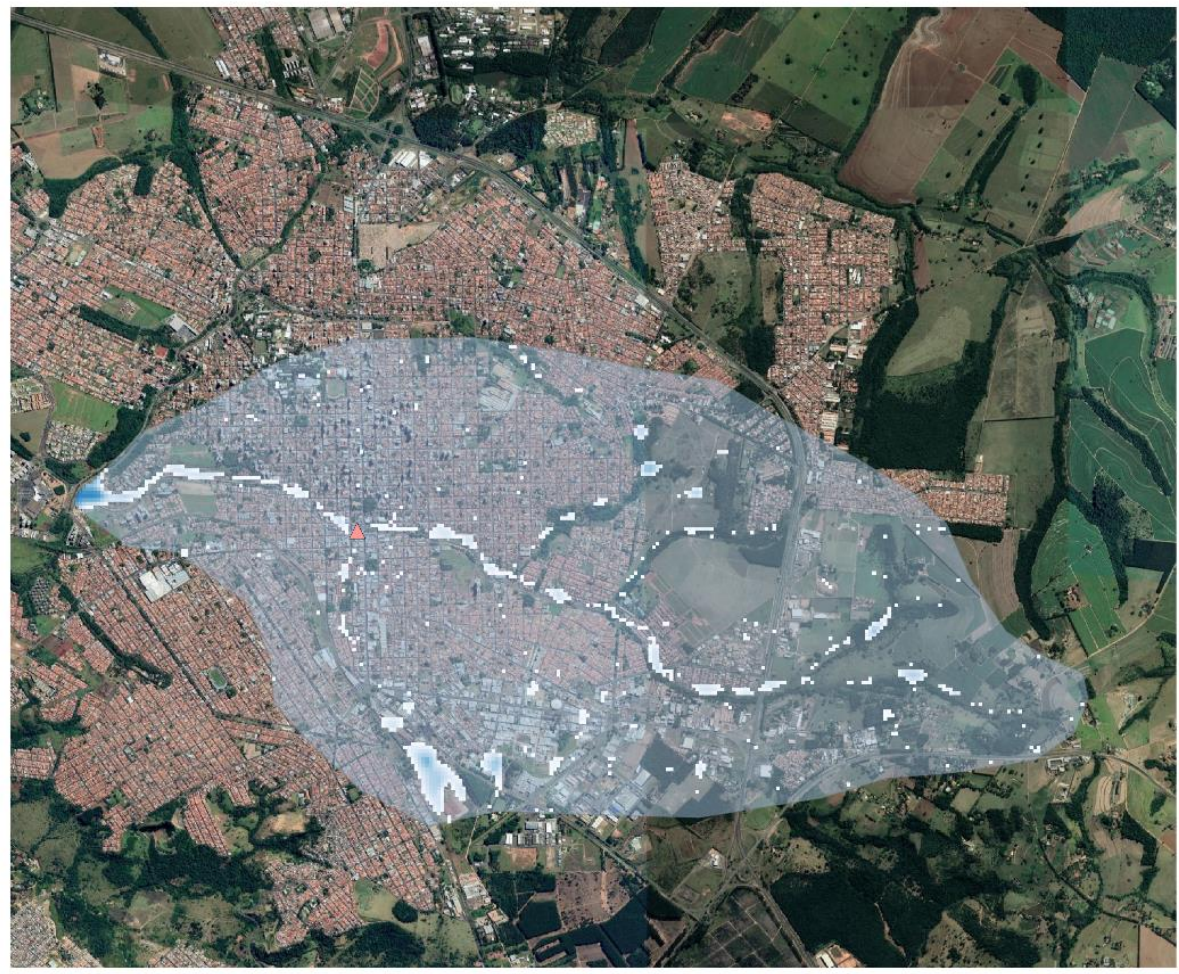

\section{Caption}

A Municipal Market

Maximum Water Depth (m)

\begin{tabular}{|l|l}
\hline & 0.01 \\
$\mid$ & 1.37 \\
$\square$ & 2.73 \\
$\square$ & 4.09 \\
$\square$ & 5.45 \\
& 6.81 \\
$\square .18$ \\
$\square .43$ \\
10.48 \\
Gregório Creek Catchment
\end{tabular}


b) SOCIO-HYDROLOGICAL MODEL SOURCE CODE

The source code of the socio-hydrological model developed by Di Baldassarre et al. (2015), which was applied in this study, was made available by Di Baldassarre et al. (2017) and is described as it follows.

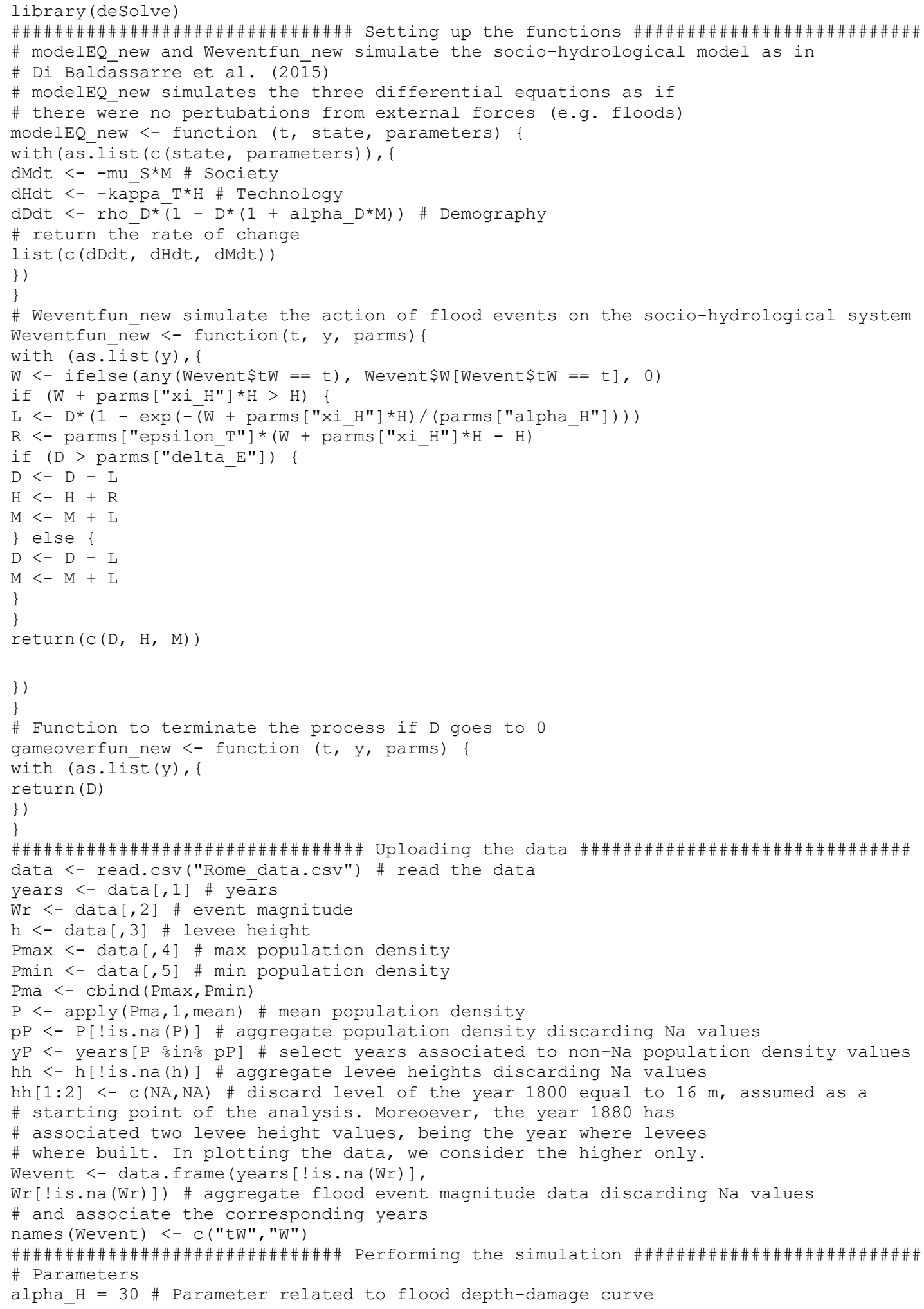




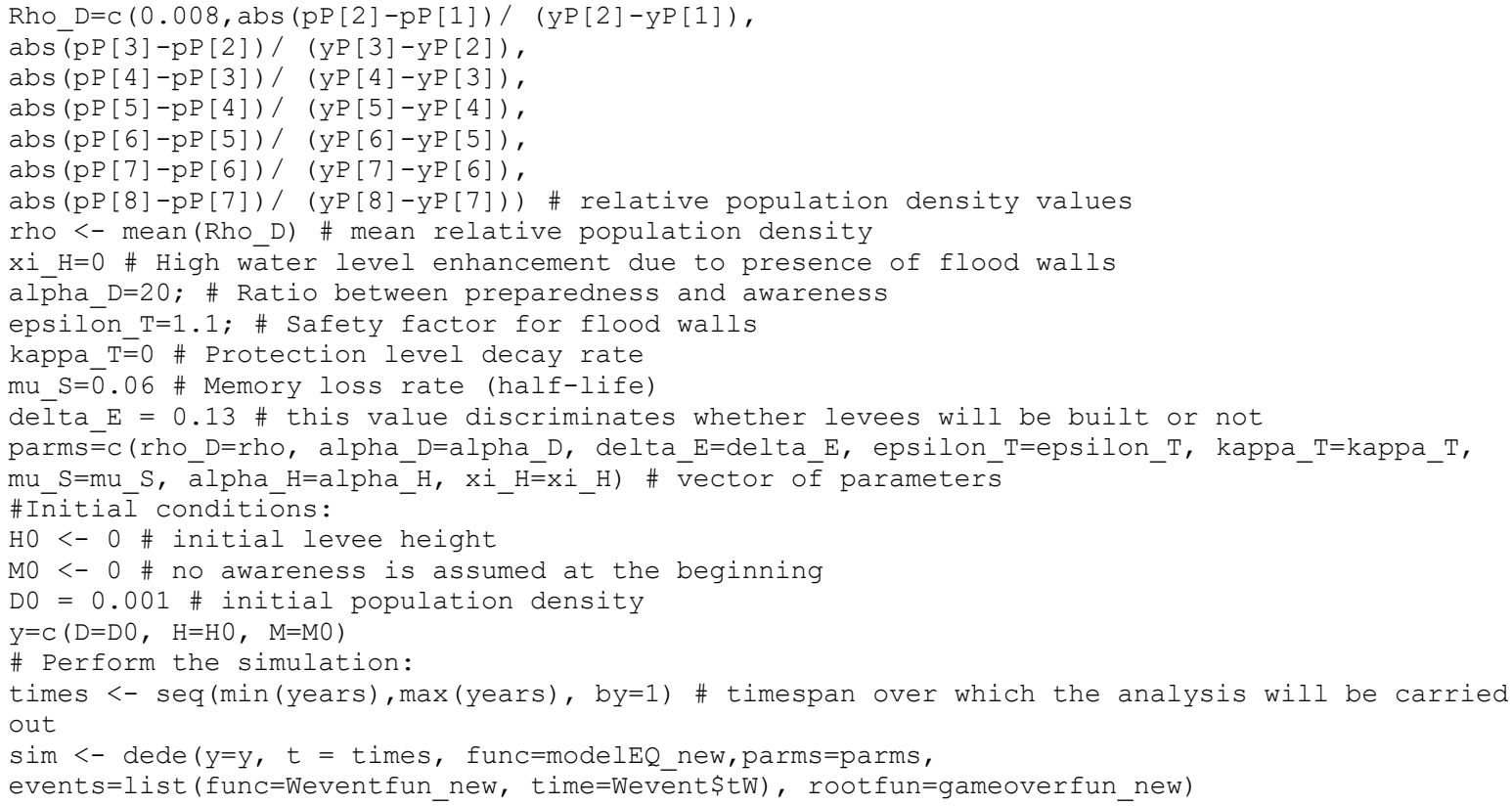

\section{REFERENCES}

Di Baldassarre, G., Saccà, S., Aronica, G. T., Grimaldi, S., Ciullo, A., \& Crisci, M. (2017). Human-flood interactions in Rome over the past 150 years. Adv. Geosci, 44, 9-13. 